

\title{
Lattes/Lattara (Hérault), comptoir étrusque du littoral languedocien
}

Eric Gailledrat, Ariane Vacheret

\section{To cite this version:}

Eric Gailledrat, Ariane Vacheret. Lattes/Lattara (Hérault), comptoir étrusque du littoral languedocien. Gallia - Archéologie des Gaules, 2020, 77 (2), pp.1-32. 10.4000/gallia.5147 . hal-02865893v2

\section{HAL Id: hal-02865893 \\ https://hal.science/hal-02865893v2}

Submitted on 16 Sep 2020

HAL is a multi-disciplinary open access archive for the deposit and dissemination of scientific research documents, whether they are published or not. The documents may come from teaching and research institutions in France or abroad, or from public or private research centers.
L'archive ouverte pluridisciplinaire HAL, est destinée au dépôt et à la diffusion de documents scientifiques de niveau recherche, publiés ou non, émanant des établissements d'enseignement et de recherche français ou étrangers, des laboratoires publics ou privés.

\section{(ㅇ)(1) $\$$}

Distributed under a Creative Commons Attribution - NonCommercial - NoDerivatives| 4.0 


\title{
Lattes/Lattara (Hérault), comptoir étrusque du littoral languedocien
}

\author{
Éric Gailledrat* et Ariane VACHeReT ${ }^{* *}$
}

Mots-clés. Gaule méridionale, colonisation, comptoir commercial, urbanisme, architecture, métrologie.

Résumé. Les fouilles récemment menées à Lattes/Lattara (Hérault) ont permis d'ouvrir une nouvelle fenêtre sur les niveaux de fondation de ce comptoir lagunaire protohistorique, peu accessibles en raison de l'épaisseur de la séquence stratigraphique. Ces nouvelles données invitent à dresser un bilan de nos connaissances relatives à la nature de cette première occupation et du rôle alors joué par les Étrusques. L'ampleur du programme urbanistique conduit par ces derniers au début du ves. av. J.-C. est confirmée, tout autant que la destruction brutale qui affecte le site vers 480/470 av. J.-C.
La morphologie de lîlot suggère l'existence de maisons à plusieurs pièces et d'un plan orthonormé rigoureux. En revanche, une séquence antérieure inédite a ici été mise en évidence et correspond à la phase d'installation étrusque à proprement parler. Une division régulière du terrain précède la construction d'une maison absidiale en torchis dont le plan et la métrologie trouvent des parallèles probants en Étrurie padane. Cette succession entre une division foncière, une installation provisoire et un programme de lotissement urbain témoigne d'une véritable entreprise planifiée, qui doit être mise en rapport avec le regain de la dynamique commerciale des cités d'Étrurie méridionale à la fin $d u$ vi ${ }^{e}$-début du ve s. av. J.-C.

\section{Lattes/Lattara (Hérault), Etruscan trading post of the Languedoc coastline}

Keywords. Southern Gaul, colonisation, trading post, urbanism, architecture, metrology.

Abstract. Excavations recently carried out in Lattes/Lattara (Hérault) had revealed a new window onto the foundation levels of that lagoonal protohistoric trading post, sparsely accessible due to the thickness of the stratigraphic sequence. These new data invite us to take stock of our knowledge about the nature of this first occupation and the role played by the Etruscans. The scale of the urbanistic program conducted by the latter at the beginning of the 5th c. BC is confirmed, as well as the brutal destruction that affects the site around
480/470 BC. The morphology of the block suggests the evidence of multi-room houses and a rigorous orthonormal plan. However, a new previous sequence was highlighted here, and corresponds to the strictly speaking installation phase. A regular division of the land precedes the building of a wattle-and-daub apsidal house which plan and metrology find convincing parallels in Padanian Etruria. This succession between a land division, a temporary settlement and an urban program testify of a real planned undertaking, that must be linked to the renewed commercial dynamic of the City-States of Southern Etruria at the end of the 6th-beginning of the 5th c. BC.
L'antique Lattara, le Castellum Latara mentionné au $\mathrm{I}^{\mathrm{er}} \mathrm{s}$. apr. J.-C. par Pomponius Mela (Chorographie, II, 80), la Civitas Latara citée au $\mathrm{VII}^{\mathrm{e}}$ s. apr. J.-C. par l'Anonyme de Ravenne (Cosmographia), a de longue date été localisée par divers érudits ou chercheurs sous l'actuelle Lattes (Hérault), ville du littoral languedocien située à quelques kilomètres au sud de Montpellier (Hérault), en bordure de l'étang du Méjean - dans lequel il faut reconnaître le Stagnum Latera de Pline l'Ancien (Histoire Naturelle, IX, 29-32) (Barruol 1988) (fig. 1). Il a fallu néanmoins attendre 1963 pour que cette identification, jusque-là seulement pressentie, trouve une véritable confirmation suite aux recherches activement menées dans ce secteur par Henri Prades et les amateurs du Groupe archéologique Painlevé (GAP). Plus précisément, dans le tènement du Mas Saint-Sauveur, les sondages opérés à l'époque ont révélé un gisement de plusieurs hectares, puissamment stratifié, occupé entre la fin du premier âge du Fer et le $\mathrm{III}^{\mathrm{e}}$ s. apr. J.-C. En cette occasion, la découverte de la stèle dite d'Astrapton portant une dédicace mentionnant les Lattar[enses] est venue confirmer ce que l'ensemble des recherches tendait chaque jour un peu plus à démontrer.

\footnotetext{
* ASM - Archéologie des Sociétés Méditerranéennes. UMR 5140, CNRS, LabEx ARCHIMEDE programme IA - ANR-11-LABX-0032, université Paul-Valéry, Route de Mende F-34199 Montpellier Cedex 5. Courriel : eric.gailledrat@cnrs.fr

** ASM - Archéologie des Sociétés Méditerranéennes. UMR 5140, LabEx ARCHIMEDE programme IA - ANR-11-LABX-0032, université Paul-Valéry, Route de Mende F-34199 Montpellier Cedex 5. Courriel : ariane.vacheret@gmail.com
} 


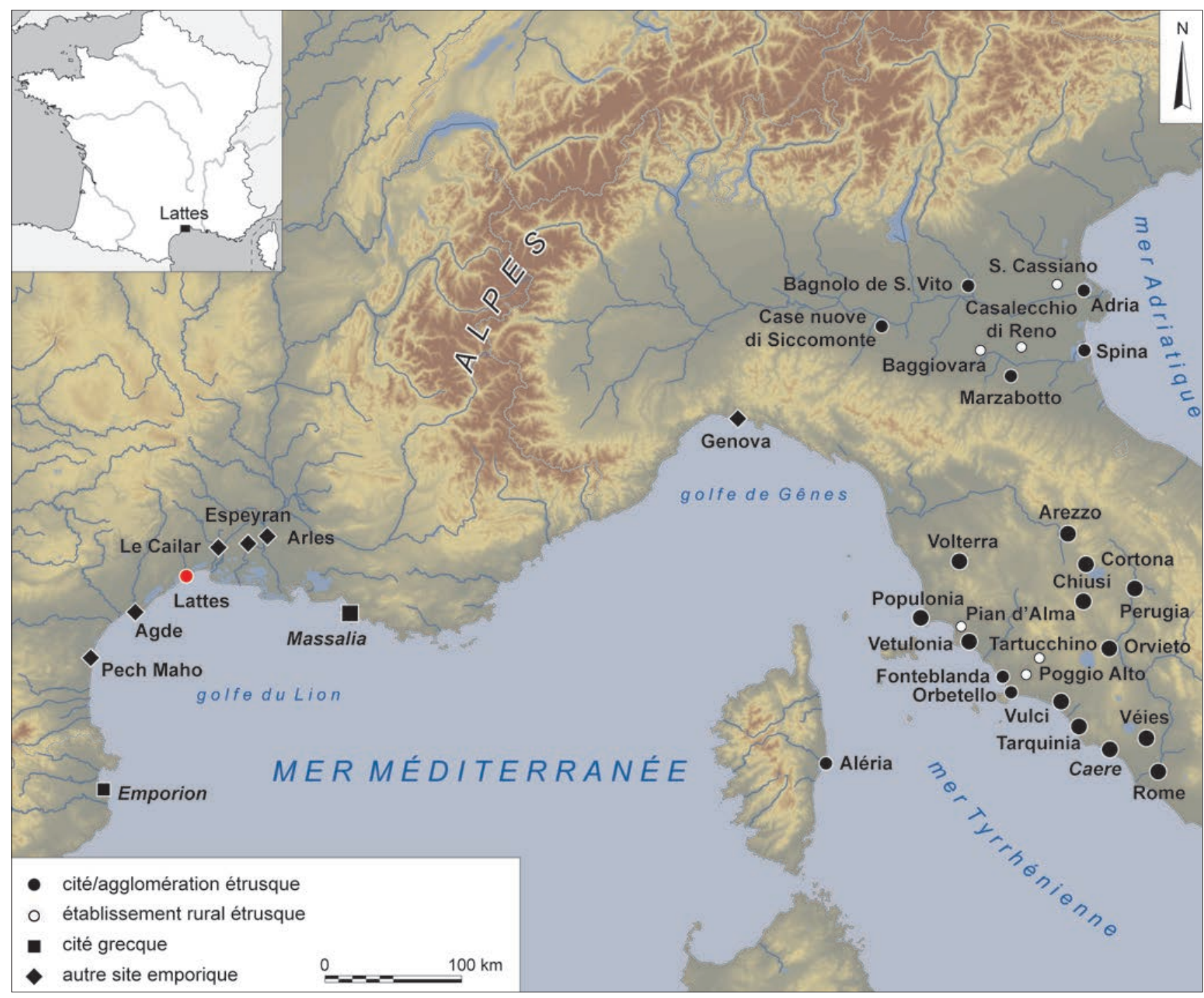

Fig. 1 - Carte de la Méditerranée nord-occidentale aux environs de 500 av. J.-C. Principaux sites étrusques et autres établissements mentionnés dans le texte ou étant impliqués dans les réseaux tyrrhéniens (DAO : É. Gailledrat, CNRS-ASM ; fond de carte : H. Bohbot, CNRS-ASM).

Les travaux conduits par la suite, depuis le début des années 1980 jusqu'à aujourd'hui, ont considérablement enrichi notre connaissance du site, lequel s'est progressivement imposé comme une référence incontournable, non seulement pour l'âge du Fer en Gaule méridionale, mais encore pour la compréhension des mécanismes d'échanges et d'interactions culturelles en Méditerranée occidentale entre mondes indigènes et coloniaux (Janin, Py dir. 2008 ; Py 2009).

Le site de Lattes/Saint-Sauveur occupe à l'âge du Fer une position bien particulière, entre terre et eau, dans un environnement lagunaire caractéristique des paysages du golfe du Lion. Telle qu'elle peut être restituée, la paléotopographie du lieu correspond à une étroite langue de terre sableuse s'avançant dans l'étang du Méjean, un cône deltaïque résultant de la progradation du delta du Lez. Ce qui se présentait alors comme une presqu'île de plan sensiblement triangulaire se voyait manifestement encadrée par deux des bras du fleuve, dont le principal passait à l'ouest et le cours mineur longeait le site côté est (Jorda et al. 2008) (fig. 2). Le tracé du cours majeur a évolué au long des quelques siècles d'existence de Lattara, avec comme conséquence son déplacement progressif vers l'ouest et, surtout, un atterrissement relativement rapide de ce secteur lagunaire.
À la fin du second âge du Fer, l'habitat connaît une extension importante au nord sur la terre ferme ainsi qu'au sud sur les espaces récemment colmatés, de sorte qu'aux $\mathrm{III}^{\mathrm{e}}-\mathrm{II}^{\mathrm{e}} \mathrm{s}$. av. J.-C. la surface occupée avoisine les 20 ha. Ce développement semble avoir été progressif, à partir d'un noyau initial constitué par la presqu'île dont la superficie ne dépasse pas 3,50 ha (fig. 3), et dont les niveaux d'occupation les plus anciens connus à ce jour datent de la charnière des $\mathrm{VI}^{\mathrm{e}}-\mathrm{v}^{\mathrm{e}} \mathrm{s}$. av. J.-C. Rapidement, dès le $\mathrm{v}^{\mathrm{e}} \mathrm{s}$. av. J.-C., des quartiers qualifiés, faute de mieux, de suburbains, se développent au Nord, au-delà du périmètre fortifié dont le tracé reflète la topographie initiale de cette langue de terre baignée des eaux de la lagune. Comme le montrent plusieurs sondages réalisés à l'occasion des premières recherches menées sur le site, l'occupation de ce secteur extra muros semble avoir été relativement dense, mais tant la morphologie de cette partie de l'habitat que le détail de son évolution demeurent imprécis (Py 1988 ; Py 2009, p. 79-81).

L'histoire de Lattara s'avère de fait plus complexe que ce que laissent entrevoir les seules recherches menées sur le site de Lattes/Saint-Sauveur. Elle renvoie, à l'échelle de la basse-vallée du Lez et de ses alentours, à un processus continu d'interactions entre le monde indigène et le monde colonial, synonyme d'un 
développement croissant des échanges et d'une présence régulière des intervenants allochtones - Étrusques et Grecs - qui animent alors le négoce méditerranéen. La fondation de Lattara s'inscrit de fait dans une logique plus globale de structuration de l'espace littoral et de consolidation des mécanismes du commerce qui, à l'échelle de la Méditerranée nord-occidentale, se traduit à partir $\mathrm{du} \mathrm{VI}^{\mathrm{e}} \mathrm{s}$. av. J.-C. par la multiplication de ces lieux de rencontre et d'échange que sont les emporia (Gailledrat 2014).

\section{ÉVOLUTION DE L'HABITAT DANS LA BASSE-VALLÉE DU LEZ AU PREMIER ÂGE DU FER}

Dans le secteur de la basse-vallée du Lez, l'occupation de l'espace littoral témoigne, comme ailleurs, de logiques complexes, parfois antinomiques. Les lagunes qui émaillent cette partie de la Méditerranée, interfaces naturelles entre terre et eau, sont alors mises à profit, aux marges de ce qui constitue le domaine proprement indigène (Gailledrat 2014 ; 2018). La notion de réseau de peuplement est ici importante, et force est de constater que le secteur de Lattes correspond aux franges méridionales d'un territoire cohérent, que l'on restitue à la fin du premier âge du Fer autour de l'oppidum de Sextantio à Castelnau-le-Lez (Hérault), habitat majeur sur le plan régional, situé sur le cours du Lez, à quelque $8 \mathrm{~km}$ de la côte, et occupé depuis le Bronze final IIIb.

$\mathrm{Au}$ début $\mathrm{du} \mathrm{VI}^{\mathrm{e}}$ s. av. J.-C., tandis que commencent à être diffusées amphores vinaires, vaisselle fine et autres produits acheminés en Gaule méridionale par l'emporia gréco-étrusque, on assiste à l'éclosion de plusieurs habitats de dimensions réduites, localisés en bordure des étangs du Méjean et de Mauguio (Hérault). Ces hameaux sont généralement situés sur des emplacements déjà occupés au Bronze final mais désertés au début du premier âge du Fer ; le viI ${ }^{\mathrm{e}}$ s. av. J.-C. est, en effet, une période de rupture durant laquelle ne sont fréquentés que quelques points du littoral qui, à l'image du secteur de la basse-vallée du Lez, correspondent à des lieux d'attraction privilégiés des navigations «précoloniales » (Gailledrat 2014, p. 71-80).

Parmi ces habitats ressort celui de la Cougourlude, à Lattes, implanté le long de la Lironde, un cours d'eau passant à environ $1 \mathrm{~km}$ à l'est de l'embouchure du Lez et se jetant comme lui dans l'étang du Méjean (Daveau, Py 2015 ; Daveau et al. 2015) (fig. 2). Durant les premières décennies du vi ${ }^{\mathrm{e}} \mathrm{s}$. av. J.-C., le site ne se distingue pas véritablement des autres habitats lagunaires, à cette nuance près qu'il témoigne d'une pérennité dans l'occupation de ce secteur. En revanche, il connaît un développement spectaculaire à partir du milieu de ce siècle, et plus spécialement encore durant les années 530/510 av. J.-C. Au cours de cette période, la superficie globale de l'habitat atteint en effet une trentaine d'hectares ${ }^{1}$, associant une occupation de hauteur abritée derrière une puissante fortification à une installation de bas de coteau, elle-même protégée par un système de fossés. Ce développement à la fois rapide et spectaculaire, synonyme d'une augmentation de la population installée sur place, doit

1. Communication orale : Isabelle Daveau.



Fig. 2 - Paléotopographie de la basse-vallée du Lez (DAO et fond de carte : C. Jorda, Inrap-ASM, H. Bohbot, CNRS-ASM).

être mis en rapport avec l'abandon concomitant des petits sites lagunaires préexistants (Py 1985) ; et, peut-être également, par d'autres mobilités ayant pour origine les habitats de l'intérieur des terres, tel Sextantio.

Le faciès mobilier atteste alors une forte implication de la Cougourlude dans les échanges méditerranéens, comme en témoignent les taux d'importation (amphores et vaisselle) particulièrement élevés constatés durant cet intervalle chronologique (Daveau, Py 2015). Cette agglomération constitue alors un pôle de première importance sur le plan régional et révèle le regain d'attractivité exercé par les espaces littoraux, qui deviennent alors un enjeu de pouvoir, eu égard aux opportunités de contrôle des flux commerciaux avec la Méditerranée. Le développement de la Cougourlude reflète-t-il une sorte de projection vers le littoral d'un pouvoir centré sur l'intérieur des terres, ou bien marque-t-il l'émergence d'une nouvelle entité à la fois sociale, politique et économique ? Quoi qu'il en soit, l'ensemble des données aujourd'hui disponible confirme un peu plus la dynamique toute particulière qui anime cette partie du golfe du Lion durant l'âge du Fer, dynamique d'autant plus singulière 


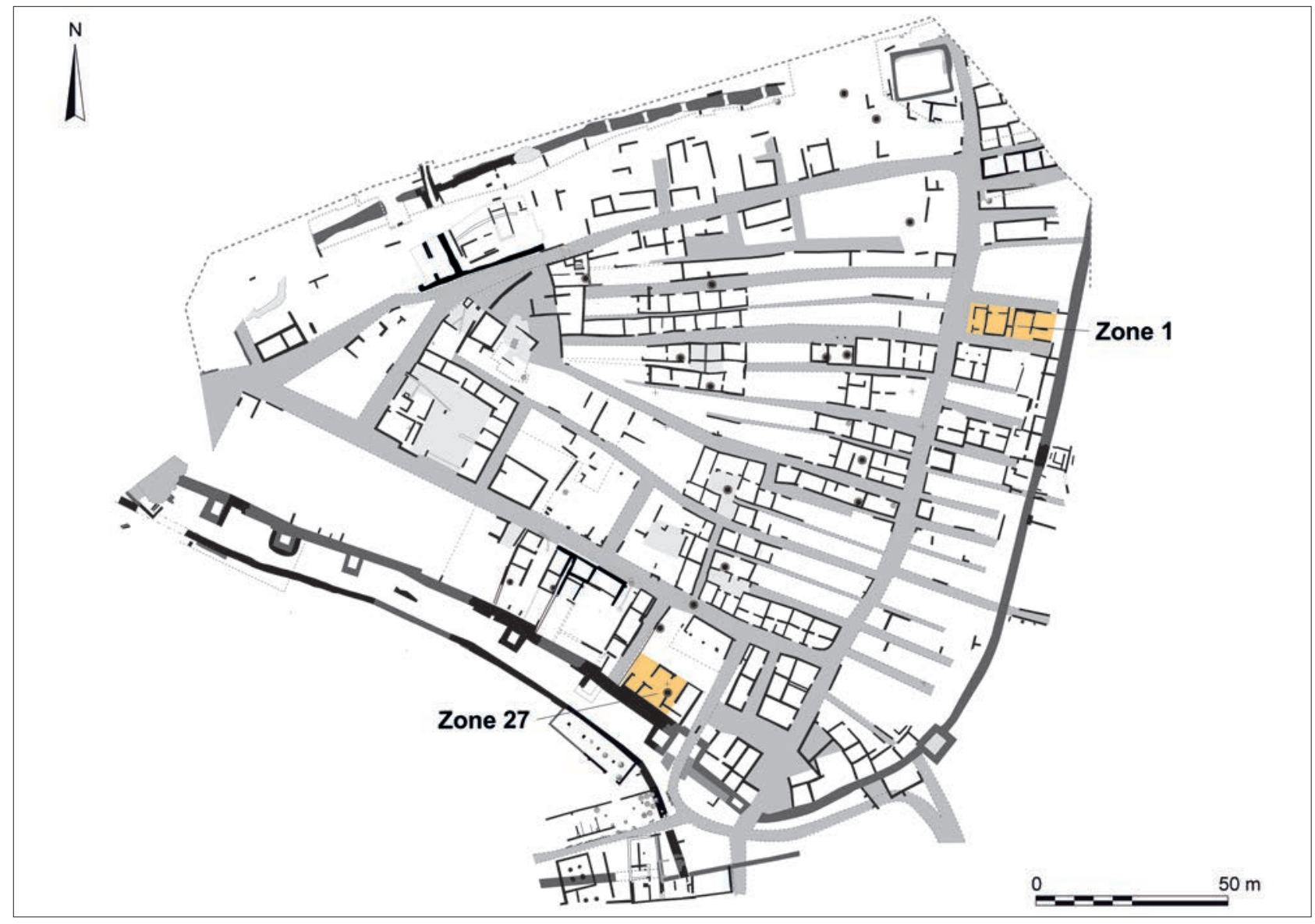

Fig. 3 - Plan d'ensemble du site de Lattes/Saint-Sauveur avec localisation des zones 1 et 27 où ont été atteints les niveaux de fondation (DAO : ASM-UMR 5140).

que la vallée du Lez ne constitue pas, de prime abord, un axe de pénétration majeur vers l'intérieur des terres et vers d'éventuelles ressources minières ou agricoles.

Le choix opéré quant à l'implantation du site pose question au regard de sa situation en bordure orientale du delta du Lez, le fleuve constituant à l'évidence le trait d'union privilégié avec l'hinterland et, à tout le moins, l'oppidum de Sextantio. Nul doute que la topographie a ici joué un rôle décisif au moment de l'extension de l'habitat, qui s'est probablement accompagné d'un changement de statut. En effet, ce qui n'était qu'un village de plaine ouvert devient dans la seconde moitié du $\mathrm{vi}^{\mathrm{e}} \mathrm{s}$. av. J.-C. une vaste agglomération, adossée à un noyau fortifié établi sur la seule éminence véritablement proche de l'embouchure du Lez, à savoir la butte de Pérols (fig. 2). L'habitat, de même que le sanctuaire qui lui est associé au Mas de Causse, sur la bordure méridionale de ce relief (Gailledrat 2014, p. 188-196), joue alors le rôle d'interface avec la Méditerranée, accueillant dans un premier temps (vers 600/570 av. J.-C.) des produits essentiellement étrusques, rapidement concurrencés puis supplantés par des importations grecques, qui témoignent par ailleurs du poids croissant de l'économie massaliète dans le secteur (Daveau, Py 2015).

La charnière des $\mathrm{VI}^{\mathrm{e}}-\mathrm{v}^{\mathrm{e}} \mathrm{s}$. av. J.-C., phase d'extension et de densité maximale de l'habitat de la Cougourlude, est marquée par un regain notable des importations d'amphores étrusques. Or, c'est précisément à ce moment que survient à l'embouchure du Lez la fondation d'un établissement qui n'est autre que Lattara, un habitat de dimensions alors très réduites, confiné dans un espace dont on a évoqué le caractère bien particulier. Pour cette période, l'emploi du terme «fondation » repose sur l'évidence de niveaux d'occupation bien caractérisés associés à du bâti. En revanche, la présence erratique de matériels plus anciens, trouvés hors contexte, a très tôt été soulignée (Py 1988, p. 124 ; Py 1995) et laisse entrevoir a minima une fréquentation du site durant le plein $\mathrm{vl}^{\mathrm{e}} \mathrm{s}$. av. J.-C. Quoi qu'il en soit, Lattara présente alors à la charnière des $\mathrm{VI}^{\mathrm{e}}-\mathrm{v}^{\mathrm{e}} \mathrm{s}$. av. J.-C. un faciès fortement empreint d'éléments étrusques, au point qu'est désormais admis le postulat de l'installation sur place d'une communauté tyrrhénienne.

Cette nouvelle configuration semble toutefois n'avoir fonctionné qu'un temps. En effet, à la fin du premier quart du $\mathrm{V}^{\mathrm{e}} \mathrm{s}$. av. J.-C., une rupture franche - et semble-t-il brutale - est perceptible à Lattara, tant sur le plan architectural qu'au niveau du répertoire mobilier, avec l'évidence d'un faciès plus spécifiquement indigène assorti d'importations à mettre désormais très largement au compte du commerce massaliète (Py 2009). De fait, tandis que les Étrusques auparavant installés sur place semblent avoir déserté les lieux, ceux-ci sont rapidement réinvestis par une population fondamentalement gauloise. Or dans le même temps, la Cougourlude connaît une récession rapide, au point que seules quelques traces d'occupation subsistent encore au milieu du $\mathrm{v}^{\mathrm{e}} \mathrm{s}$. av. J.-C., en marge du sanctuaire du Mas de Causse qui, quant à lui, semble perdurer jusqu'à l'époque républicaine.

Au vu des données disponibles, l'hypothèse d'un déplacement de population depuis les bords de la Lironde vers l'embouchure du Lez, à Lattara intra muros comme dans ses faubourgs 
septentrionaux, apparaît des plus vraisemblables (Daveau, Py 2015 , p. 42). Lattara semble alors accaparer les fonctions emporiques naguère dévolues à la Cougourlude (Gailledrat 2015), et son développement tout au long du second âge du Fer témoigne de son intégration croissante dans l'orbite commerciale de Marseille grecque. Marchands et artisans phocéens fréquentent régulièrement cet emporion et il est probable que certains y résident même à demeure. Au même titre que Théliné (Arles), Espeyran (Saint-Gilles-du-Gard) et probablement le Cailar (Gard), Lattara fait partie d'une chaîne de comptoirs assurant un maillage du territoire rhodanien (fig. 1), confirmant l'emprise commerciale, et peut-être politique, de Marseille sur cette région (Py 2009). Si des incertitudes subsistent sur cette période charnière, c'est peut-être avant tout en fonction de ce contexte expansionniste qu'il faut apprécier les changements brutaux qui interviennent aux environs de 475 av. J.-C. avec l'éviction des Étrusques installés sur place.

\section{LATTARA ÉTRUSQUE, UNE RÉVÉLATION PROGRESSIVE}

De nombreuses incertitudes subsistent, qui ne portent pas uniquement sur le pourquoi et le comment de ce basculement visible à Lattes entre le deuxième et le troisième quart $\mathrm{du} \mathrm{V}^{\mathrm{e}} \mathrm{s}$. av. J.-C., mais également, en amont de tout cela, sur la caractérisation et la signification même de cette présence étrusque au sein d'un établissement dont le statut ne s'est éclairé que progressivement, à la lumière des recherches menées sur le site de Lattes/Saint-Sauveur ainsi que dans son environnement proche, notamment à la Cougourlude.

L'hypothèse d'une fondation tyrrhénienne est ancienne, comme en témoignent les premiers écrits d'Henri Prades qui, distinguant neuf « niveaux » successifs, a très tôt souligné l'abondance des matériels étrusques (amphores et bucchero nero) dans les couches d'occupation les plus profondes du site, entrevues dans différents sondages. La datation de ce qu'il définissait comme le « niveau IX » de Lattara a ainsi été fixée dans un premier temps à la fin du $\mathrm{VII}^{\mathrm{e}}$-début du $\mathrm{VI}^{\mathrm{e}} \mathrm{s}$. av. J.-C. Cette datation haute a toutefois été rapidement corrigée, abaissant de près d'un siècle la chronologie des premiers niveaux d'occupation du site, « entre 525 et 500/475 av. n. è., la "fondation" de la ville intervenant au cours du dernier quart du $\mathrm{VI}^{\text {e }}$ s. » (Py 1988, p. 128).

L'extension de cette première installation a elle aussi été l'objet de spéculations diverses, largement conditionnées par la faible visibilité que les premiers sondages pouvaient offrir pour ces horizons, aujourd'hui enfouis sous plusieurs mètres de sédiments et situés sous le niveau de la nappe phréatique. Les fouilles opérées par le GAP ont ainsi été réalisées dans des conditions particulièrement difficiles, sur des surfaces réduites ; elles ont néanmoins permis de restituer dès cette époque une occupation étalée sur plusieurs hectares, dont la densité ne pouvait certes être précisée mais qui, en revanche, affichait un certain nombre de singularités (Py 1988, p. 128-130). En premier lieu a ainsi été relevée l'existence de recharges de sols à base de pierres et tessons d'amphores « comme si l'on avait voulu assainir d'entrée un terrain encore en partie humide » (Py 1988, p. 128), mais aussi et surtout de constructions « en dur » sur solins de pierres liées à la terre et, « dans cette première phase d'occupation, sinon à son début » (ibid.), d'un rempart dont subsiste la base maçonnée, soit autant d'éléments qui, encore au début du $v^{\mathrm{e}} \mathrm{s}$. av. J.-C., demeurent rares, sinon en Gaule méditerranéenne, du moins dans le contexte indigène du Languedoc oriental (Py 1990).

L'étude détaillée du mobilier issu des fouilles anciennes de Lattes, au-delà des précisions apportées quant aux limites chronologiques de cette phase initiale (réserve étant faite des quelques documents plus anciens évoqués plus haut), a permis d'avancer des arguments probants pour pouvoir traduire cette abondance de mobilier importé en quelque chose d'autre qu'une simple ouverture privilégiée à un flux commercial venant des côtes tyrrhéniennes. En premier lieu, les amphores étrusques sont de loin majoritaires. Parmi ces dernières, prédomine de manière écrasante le type A-ETR 4 (Py et al. 2001, p. 23-38) ; équivalent du type EMD [1] de Michel Gras (Gras 1985), dont l'apparition est à situer à la fin $\mathrm{du}_{\mathrm{VI}}^{\mathrm{e}} \mathrm{s}$. av. J.-C., mais dont la diffusion maximale s'opère durant le siècle suivant. Elles sont accompagnées de vaisselle fine en bucchero nero pesante, autrement dit de séries tardives, avec un répertoire de formes peu diversifié. Celui-ci est presque exclusivement constitué de bols à pied bas annulaire (B-NERO Bo4), qui renvoient au même horizon chronologique centré sur le $\mathrm{v}^{\mathrm{e}} \mathrm{s}$. av. J.-C. En revanche, ce type de bucchero est pour ainsi dire absent des contextes indigènes contemporains. Qui plus est, on relève l'abondance de la céramique commune importée d'Étrurie, ici représentée par des vases de cuisine, à savoir des mortiers ainsi que des pots à cuire de type olla, accompagnés de leurs couvercles. Très peu attestée sur les autres sites de Gaule méditerranéenne, cette vaisselle semble témoigner, sinon d'usages spécifiques, du moins d'habitudes de consommation bien définies.

Enfin, c'est l'existence de nombreux graffites en écriture étrusque qui fait définitivement de Lattara un site à part. Transcrivant pour certains des anthroponymes étrusques, y compris - dans deux cas - un prénom féminin (Colonna 1980), ils sont pour la plupart interprétés comme étant des marques de propriété plutôt que des marques commerciales. On les trouve aussi bien sur des pièces du service de table en bucchero nero que sur des vases de cuisson et ils semblent bien avoir été réalisés sur place (Py 1995, p. 268). En définitive, ils constituent un argument de poids permettant de valider l'hypothèse d'une communauté étrusque installée à demeure, utilisant de manière préférentielle une vaisselle importée à laquelle elle était habituée.

Néanmoins, ces données sont longtemps demeurées insuffisantes pour pouvoir mieux caractériser cet établissement archaïque au sein duquel le rôle éventuel des indigènes a constitué - et constitue encore - une interrogation de taille. $\mathrm{Si}$, à l'évidence, la fondation du site résulte d'une entente entre Gaulois et négociants méditerranéens, selon des processus largement observés par ailleurs (Gailledrat 2014), le caractère plus ou moins mixte de la communauté installée à l'embouchure du Lez n'a, durant longtemps, pu être appréhendé que sur la base des seuls sondages évoqués précédemment. Lattara, certes ouverte durant le second âge du Fer aux influences grecques, avec à la clé des signes tangibles d'acculturation, n'en demeure pas moins un site dont le caractère fondamentalement indigène a été rappelé avec insistance, tout autant qu'était soulignée la difficulté à démontrer archéologiquement une présence allochtone sur un site de cette nature (Py 1995). 
De fait, tandis que les fouilles entreprises à partir de 1983 n'avaient pas encore permis d'appréhender les niveaux antérieurs à la fin $d u v^{\mathrm{e}} \mathrm{s}$. av. J.-C., la question étrusque a été traitée sous l'angle d'une inévitable imbrication des sociétés ainsi mises en présence, avec deux scénarios envisagés : «Le premier serait de penser à la création d'un petit comptoir étrusque assez actif pour agréger rapidement une population indigène et voir se former en quelques années autour de lui une "ville" fortifiée. Le second à l'inverse supposerait une impulsion locale, dans le contexte de croissance économique et de structuration sociale [...] : et ce serait la création d'une agglomération indigène au bord de l'étang » (Py 1995, p. 274).

Le discours a évidemment été développé à l'aune des travaux qui ont mis en lumière l'importance d'un courant tyrrhénien en Languedoc dès le tout début $\mathrm{du} \mathrm{vI}^{\mathrm{e}} \mathrm{s}$., voire dès l'extrême fin $\mathrm{du} \mathrm{VII}^{\mathrm{e}}$ s. av. J.-C., suggérant ainsi l'existence d'un commerce étrusque antérieur à la fondation de Marseille (Py 1990). Cette chronologie haute, pour partie fondée sur la séquence stratigraphique de l'oppidum de la Liquière (Calvisson) (Py 1984) a été ensuite discutée, tout autant que le rôle potentiellement joué par les Phocéens dans la diffusion même des produits étrusques, dans le cadre d'un commerce emporique ouvert (Bats 1998 ; 2012). Avec la question de l'existence même d'un véritable commerce étrusque durant l'époque archaïque, notion à laquelle a parfois été préférée celle de « trafics », autrement dit de réseaux de distribution multiples (Gras 1985), se pose de fait celle des relations directes entretenues ou non entre l'Étrurie et la Gaule méridionale, relations qui pourraient fournir des clés pour comprendre la situation à Lattes à la fin du VI ${ }^{\mathrm{e}}$ s. av. J.-C. Si Marseille, elle-même consommatrice de vin toscan, a très bien pu fonder une partie de son activité mercantile sur la diffusion des amphores de Tarquinia, Caere ou Vulci, il n'en demeure pas moins qu'existe bel et bien un courant étrusque en Languedoc, difficilement réductible aux seuls réseaux phocéens. Très actif entre le Rhône et l'Hérault au début et au milieu de $\mathrm{VI}^{\mathrm{e}} \mathrm{s}$. av. J.-C., son importance tend néanmoins à diminuer dans la seconde moitié de ce siècle, comme conséquence visible du développement de l'emporia massaliète et plus encore de la concurrence rapide du vin produit dans la chôra de la cité phocéenne, qui diffuse en masse ses propres amphores sur le littoral gaulois à partir des années 540/530 av. J.-C.

À Lattes, la fondation d'un comptoir étrusque, ou pour le moins l'accueil d'une communauté de marchands tyrrhéniens au sein d'une agglomération indigène, a alors été présentée comme étant une conséquence logique d'un intérêt déjà ancien des Étrusques pour cette région, en dépit finalement du caractère quelque peu anachronique de cette entreprise puisqu'elle intervient précisément à un moment de repli du commerce tyrrhénien en Gaule méridionale. Dans le même temps, soulignant le parallèle avec la Genova préromaine, la nature des importations amphoriques suggère ici des liens directs et privilégiés avec l'Étrurie méridionale, et plus sûrement encore avec la zone comprise entre Caere et Vulci, qui apparaît comme l'épicentre de la production des amphores de type A-ETR 4 (Py 1995, p. 273). Quant aux graffites et autres marques de cette même période, ils évoqueraient de manière préférentielle l'aire VulciTarquinia-Orvieto (Colonna 1980). L'image d'un simple sursaut étrusque face à l'emprise croissante du commerce massaliète en Méditerranée nord-occidentale est sans doute réductrice, mais l'installation de commerçants toscans sur le littoral de Gaule méridionale est en soi suffisante pour témoigner du caractère volontariste d'une telle entreprise, que les recherches récentes n'ont fait que confirmer.

\section{UN QUARTIER ÉTRUSQUE PRÈS DU PORT}

D'emblée, le programme de fouille mis en place en 1983 sur le site de Lattes/Saint-Sauveur s'est attaché à combiner une lecture extensive de l'habitat à une exploration des niveaux les plus anciens, avec cette contrainte multiple d'un potentiel stratigraphique de plusieurs mètres d'épaisseur, d'une proximité de la nappe phréatique et d'un état de conservation des vestiges souvent exceptionnel, notamment pour ce qui concerne les architectures de terre (Py 2009). Au sud du gisement (fig. 3), la fouille de la zone 27 a été entreprise en 1995, choix dicté en partie par l'existence à cet endroit d'une puissance stratigraphique moindre, laissant envisager la possibilité d'atteindre plus rapidement qu'ailleurs les niveaux de fondation du site. Assez vite en effet, les séquences du milieu puis de la première moitié $\mathrm{du} \mathrm{V}^{\mathrm{e}} \mathrm{s}$. av. J.-C. ont pu être étudiées sur une fenêtre d'une centaine de mètres carrés, montrant à la fois le caractère original de la phase d'occupation la plus ancienne repérée dans ce secteur, datée entre l'extrême fin $\mathrm{du} \mathrm{vI}^{\mathrm{e}}$ et le premier quart du $\mathrm{V}^{\mathrm{e}} \mathrm{s}$. av. J.-C., ainsi que la réalité d'une rupture dans l'histoire du site aux alentours de 480/470 av. J.-C.

Plus précisément, les fouilles menées dans cette zone ont révélé l'existence d'une phase d'installation directement au contact du substrat, datée des environs de 500 av. J.-C. (Py et al. 2006 ; Lebeaupin, Séjalon 2008 ; Py 2009, p. 39-53 ; Lebeaupin dir. 2014). À ce moment est érigé un rempart auquel est pour ainsi dire accolé, côté intérieur, un bâtiment ou plutôt un îlot dont le plan voire les techniques de construction se distinguent radicalement des standards indigènes en vigueur dans le contexte régional. Plus encore, le mobilier associé à cette phase, scellée par un niveau d'incendie, révèle un faciès particulier, marqué par la prépondérance de la vaisselle élaborée au tour. Près de la moitié de cette vaisselle est par ailleurs constituée de céramique étrusque, avec une forte proportion de productions communes (40\% du total des fragments de vaisselle) et, dans une moindre mesure, de bucchero nero (5\%). Les amphores, presque exclusivement étrusques, sont surreprésentées au sein de cet assemblage (90\% du total des fragments), laissant à penser que des fonctions économiques particulières pouvaient être attachées à ces bâtiments.

Le rempart, dont l'élévation était constituée de briques crues, est matérialisé par un soubassement de blocs et de moellons liés à la terre reposant directement sur le substrat limono-sableux. D'une hauteur conservée de près d'1,50 m, il est percé à cet endroit d'une poterne large de $0,75 \mathrm{~m}$. Cette enceinte primitive a été repérée en divers points du site, où elle présente une structure composée de deux ou trois parements accolés l'un à l'autre, avec une largeur totale comprise entre 2,50 et 3,70 m (Py 2009, p. 25-37). On note que dans ses états plus récents, le tracé du rempart (repéré en fouille ou par prospection géophysique) reprend assez exactement celui de cette première fortification. Déroulée sur quelque $730 \mathrm{~m}$ de long, cette dernière adopte un plan subtriangulaire qui reflète à l'évidence la 


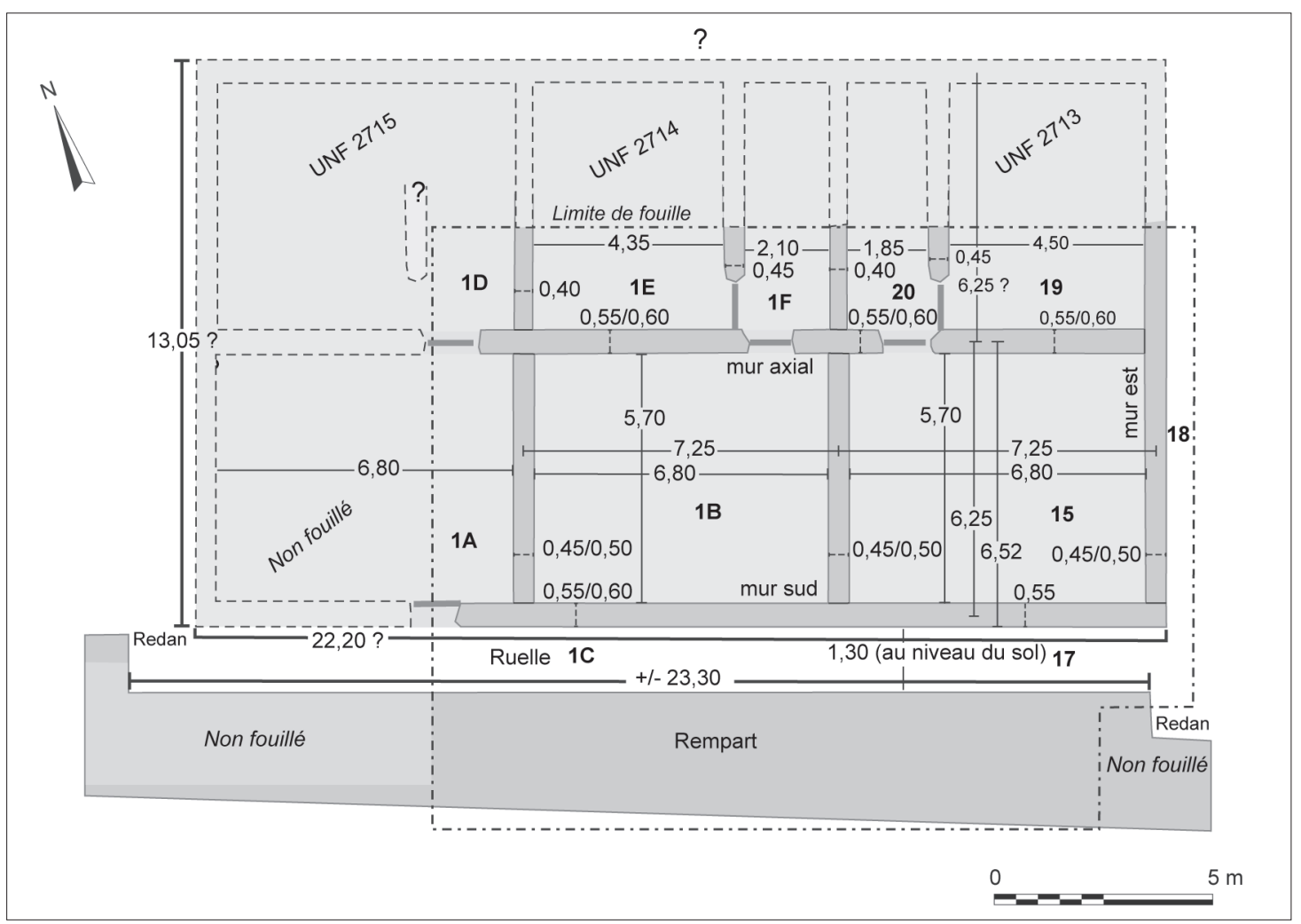

Fig. 4 - Plan de l'îlot étrusque de la zone 27. Les mesures sont exprimées en mètre (Lebeaupin dir. 2014, p. 86, fig. 26).

topographie de la presqu'île. À cette première fortification se rattache avec certitude une porte charretière, ouverte au sud-est du site et flanquée d'un bastion de 5 x 4 m environ. L'existence d'autres portes est probable, en particulier au nord du côté de la terre ferme, mais n'est pas encore démontrée. En revanche, il faut probablement dater de cette même phase initiale une tour quadrangulaire monumentale de près de $8 \mathrm{~m}$ de côté, érigée dans la partie sud-est du site. Cette tour pleine, malheureusement épierrée, a été édifiée à cheval sur la courtine. Au moins autant qu'une fonction défensive, cet ouvrage a dû revêtir une dimension ostentatoire doublée d'une fonction pratique en tant que repère visuel, « d'amer sur une côte très basse où, depuis le large, il était difficile de repérer le port » (Py 2016, p. 27).

Dans la zone 27, en arrière de ce rempart et séparé de ce dernier par une venelle d'environ 1,30 m, est édifié un îlot composé de trois maisons mitoyennes conçues selon un même schéma (fig. 4). La conception du plan, parfaitement régulier et orthonormé, est remarquable, tout autant que le soin apporté à la mise en œuvre. Les murs sont bâtis en adobes ou en terre massive (bauge) sur des solins de pierres liées à la terre. Un enduit de terre vient les recouvrir, qui supporte enfin un badigeon de chaux et, par endroits, de probables décors de bandes peintes. Les sols font l'objet d'un soin particulier, via l'apport de remblais de sable pur de 35 à $50 \mathrm{~cm}$ d'épaisseur, qui viennent s'appuyer contre la base des murs et contribuent ainsi à leur stabilité. Ces remblais, parfaitement nivelés, permettent d'assainir les lieux tout en créant une surface plane et régulière, avec comme finition de sol, dans certaines pièces, l'épandage d'une mince couche de limon sableux.

Seule une partie de cet îlot a pu être fouillée. Le plan d'ensemble peut néanmoins être restitué avec vraisemblance, présentant selon toute logique des ouvertures donnant côté nord, la « maison » ou « unité fonctionnelle » (UNF) la plus à l'ouest (UNF 2715) comportant par ailleurs une ouverture donnant au sud, sur la ruelle qui longe le rempart. À tout le moins, les deux unités fonctionnelles composant la partie orientale de l'îlot (UNF 2713 et 2714) se composent de trois pièces chacune et présentent la même organisation interne. Au nord, une étroite pièce rectangulaire oblongue d'une superficie de 11 à $12 \mathrm{~m}^{2}$ (restitués) fait peut-être office de couloir ou de vestibule. Deux portes sont ouvertes côté sud : l'une donne accès à une pièce rectangulaire oblongue d'une superficie de 25 à $26 \mathrm{~m}^{2}$ environ (restitués) ; l'autre à une vaste pièce de près de $39 \mathrm{~m}^{2}$ occupant tout l'arrière de l'édifice. Autant les mesures de la moitié nord des UNF 2713 et 2714 accusent de légères variations, autant les dimensions de leur moitié sud sont strictement identiques. Compte tenu de la configuration des lieux, ces pièces situées à l'arrière des habitations n'ont dû être que faiblement éclairées, en particulier en ce qui concerne la maison centrale (UNF 2714).

Le fonctionnement de ces différents espaces ne peut qu'être entrevu, d'une part en raison de l'aspect lacunaire de la fouille, d'autre part en raison du pillage systématique qui a manifestement précédé l'incendie de ces bâtiments, avec comme conséquence un certain nombre de manques et le bouleversement des agencements initiaux. Dans le cas de l'UNF 2713, les quantités d'amphores mises au jour dans la grande pièce arrière (pièce 15) font néanmoins penser à un entrepôt, peut-être associé à un espace de préparation des repas, tandis qu'au nord-est se trouve une pièce de vie (pièce 19) plus spécifiquement vouée au séjour/repos ainsi qu'à la cuisine. Le plan de l'UNF 2714 affiche une répartition fonctionnelle similaire, avec la pièce arrière (pièce 1b) également interprétée comme un entrepôt, et une pièce de vie (le) dans laquelle les fonctions culinaires semblent prépondérantes. 


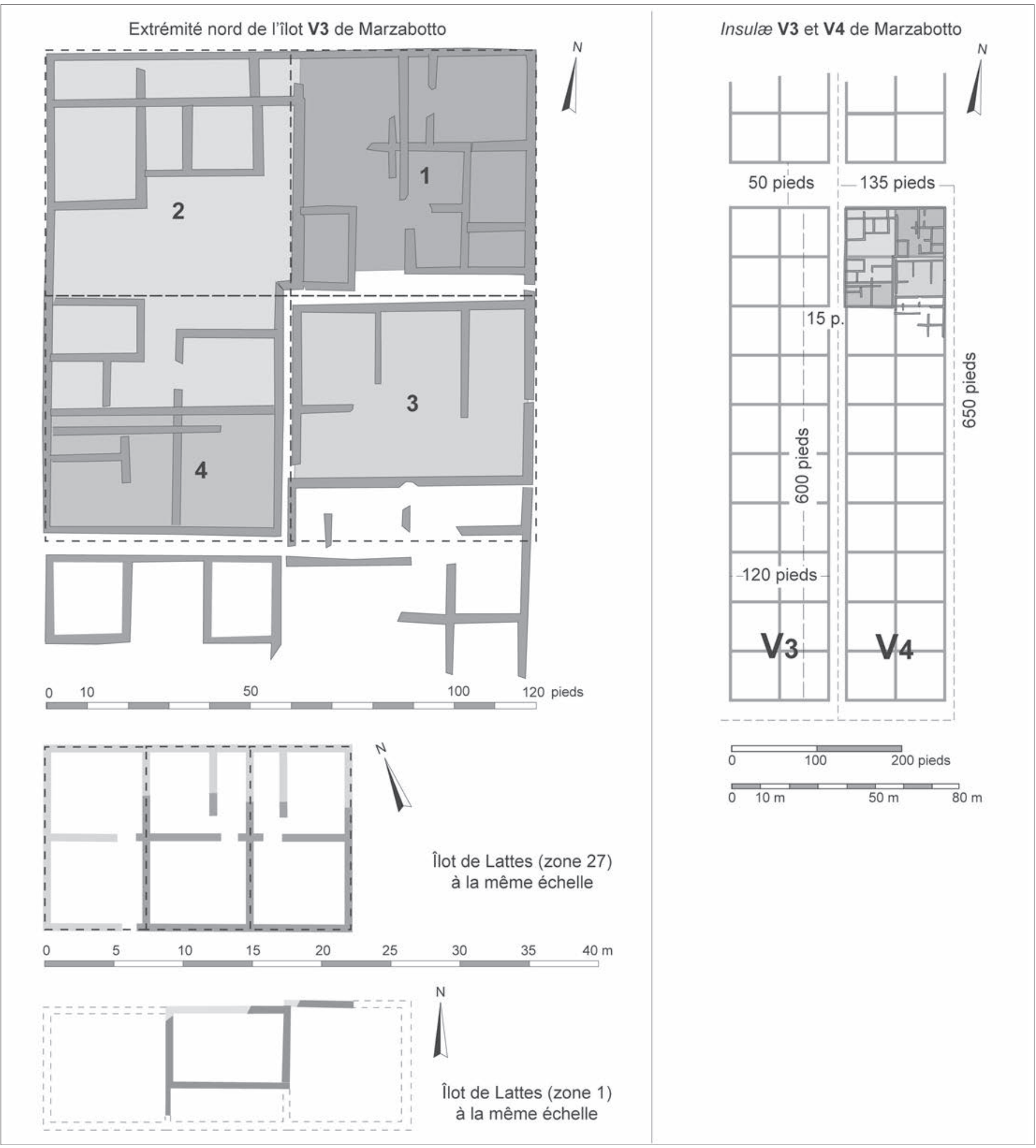

Fig. 5 - Îlot V3 de Marzabotto, détail de la partie fouillée et comparaison avec les plans restitués des îlots 27 et 1 de Lattes (Lebeaupin dir. 2014 , p. 89, fig. 29, modifiée). Îlot V3 de Marzabotto, d'après Massa-Pairault 1997 (planche hors-texte) : "L'auteur a mis en évidence quatre maisons aux dimensions variées (numérotées ici de 1 à 4), mais elle n'a pas distingué le découpage initial de l'îlot en lots carrés de 120 pieds de côté. Ces lots sont soulignés par les venelles servant à l'évacuation des eaux » (Lebeaupin dir. 2014, p. 89).

La morphologie d'ensemble de cet îlot se caractérise par une division identique des lots et une répartition symétrique du bâti, de part et d'autre d'un mur axial est-ouest. Au vu des données de fouille, on imagine ici une toiture en chaume de roseaux, avec une double pente reposant sur un faitage précisément positionné au niveau du mur axial. Par ailleurs, la présence de pans de murs effondrés à l'intérieur des pièces permet de restituer une hauteur minimale de $4 \mathrm{~m}$ pour la façade méridionale, et donc probablement autant pour la façade septentrionale. Cette construction est d'autant plus imposante qu'il faut alors considérer pour 
la toiture une pente minimale de $35^{\circ}$, ce qui suppose un mur axial d'au moins 8,50 $\mathrm{m}$ de haut. Des aménagements de type mezzanine ont pu exister, mais la fouille n'en a pas livré trace.

Plus encore par son plan que par sa mise en œuvre, il s'agit en tout état de cause d'un édifice hors-norme si on le compare à l'habitat indigène contemporain. La régularité du plan a en outre permis de reconnaître l'emploi de modules précis, définis par une unité de base qui n'est autre que le pied attique « solonien » de 29,60 cm. Le tracé de l'îlot aurait ainsi pour base un rectangle (restitué) de 75 pieds de long $(22,20 \mathrm{~m})$, divisé en trois lots de 25 pieds chacun. Cette unité, absente de la métrologie massaliète, est en revanche utilisée précisément en Étrurie, notamment dans le temple B de Pyrgi, ou encore à Marzabotto, où l'unité de base est constituée d'un carré de 60 pieds de large (Lebeaupin dir. 2014, p. 90-91) (fig. 5).

L'architecture et le faciès mobilier de la zone 27 ont éclairé d'un jour nouveau la problématique étrusque inhérente aux premiers temps de Lattara, apportant des indices probants à ce qui jusque-là n'était que pressenti, à savoir l'installation sur place d'une composante tyrrhénienne, allant de pair avec la mise en œuvre de schémas architecturaux exogènes. Sur ce point, la question du rempart s'avère moins décisive, mais rien ne permet de dissocier l'érection de cette fortification d'une quelconque initiative ou d'une réalisation étrusque. En soi, l'aspect des fortifications de Lattes reflète celui des enceintes de Gaule méridionale qui, en adoptant le principe d'élévations en adobes sur soubassements de pierres, s'inscrit de fait dans une tradition pan-méditerranéenne. Hormis les appareils cyclopéens (Roselle, Orbetello...) ou en grand appareil (Cortona, Volterra...) connus en Étrurie, un parallèle plus direct peut néanmoins être fait entre la muraille de Lattes et celles de certains sites étrusques tels Castellina del Marangone ou encore Poggio Civitella (Montalcino) (Py 2016, p. 228).

\section{LATTARA ÉTRUSQUE, DE NOUVEAUX ENJEUX}

Les fouilles de la zone 27 de Lattes/Saint-Sauveur ont apporté une confirmation pour ainsi dire indiscutable, non seulement de l'hypothèse d'une présence étrusque, mais encore du rôle actif de ces populations dans la genèse de l'établissement, constitué aux environs de 500 av. J.-C. à l'embouchure du Lez. Néanmoins, aussi importante qu'elle soit, cette confirmation a immédiatement suscité de nouvelles interrogations quant à la portée des observations réalisées (Lebeaupin, Séjalon 2008, p. 57). « Comptoir, emporion ou colonie ? » (Py 2009, p. 50) : la question a logiquement été posée en fonction d'une problématique fondamentale qui est celle du caractère strictement étrusque - ou pas - de cette installation. Dans la mesure où seule une fenêtre d'ampleur limitée avait pu être ouverte sur les périodes anciennes, rien ne permettait alors d'affirmer qu'un faciès différent n'aurait pu être révélé en d'autres points du site. En d'autres termes - avec en arrière-plan la question persistante d'une éventuelle présence indigène aux côtés des marchands tyrrhéniens -, si un quartier étrusque se trouvait près de la zone portuaire, pourquoi ne pas imaginer ailleurs un quartier grec, conférant au site un caractère multi-ethnique tout à fait envisageable dans le cadre d'un emporion, a fortiori au moment de considérer la pluralité des importations méditerranéennes sur le site voisin de la Cougourlude?

De fait, des éléments de réponse sont fournis dans la partie orientale du site, où un second espace de fouille a été consacré à l'exploration des phases anciennes de l'habitat. Sur une superficie de plus de $200 \mathrm{~m}^{2}$, cette zone munie d'un dispositif de palplanches a ainsi offert des conditions d'observation optimales pour suivre l'évolution d'un quartier d'habitation entre la fin $\mathrm{du} \mathrm{VI}^{\mathrm{e}}$ et le $\mathrm{II}^{\mathrm{e}}$ s. av. J.-C., livrant au passage une stratigraphie complexe de près de $4 \mathrm{~m}$ d'épaisseur ${ }^{2}$.

Le fait est que, pour le début du $\mathrm{v}^{\mathrm{e}} \mathrm{s}$. av. J.-C., la zone 1 a livré des vestiges largement comparables à ceux mis au jour dans la zone 27. Un îlot d'habitation fait de constructions mitoyennes quadrangulaires sur solins de pierre y est ainsi aménagé durant cette phase qui, ici encore, s'achève de manière brutale vers 480/470 av. J.-C., conséquence d'un incendie ayant affecté le quartier (fig. 6). Par ailleurs, de nombreux détails de la construction renvoient très directement aux observations réalisées dans le quartier étrusque de la zone 27. C'est d'abord le cas pour l'aspect parfaitement maîtrisé - et dans une certaine mesure innovant - des techniques mises en œuvre ; c'est également le cas des choix opérés en termes de préparation de l'espace, puisqu'on retrouve ici les mêmes remblais de sable d'origine fluviatile, destinés tant au nivellement qu'à l'assainissement des surfaces. En revanche, plusieurs différences notables se font jour.

La première tient à la plus grande complexité de la stratigraphie qui, loin de correspondre à une phase d'occupation unique, révèle en fait l'existence de deux séquences, à la fois distinctes et comprises dans un intervalle de temps resserré sur le premier quart du ve s. av. J.-C. Dans la zone 27, seules quelques traces fugaces avaient été repérées sur le paléosol de la fin $\mathrm{du} \mathrm{VI}^{\mathrm{e}}$ s. av. J.-C., mises en rapport avec le chantier de construction initié à la suite, « sur un espace peut-être fréquenté sporadiquement, mais non occupé avant le début des travaux » (Lebeaupin dir. 2014, p. 20). Or ici, c'est bien un état antérieur à la phase d'urbanisation évoquée plus haut (phase $1 S$ ) qui a pu être mis en évidence, avec l'existence d'un bâti à trame lâche directement au contact du substrat (phase 1T), nous amenant à reconsidérer la question des « niveaux de fondation » (fig. 6).

La deuxième tient à l'aspect que présente ce quartier au début $d u v^{e}$ s. av. J.-C., la fouille ayant démontré que l'incendie qui clôt cette phase de manière brutale a eu lieu avant que les travaux de construction aient pu être menés à terme. Dans une certaine mesure, le programme d'urbanisation mis en œuvre à Lattara a donc été progressif, ce qui n'a évidemment rien d'étonnant si l'on prend en compte l'ampleur d'un chantier potentiellement étalé sur plusieurs hectares. Cela permet malgré tout de considérer l'hypothèse d'étapes successives, non nécessairement coordonnées en fonction d'une même logique de départ. Quoi qu'il en soit, il faut remettre ces observations en perspective avec celles réalisées dans la zone 27, qui convergent pour attribuer à cette phase une durée très courte : « il y a bien

2. La zone 1 a été ouverte en 1984, dès le début des fouilles programmées pilotées par l'UMR 5140 (anciennement UPR 290 du CNRS). La fouille de cette zone, achevée en 2015, a été conduite jusqu'en 2004 par JeanClaude Roux (MCC) puis, à partir de cette date, par Éric Gailledrat (CNRS), avec la collaboration de Maria-Carme Belarte (ICAC) (1998-2008), puis celle d'Ariane Vacheret (2009-2015). 


\section{Phase 1T (état 1)}

Phase 1T (état 2)

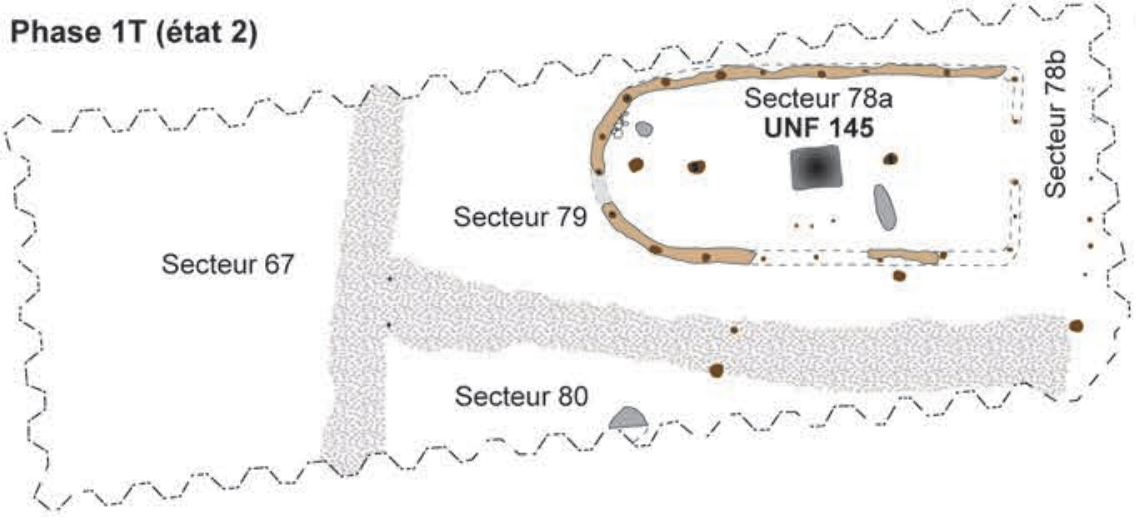

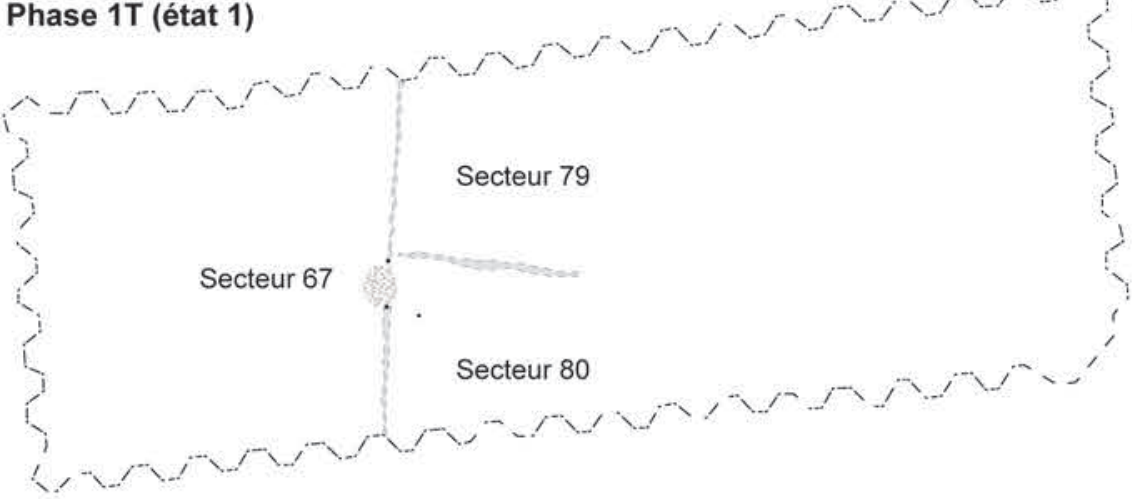

A

B

(C)

Phase 1S (état 1)

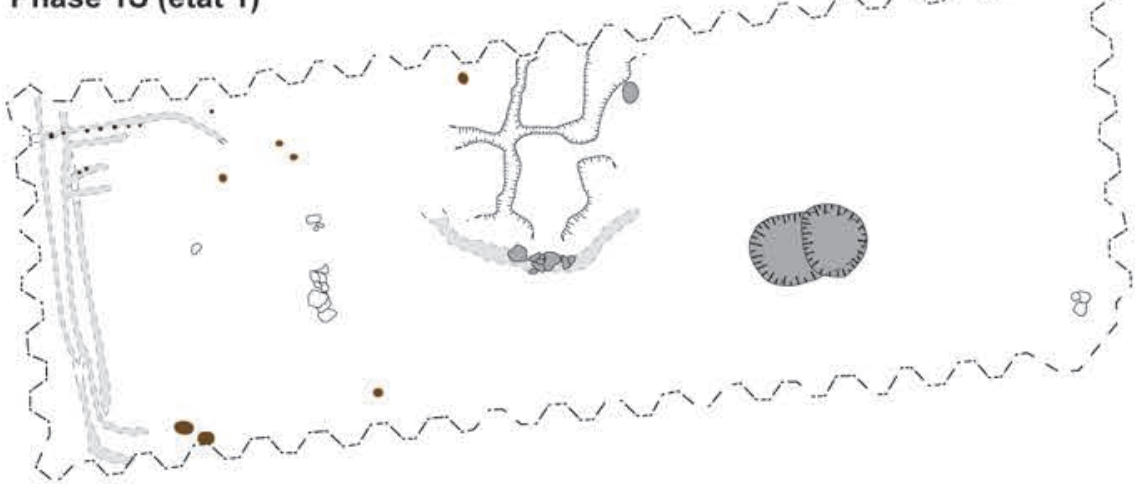

A)

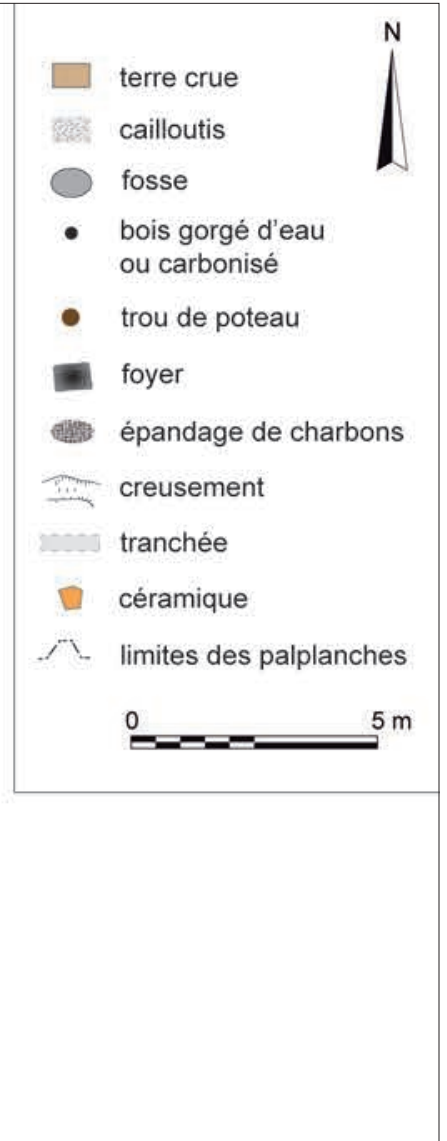






Fig. 7 - Comparaison des faciès céramique établis pour les zones 1 (phases 1T/1S) et 27 (phase 27I2). Les pourcentages sont exprimés en nombre de fragments. Les abréviations de catégories renvoient à la nomenclature Dicocer; A-ETR : amphore étrusque ; A-MAS : amphore massaliète ; B-NERO : bucchero nero ; CNT-LOR : céramique non tournée du Languedoc oriental ; COM-ETR : commune étrusque (DAO : É. Gailledrat).

une vie dans ces bâtiments, mais elle a pu ne durer que quelques années, voire quelques mois ; la prolonger sur un quart de siècle est probablement excessif » (Lebeaupin dir. 2014, p. 326).

Enfin, le faciès mobilier associé à ces deux phases successives appelle un certain nombre de remarques, qui vont dans le sens d'une accentuation du caractère étrusque des niveaux anciens de Lattara. En termes de chronologie absolue, et pour faire écho à ce que suggère la stratigraphie, la phase d'urbanisation du quartier (1S) doit être calée sur un laps de temps très court, contraint aux limites du premier quart du v e s. av. J.-C. La phase la plus ancienne (1T) en revanche affiche à l'évidence une certaine durée, mais rien ne permet de suggérer un terminus post quem plus ancien que le début de ce siècle. Ce cadre établi, la comparaison des faciès céramique (fig. 7) montre en premier lieu que si, effectivement, la part des amphores est anormalement élevée dans la zone 27, ce taux n'en demeure pas moins particulièrement important dans la zone 1. Quelle que soit la phase retenue, il se place à un niveau plus élevé que sur l'habitat voisin de la Cougourlude (phase 6), où les amphores représentent à la même époque $51 \%$ du total des fragments (Daveau, Py 2015, p. 35). La domination écrasante des amphores étrusques est en outre remarquable d'une zone à l'autre, 
confirmant la singularité de Lattara dans son contexte régional, y compris face à la Cougourlude où ces mêmes apports ne constituent alors que $41 \%$ des fragments de cette catégorie, somme toute assez loin derrière les produits massaliètes (51 \%) (ibid.). Cette abondance, qui peut refléter des habitudes de consommation spécifiques, n'en demeure pas moins indicatrice d'un volume d'échanges élevé, en lien avec les fonctions économiques inhérentes au site. En ce sens, l'existence de véritables entrepôts dans la zone 27 s'inscrit bien dans cette vision de Lattara en tant que débarcadère constituant un point d'entrée privilégié pour les produits du négoce méditerranéen - en l'occurrence tyrrhénien -, dont une part significative est bel et bien destinée aux échanges avec le monde indigène.

L'examen de la vaisselle confirme également l'importance de la composante étrusque, au sens large du terme, au sein de la zone 1. Le parallèle est ainsi frappant entre le mobilier de la phase d'installation (1T) et celui du quartier de la zone 27, en ce qui concerne la part respective des céramiques non tournées et de la vaisselle commune étrusque. Plus encore, la phase d'installation de la zone 1 recèle des quantités notables de vaisselle en bucchero nero. Cette catégorie est ensuite présente dans des proportions comparables d'un quartier à l'autre durant la séquence la plus récente (phases $1 \mathrm{~S}$ et 27I2); si les taux sont relativement minimes en termes de valeurs absolues, ils n'en demeurent pas moins largement supérieurs à ceux constatés à la même époque à La Courgourlude. Un écart non moins significatif est indiqué par la céramique commune tournée étrusque, d'un usage fréquent à Lattara et, à l'inverse, rarissime dans la grande agglomération indigène voisine.

L'image fournie par Lattara est globalement homogène, mais révèle toutefois certaines différences entre les deux quartiers explorés. On note ainsi que, durant la séquence récente (phases 1S et 27I2), la zone 1 affiche un taux de céramique non tournée indigène bien supérieur à celui de la zone 27 . Cette répartition doit toutefois être pondérée en fonction du panorama d'ensemble de la vaisselle, dans la mesure où l'on constate que le cumul des céramiques dites communes (tournées ou non) - largement destinées à la cuisine et au petit conditionnement domestique -, est strictement équivalent entre la zone 1 (1S) et la zone 27 (27I2). En tout état de cause, cette variation observée d'un quartier à l'autre ne saurait être surinterprétée comme étant le reflet d'une meilleure représentation de la composante indigène. En d'autres termes, rien ne permet de supposer que nous ayons à ce moment, dans la partie orientale du site, un quartier plus indigène ou plus mixte que dans la zone méridionale.

En définitive, si des nuances peuvent être apportées en termes d'assemblages typologiques et fonctionnels, tant d'une phase à l'autre que d'une zone à l'autre, l'importance de la composante étrusque durant les premiers temps de Lattara se voit globalement confirmée au vu du mobilier, a fortiori en considérant la présence de graffites sur céramique en écriture étrusque, présents dans la zone 1 au même titre que dans la zone 27 . Dans ces deux quartiers distants d'une centaine de mètres, le faciès mobilier se distingue donc radicalement, non seulement de celui constaté à la même époque sur les sites indigènes, mais encore de celui de l'agglomération voisine de la Cougourlude, qui se présente alors pourtant comme un site à vocation emporique largement ouvert aux apports méditerranéens.

\section{LA PHASE D'INSTALLATION (VERS 500/480 AV. J.-C. ?)}

Cette première phase est caractérisée par un niveau de sédimentation faiblement anthropisé, un paléosol ne se distinguant du substrat limoneux sous-jacent que par une matrice plus hétérogène, associée à une teinte brun-gris sombre, et par un aspect légèrement plus compact.

Une première série d'aménagements intervient avec le creusement de tranchées étroites, correspondant à l'implantation d'un dispositif en matériaux périssables, plus précisément d'une palissade légère probablement constituée d'une armature de piquets en bois et d'un treillis de branches entrelacées. Une première tranchée orientée nord-est - sud-ouest se prolonge, au nord comme au sud, au-delà des limites de la fouille. Elle présente en son centre une interruption de $0,85 \mathrm{~m}$ de large, encadrée par deux poteaux en bois encore en place et indiquée au sol par une nappe de petits galets. À partir de cette ouverture, on observe le départ d'une autre tranchée implantée perpendiculairement vers l'est, conservée sur environ $4 \mathrm{~m}$ de long. Ce dispositif, rapidement démantelé, semble avoir matérialisé une division de l'espace. Son caractère orthonormé est remarquable, tout autant que sa chronologie relative, en ce sens qu'il intervient ici avant la réalisation de toute autre construction ou trace d'activité dans ce secteur. De fait, cet aménagement semble bien témoigner d'une forme de cadastration préalable au lotissement de cette portion de terrain en bordure orientale du site (fig. 6a).

De nouveaux aménagements voient rapidement le jour, qui reprennent sensiblement le tracé des tranchées préexistantes et se superposent en partie à celles-ci. Ils prennent la forme d'un important apport de sédiment homogène argilosableux de couleur gris-jaune clair, mêlé de nombreux petits galets. Ces matériaux font l'objet d'un épandage régulier en deux bandes perpendiculaires d'une épaisseur maximale d'une vingtaine de centimètres, indurées en surface. Une première bande nord-est - sud-ouest, d'une largeur moyenne d'un mètre, se prolonge au-delà des limites de fouille. La seconde, sensiblement orientée est-ouest, est conservée sur une longueur de près de $14 \mathrm{~m}$ et présente une largeur irrégulière, comprise entre $0,90 \mathrm{~m}$ et $1,60 \mathrm{~m}$ environ. Outre le fait que ces aménagements reprennent assez fidèlement les orientations des palissades préexistantes, ils semblent bien devoir être interprétés comme de véritables recharges de rue. On assiste donc à ce moment à la mise en place d'un réseau viaire orthonormé qui vient en quelque sorte pérenniser la division de l'espace opérée en amont. Des décaissements survenus par la suite dans la partie ouest de la zone ne permettent pas de savoir si l'axe est-ouest correspondant à la rue 146 trouvait un prolongement de ce côté. En revanche, à l'est de la rue 145, deux lots sont ainsi clairement définis, d'une longueur minimale de $15 \mathrm{~m}$ (est-ouest) et d'une largeur minimale de $6 \mathrm{~m}$ (nord-sud).

Si ce n'est dès l'origine, du moins à partir du moment où sont mises en place les rues 145 et 146, un édifice de plan absidial (UNF 145) est bâti dans le lot ainsi formé dans la partie nord-est de la zone de fouille (fig. 6b). Son état de conservation remarquable, lié notamment à la préservation de bon nombre d'éléments en bois (bases de poteaux ou de piquets), permet à la fois une restitution très précise du plan et des techniques mises en œuvre. 


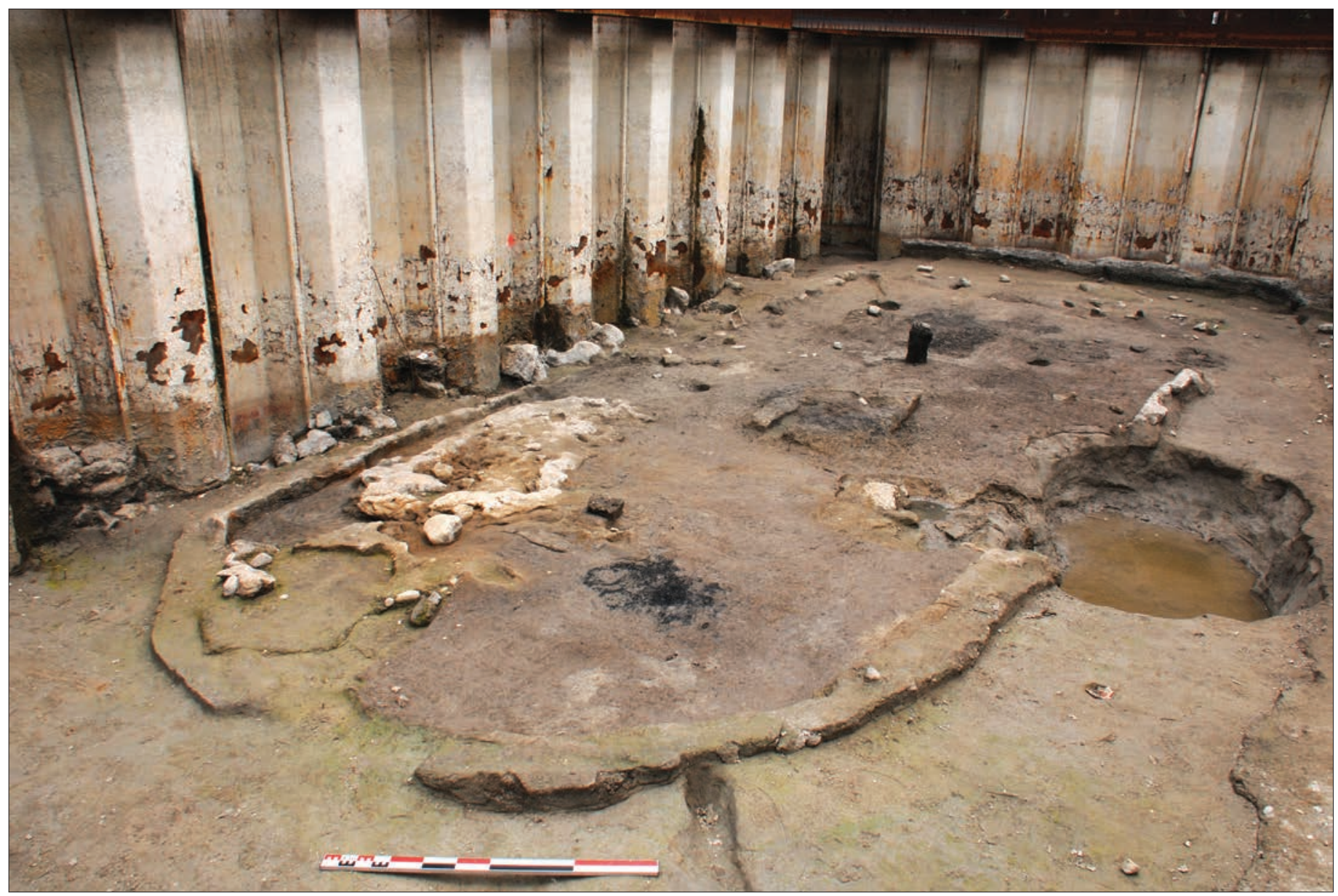

Fig. 8 - Lattes, zone 1 (phase 1T). Vue depuis le sud-ouest du bâtiment absidial (UNF 145).

La paroi méridionale est en partie recoupée par une fosse de la phase suivante (1S) (cliché : É. Gailledrat).

Lédifice en question se présente sous la forme d'une construction mono-absidiale sur poteaux porteurs, strictement orientée est-ouest avec l'entrée située côté est. Il se compose de deux parties distinctes, avec d'un côté le corps du bâtiment parfaitement circonscrit par les restes d'une paroi en torchis, de l'autre une série de poteaux et piquets interprétés comme les restes d'un auvent protégeant l'entrée, ici matérialisée par une ouverture de 1,10 m de large. Les dimensions hors œuvre sont de $8,80 \mathrm{~m}$ de long (chiffre auquel il faut ajouter la largeur de l'auvent, soit $1,36 \mathrm{~m}$ ) pour $4,12 \mathrm{~m}$ de large. La surface utile est d'environ $27 \mathrm{~m}^{2}$, auxquels il faut adjoindre les quelque $4,70 \mathrm{~m}^{2}$ de l'auvent, soit un total de $31,70 \mathrm{~m}^{2}$. Conservées de manière inégale, les parois sont indiquées au sol par un bourrelet de terre argilo-limoneuse très compacte et homogène, de couleur brune. D'une largeur moyenne de 30 à $32 \mathrm{~cm}$, marquant à l'origine la base de la paroi en clayonnage, ce dernier est installé dans une légère semelle de fondation. Des poteaux et piquets en bois destinés à supporter une élévation en torchis sont préalablement implantés à intervalles réguliers (fig. 8). L'axe du bâtiment est matérialisé par deux poutres de grande section profondément enfoncées dans le sol et destinées au soutènement du faitage. L'emplacement du poteau situé côté ouest marque le début de l'abside correspondant à la partie arrière de l'habitation. Il faut ainsi restituer un édifice à deux nefs sur poteaux porteurs avec une toiture à double pente réalisée en chaume, probablement de roseaux (phragmites). Dans cette configuration, le poids des chevrons de la charpente porte principalement sur une panne faîtière, tandis que l'autre extrémité repose sur des sablières hautes reliant entre eux les poteaux du mur. Avec une inclinaison de $45^{\circ}$ pour la toiture et des parois d'une hauteur d'environ $1,70 \mathrm{~m}$, la hauteur sous faîtage serait de 3,50 m environ. La restitution proposée, qui inclut celle d'un auvent ouvert sur trois côtés, tient compte de l'ensemble de ces observations (fig. 9).

Le centre de la pièce est occupé par un foyer de plan rectangulaire construit à même le sol, ayant connu un minimum de quatre réfections. L'emplacement de cette structure de combustion, destinée tant au chauffage qu'à l'éclairage, ou encore à la cuisine, n'a pas varié tout au long de la durée de vie du bâtiment, qu'il faut à l'évidence interpréter comme une unité d'habitation. Aucune division interne n'a été clairement observée sur le plan architectural, mais l'aspect des sols - constitués de recharges de sable ou de limon-, ainsi que la présence de divers aménagements - fosses, trous de piquets, possibles restes de banquette en terre... - laissent toutefois entrevoir une certaine sectorisation de l'espace. Celle-ci se traduirait d'est en ouest par la présence d'un «vestibule » situé au niveau de l'entrée, par celle d'un espace de vie principal entre les deux poteaux de la travée centrale et enfin par un espace plus confiné (réserve ?) au niveau de l'abside.

Indépendamment de son état de conservation et des possibilités de lecture ainsi offertes au niveau du plan, la régularité de ce bâtiment appelle un certain nombre de commentaires. En effet, le tracé au sol s'inscrit dans une forme géométrique composée de deux modules carrés d'environ $4 \mathrm{~m}$ de côté, l'un coïncidant 

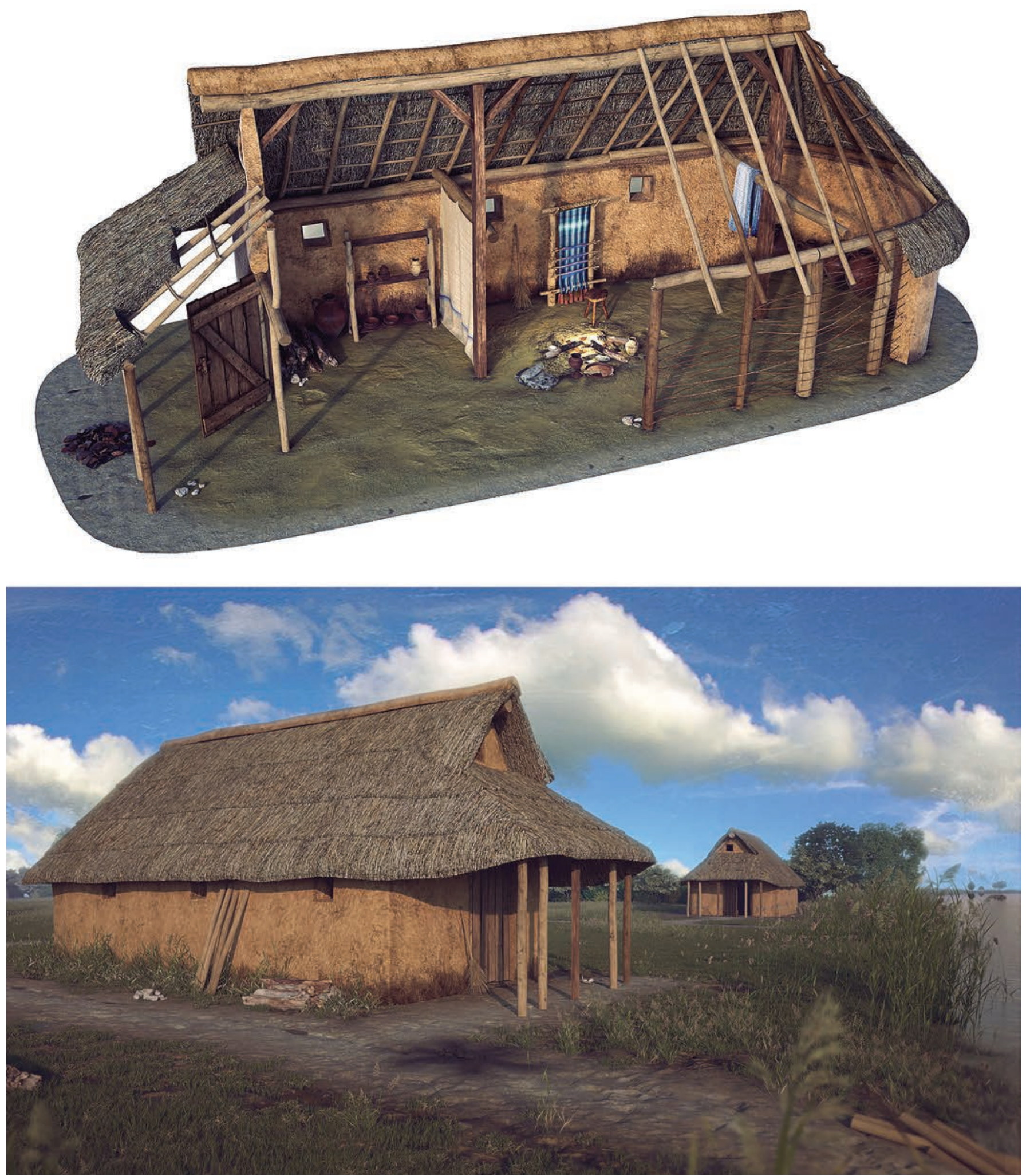

Fig. 9 - Proposition de restitution volumétrique et paysagère du bâtiment absidial d'après les données de fouille (site archéologique Lattara - Musée Henri-Prades ; Réalisation : M. Mondou).

Il est alors tentant de pousser plus loin l'analyse, en cherchant à identifier des mesures précises associées à une unité de base un tant soit peu normalisée. Compte tenu des interprétations proposées par ailleurs sur le site, plus concrètement au niveau de la zone 27, l'hypothèse de l'emploi du pied attique « solonien » de 29,60 $\mathrm{cm}$ peut ainsi être formulée, avec toutes les réserves que présuppose ce type d'approche (Tréziny 1989). 
Différentes solutions peuvent être envisagées, partant du principe que les mesures au sol peuvent définir, tantôt l'emprise de la construction (superficie hors œuvre), tantôt la surface utile, voire plus simplement le tracé du bâti, ici matérialisé par l'alignement des poteaux constituant l'armature des parois. Dans ce cas néanmoins, l'hypothèse de l'emploi d'un pied de 29,60 cm ne s'accommode véritablement que de la première solution, avec un bâtiment de 35 pieds de long pour 14 de large, et la juxtaposition de deux modules carrés de 14 pieds de côté, avec une abside inscrite dans un cercle de 7 pieds de rayon (fig. 10b). Si le schéma global apparaît cohérent, en dépit d'une relative déformation du plan au niveau de l'abside, on peine cependant à reconnaître dans ces mesures l'emploi de multiples connus par ailleurs, comme peut l'être la brasse de 6 pieds, ou même celui des divisions restituées pour l'îlot de la zone 27 (Lebeaupin dir. 2014, p. 86-91).

De fait, il est légitime de s'interroger sur l'éventuel emploi d'une autre unité de base, avec à la clé des alternatives d'autant plus complexes à mettre en évidence que l'utilisation d'un système de mesure autre que celui fondé sur le pied attique n’a pas, à ce jour, été explicitement démontré en Étrurie pour la fin de l'époque archaïque. De même, compte tenu du contexte, il faudrait ici prendre en compte la question (non moins délicate) de la métrologie ionienne, voire des systèmes en cours dans le registre architectural indigène, indépendamment de toute influence exogène (Tréziny 1989). Or force est de constater que le tracé du bâtiment absidial de la zone 1 s'accommode parfaitement de l'emploi d'une unité de base de $33 \mathrm{~cm}$, qui donnerait alors un édifice de 30 pieds de long pour 12 de large, avec la juxtaposition de deux modules carrés de 12 pieds de côté et une abside de 6 pieds de rayon; dans cette configuration, la partie orientale de la maison adopterait une division régulière en deux tiers (vestibule) - un tiers (porche). Enfin, a contrario de la restitution faite sur la base du pied de $29,60 \mathrm{~cm}$, on n'observerait ici qu'un décalage minimal du tracé de l'abside vis-à-vis du plan de base, tandis que l'implantation des poteaux de la travée axiale coïnciderait parfaitement avec la division interne du bâtiment, telle qu'elle peut être restituée (fig. 10c). Au demeurant, cette unité de $33 \mathrm{~cm}$ est proche d'une autre mesure grecque, le pygmè attique solonien de $33,30 \mathrm{~cm}$, équivalant non pas à 16 doigts de $1,85 \mathrm{~cm}$ comme l'est le pied, mais à 18 .

En soi, cette mesure intermédiaire entre le pied et la coudée n'est pas totalement inconnue à Lattes, puisqu'elle correspond à la longueur de certaines briques crues mises en œuvre au début du ve s. av. J.-C. dans la zone 27 (Lebeaupin dir. 2014, p. 83). Dans ce contexte, où le calibre moyen le plus représentatif est de 31-35 x 45-49 x 7-7,50 cm, les adobes utilisés présentent néanmoins des dimensions assez variées, de même que les formes, tantôt rectangulaires, tantôt carrées, suggérant l'existence de savoir-faire distincts employés simultanément à l'occasion du chantier de construction (ibid.). À Lattara, la même remarque vaut d'ailleurs pour les phases postérieures, en ce sens que durant tout le $\mathrm{v}^{\mathrm{e}} \mathrm{s}$. av. J.-C., deux grands types d'adobes sont utilisés, l'un carré de 35 à $45 \mathrm{~cm}$ de côté, l'autre rectangulaire, représentant un demi-module de 35 x $20 \mathrm{~cm}$ en moyenne (Py 2009 , p. 184). Plus généralement, au regard des plans de l'habitat du second âge du Fer, si l'emploi de modules ne fait aucun doute, permettant de caractériser autant de lots sujets à de multiples remaniements (Py 2009, p. 105-197 ; Garcia 2014, p. 181-186),

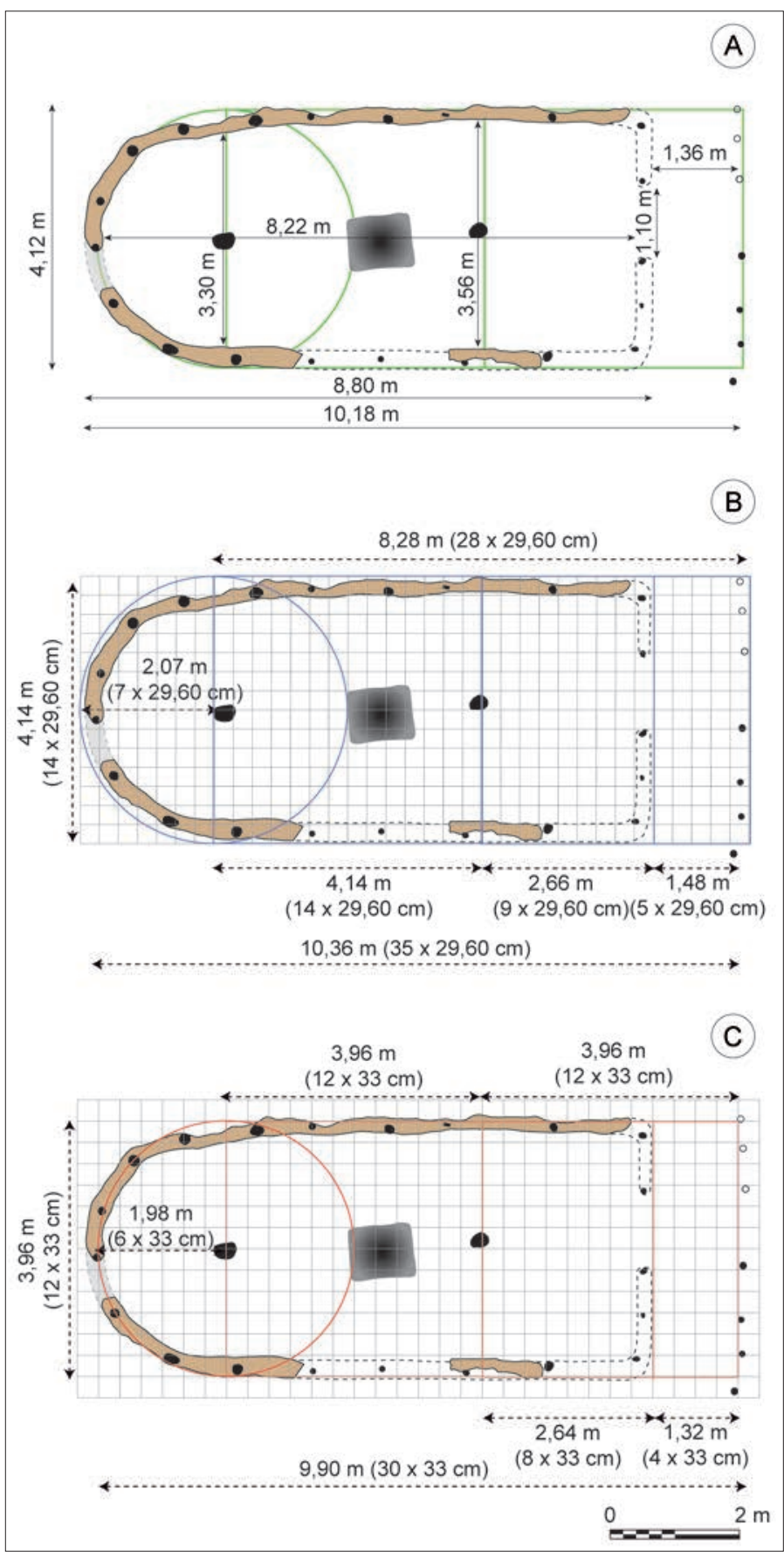

Fig. 10 - Plan coté de I'UNF 145 (A) et propositions de lecture métrologique sur la base du pied attique de $29,60 \mathrm{~cm}$ (B) ou du pygmè de $33 \mathrm{~cm}$ (C) (DAO : É. Gailledrat).

la reconnaissance d'un ou de plusieurs systèmes métrologiques demeure d'autant plus délicate que l'on envisage un contexte culturel fait d'une juxtaposition de traditions différentes (locales d'un côté, grecques de l'autre), traductible en termes d'héritages et d'emprunts ${ }^{3}$. Les propositions énoncées dans le cas du bâtiment absidial de la zone 1 reposent, tout comme pour le quartier de la zone 27 , sur le double constat d'une régularité

3. «L'expérience paraît prouver en fait que les unités métrologiques utilisées sur un site sont relativement variées et nombreuses, soit qu'elles aient changé avec le temps, soit que l'appel à des artisans étrangers ait entraîné, sur un chantier, l'utilisation d'un étalon spécifique : il faut tenir compte également des variations possibles autour d'une mesure-étalon, en fonction du maître d'œuvre » (Tréziny 1989, p. 2). 
manifeste du plan et de l'existence d'une tradition architecturale bien établie qui, en l'occurrence et au vu du faciès mobilier, devrait être rattachée au monde étrusque. Pour autant, et faute d'éléments de comparaison directs, la proposition énoncée ici de l'emploi d'une mesure assimilée au pygmè ne doit être considérée qu'à titre d'hypothèse. Elle invite néanmoins à ouvrir le champ des possibles au moment de considérer les conditions humaines et matérielles qui entourent cette phase d'installation.

\section{LA MISE EN PLACE D'UNE TRAME URBAINE (VERS 480/470 AV. J.-C. ?)}

Peu de temps après se produit un changement important du cadre architectural, qui se traduit par la présence de constructions à soubassement en pierres liées à la terre, et élévation en bauge ou adobe, prenant la forme d'un îlot constitué de pièces mitoyennes. Le plan témoigne d'un changement d'orientation au regard de la phase précédente, puisque la trame orthonormée qui régit l'implantation de l'îlot est établie selon deux axes strictement nord-sud - est-ouest. Le décalage d'environ $5^{\circ}$ constaté dans l'orientation du lotissement opéré au moment de l'installation n'est donc pas repris ici, mais on a vu qu'une disposition strictement est-ouest caractérisait déjà le bâtiment absidial de la phase 1T, préfigurant en quelque sorte le choix opéré par la suite. Deux états, très rapprochés dans le temps, peuvent être distingués au sein de cette nouvelle phase, constituant l'un comme l'autre deux étapes successives d'un même programme de construction demeuré inachevé. La compréhension du plan d'ensemble est évidemment d'autant plus compliquée que les limites de l'îlot débordent du cadre contraint de la zone de fouille. Un certain nombre de remarques peuvent néanmoins être formulées, qui suggèrent à la fois la complexité du schéma urbanistique mis en place et l'existence d'un certain nombre de contraintes liées au terrain, tandis qu'est posée la question de la date d'érection du rempart, dont la présence est confirmée à quelques mètres plus à l'est.

Dans un premier temps, après le démantèlement de la construction absidiale préexistante et un nivellement sommaire du terrain, différents aménagements prennent place sur l'ensemble de la zone (fig. 6c). À l'ouest, une série de tranchées peu profondes et étroites entaillent le substrat sablo-limoneux. Elles correspondent manifestement à l'implantation de structures légères en matériaux périssables, comme en témoignent plusieurs bases de piquets en bois encore en place ici ou là. Leur tracé est sensiblement nord-sud, mais ne correspond pas aux orientations qui régissent ensuite l'implantation du bâti. $\mathrm{Au}$ nord, elles se prolongent au-delà des limites de fouille, tandis qu'au sud elles s'infléchissent vers l'est, formant un retour d'environ $1 \mathrm{~m}$. De tels retours sont également présents plus au nord, donnant l'image de dispositifs plus ou moins quadrangulaires et ouverts du côté est. Restes de cabanes ou de palissades ? Plusieurs arguments permettent de souligner le caractère particulièrement hydromorphe de cette portion de terrain et d'avancer l'hypothèse, sinon d'un aménagement de berge, du moins d'un dispositif destiné à stabiliser le terrain, probablement constitué de lignes de clayonnage ou de fascines. Le relatif enchevêtrement des tranchées laisse à penser que ces dispositifs ont pu faire l'objet de réfections, mais il est également probable qu'elles aient fonctionné de manière groupée, l'espace compris entre deux lignes de clayonnage ayant pu être garni de végétaux ligneux. Un défluent du Lez passant à faible distance de là, côté est, il est donc possible que l'on se retrouve face à une langue de terre encore partiellement inondable, traversée par un diverticule - peut-être temporaire - du fleuve, justifiant ainsi de tels travaux. Quoi qu'il en soit, un léger décaissement a ensuite été opéré dans le tiers occidental de la zone, qui a partiellement amputé le chemin nord-sud (rue 145) de la phase précédente. Dans la foulée, l'espace a été remblayé à l'aide d'une épaisse couche stérile de sable, dont la limite ouest est précisément marquée par le négatif des aménagements venant d'être décrits.

Vers le centre de la zone, on note la présence d'amas de sédiments rapportés, en l'occurrence de limon. Dans ces amas aux contours irréguliers, partiellement délimités au sud par une tranchée au tracé courbe (implantation d'une structure en élévation ?) sont encore visibles des traces de creusement qui suggèrent l'extraction de sédiment à l'aide d'une houe ou d'un outil comparable. Il semble s'agir ici d'une aire de travail, destinée à la préparation de matériaux de construction en terre crue (bauge ou adobes ?), mélangés et malaxés sur place. À cette aire de travail pourraient également se rattacher les deux fosses successives creusées à proximité, dont le fond est partiellement colmaté d'un sédiment extrêmement hétérogène. En dépit de leur taille relativement réduite, plus que de simples puisards, il pourrait s'agir là de fosses destinées au foulage de la terre à bâtir.

De nouveaux travaux sont très rapidement effectués, qui se traduisent notamment par la construction de bâtiments et par l'apport d'un remblai de sable d'épaisseur variable qui, tantôt précède la construction des murs, tantôt lui succède ; l'espace est ainsi divisé en plusieurs secteurs dont les limites ne sont que partiellement reconnues (fig. 6d). Le seul ensemble complet (secteur 68) correspond à une pièce ou à une unité fonctionnelle indépendante (UNF 143) de plan rectangulaire barlong. Elle possède une longueur hors œuvre de 9 sur $6 \mathrm{~m}$, délimitant ainsi une superficie utile d'environ $38 \mathrm{~m}^{2}$. Les solins de murs sont constitués de blocs et de moellons calcaires liés à la terre, bruts ou équarris, disposés en appareil irrégulier assisé. Aucune porte n'a été repérée, mais le mur nord est partiellement occulté par les palplanches délimitant la zone de fouille, tandis que l'angle sud-est est quant à lui demeuré inachevé. À l'inverse des bâtiments de la zone 27, aucun enduit mural n'a été retrouvé. Par ailleurs, en dépit de la présence d'un foyer à plat situé dans la partie nord de la pièce, aucun niveau de sol cohérent n'a pu être mis en évidence. La présence d'amas de terre malaxée (à l'ouest) et d'un épandage de cailloux et de moellons (à l'est) évoque à nouveau un chantier en cours auquel se rattachent diverses fosses ainsi que des trous de poteau, l'implantation de certains d'entre eux faisant penser à des vestiges d'échafaudages destinés à l'érection des murs. Des amas de bauge très compacte aux contours mal définis sont en outre disposés le long des murs de la partie occidentale de la pièce. Ils évoquent des sortes de plateformes, peut-être mises à profit durant les travaux comme aire de circulation légèrement surélevée et destinées à être, par la suite, retaillées à la verticale pour en faire de véritables banquettes, à l'image de celle qui longe la façade occidentale des secteurs 68 et 69 . 


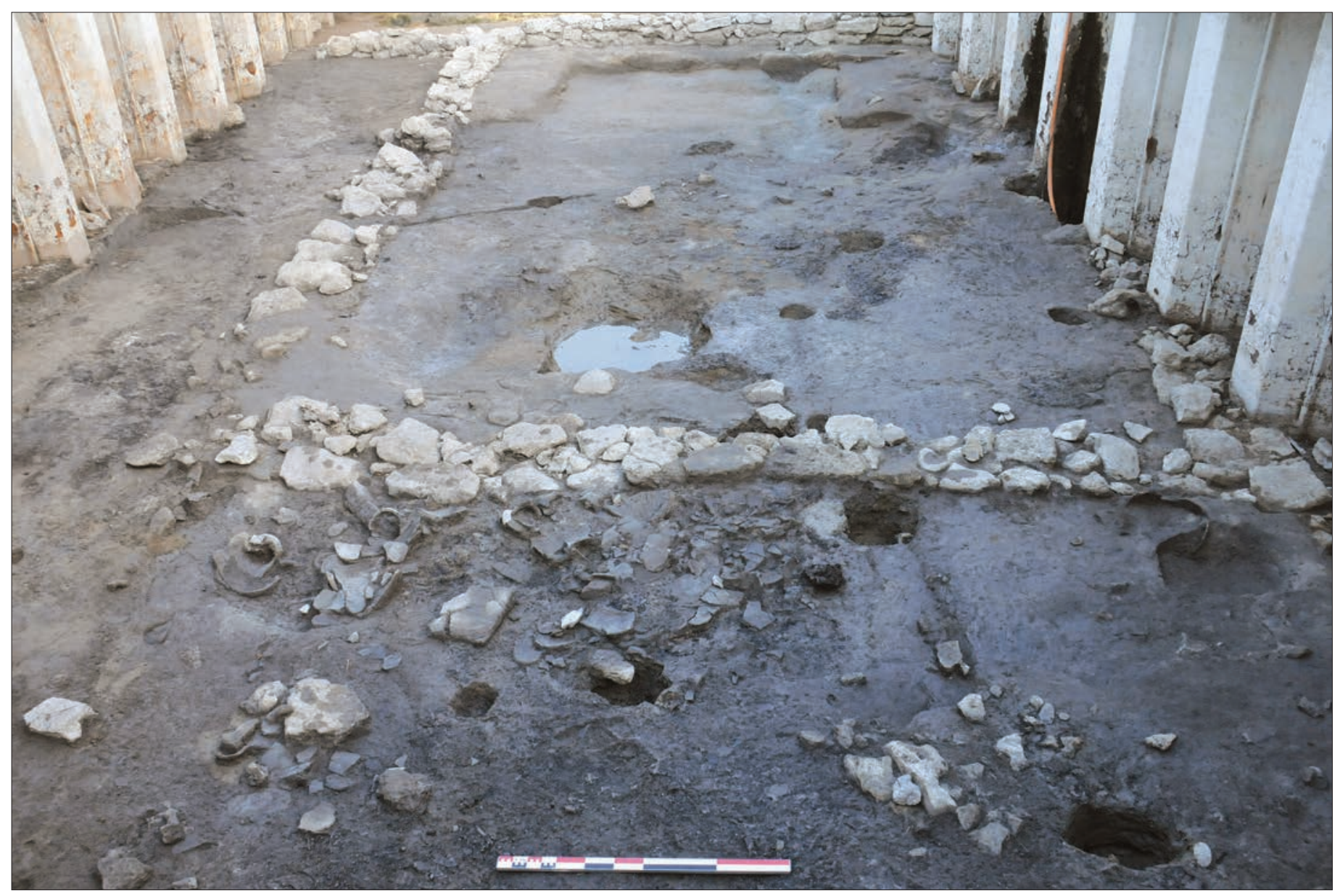

Fig. 11 - Lattes, zone 1 (phase 1S). Vue depuis l'est du niveau d'abandon consécutif à un incendie. Au premier plan, trous de poteau et céramiques étrusques écrasées sur place; au second plan, la pièce rectangulaire inachevée correspondant à l'UNF 143 (cliché : É. Gailledrat).

Ici encore se pose la question des unités de mesure ayant pu être utilisées, avec en arrière-plan la question de l'emploi du pied «attique » ou de cette mesure alternative (le pygmè) pressentie pour la construction de la phase antérieure. Force est de constater que la question est particulièrement complexe, eu égard à l'absence d'autre éléments permettant de définir les limites de l'îlot dans lequel s'insère l'UNF 143. En revanche, en comparant les plans disponibles pour l'une et l'autre phase, on constate une parfaite concordance entre la longueur de l'UNF 143 (phase 1S) et le corps de la maison absidiale (phase 1T), autrement dit la partie fermée de l'habitation, à l'exclusion de l'auvent. Simple coïncidence ou reflet de la permanence d'un module ? Cette dernière hypothèse paraît vraisemblable, et suggère que le tracé au sol de la construction correspond assez bien à l'entraxe des murs, du moins ceux nord-sud, qui a priori sont mitoyens avec d'autres pièces ou espaces adjacents.

Dans la partie occidentale de la zone (secteur 67), un remblai d'argile vient recouvrir le niveau de sable préalablement disposé et se prolonge vers l'ouest au-delà des limites de fouille. La présence de divers aménagements en lien avec un niveau de sol très régulier, de même que la présence de la banquette le long des murs situés à l'est, indiquent que l'on se trouve là dans un espace couvert (ou destiné à l'être), autrement dit d'une pièce dont les limites nord, ouest et sud ne sont malheureusement pas connues, mais qui mesure a minima $8 \mathrm{~m}$ de long pour autant de large. L'interruption régulière du mur la séparant du secteur 69 suggère enfin l'existence d'une porte à cet endroit, bien que la fouille n'ait pas permis de confirmer ce point. Ce dernier secteur n'a pu faire l'objet que d'observations partielles, mais laisse cependant apparaître une banquette inachevée ainsi que des foyers sommaires.

Aucune limite concrète n'a été mise en évidence entre les secteurs 69 et 77, ce dernier occupant toute la partie est de la zone de fouille. Au nord, le secteur 77 est limité par un mur d'orientation est-ouest dont le tracé accuse un léger décalage avec celui de l'UNF 143. Plus qu'une façade d'îlot (que l'on imagine plus volontiers rectiligne), on peut alors se demander s'il ne s'agirait pas là de simples séparations avec d'autres espaces bâtis qui se trouveraient immédiatement au nord de l'emprise de fouille, hypothèse qui demeure possible au vu de la morphologie de la pièce la plus occidentale (secteur 67). L'interruption vers l'est de ce mur fait par ailleurs penser à un piédroit de porte, ouvrant donc vers le nord, mais ici encore les observations demeurent partielles. La stratigraphie de ce secteur tranche avec celle des espaces adjacents, en ce sens que des traces explicites d'incendie ont figé un niveau d'occupation, marqué entre autres par la présence d'une meule en place sur le sol ainsi que par des vases de stockage (principalement des amphores étrusques) écrasés sur place. Leur position initiale, à la fois le long des murs ouest et nord et dessinant un alignement régulier côté est, suggère que toute la partie nord du secteur, adossée à l'UNF 143, correspond à un espace fermé ou, plus probablement, semi-ouvert (fig. 11). L'hypothèse d'une superstructure en matériaux périssables peut 
ainsi être avancée, de sorte que se dessine un espace de vie temporaire en forme d'appentis, au milieu de ce qui apparaît bien comme un chantier de construction, hypothèse que tend à confirmer non seulement l'aspect lacunaire de certains murs (qui ne doit rien à la destruction postérieure), mais aussi l'évidence de couches directement liées à la mise en œuvre de matériaux à bâtir, ou encore l'absence de finitions à l'intérieur des pièces (enduits à la chaux, par exemple) telles qu'elles ont pu en revanche être observées dans la zone 27.

Le mobilier présent dans cet espace témoigne de son utilisation en tant que lieu de vie, de préparation (mouture, cuisson ?) et de consommation des repas. À côté de nombreuses amphores vinaires, ce même mobilier renvoie en effet l'image d'un service complet associant des vases de préparation (mortiers, jattes) et de cuisson (pots), pour l'essentiel en céramique commune étrusque ou en non tournée, à des vases de consommation individuels, parmi lesquels on note la présence de plusieurs bols en bucchero nero, dont certains portent des graffites en écriture étrusque associés à des marques de propriété. La table de mouture mise au jour dans ce contexte étant elle-même importée d'Étrurie, l'ensemble ne laisse au final guère de doute quant à la présence d'Étrusques parmi les bâtisseurs de ce quartier.

À ce stade doit être posée la question du rempart, dont la tranchée d'épierrement (datée entre l'Antiquité et le Moyen Âge) a pu être mise en évidence à environ $4 \mathrm{~m}$ à l'est de la limite de fouille, telle que définie par les palplanches installées en 1996 (fig. 6c et d). Cette tranchée d'épierrement n'a fait l'objet que d'observations superficielles au moment d'étudier la morphologie de cet îlot qui, au moins depuis le IV e s. av. J.-C., s'appuyait contre le rempart (Roux 1999). Il est de fait impossible de dire s'il subsiste ou non une partie de l'élévation de ce mur, et encore plus de pouvoir disposer d'un quelconque lien stratigraphique avec les niveaux du début du $\mathrm{v}^{\mathrm{e}} \mathrm{S}$. av. J.-C. dont il est question ici. La seule certitude concerne le tracé du rempart durant le second âge du Fer et, par analogie avec ce qui a été démontré par ailleurs, la conviction que ce dernier se superpose à l'enceinte primitive érigée à la charnière des $\mathrm{VI}^{\mathrm{e}}-\mathrm{V}^{\mathrm{e}} \mathrm{s}$. av. J.-C. (Py 2009, p. 26-32). De fait, à l'image de ce qui a été observé dans la zone 27, il est à peu près certain que l'îlot bâti durant la phase $1 \mathrm{~S}$ venait pratiquement au contact du rempart archaïque côté est.

Reste la question de la contemporanéité de ces deux programmes de construction (d'un côté l'enceinte, de l'autre l'îlot 1), car si on les imagine volontiers avoir été initiés au même moment, la mise en évidence d'une phase d'occupation antérieure (1T) amène néanmoins à reconsidérer la question. En d'autres termes, peut-on suggérer que le rempart existait déjà durant cette phase dite d'installation, précédant alors le programme urbanistique lancé peu de temps après ? Le caractère fondateur lié à la construction d'un rempart a été justement évoqué par ailleurs, en soulignant la double vocation, tant pratique que symbolique, d'une telle entreprise (Py 2009, p. 26-27). La dimension symbolique, loin de se limiter à la seule matérialisation de l'espace vécu, prend d'autant plus de sens que se profile ici l'idée d'une véritable fondation tyrrhénienne, potentiellement soumise à un certain nombre de codes ou de rites précis, intrinsèquement liés à l'habitat au sens large, tel qu'il se présente dans le monde étrusque (Briquel 2008). Sans anticiper sur ce point, le fait est que la première enceinte de Lattara semble avoir englobé tout l'espace disponible sur cette presqu'île enserrée par deux bras du
Lez, pouvant même « servir à protéger la zone atterrie en jouant le rôle d'une digue contre les crues du fleuve et le battement de la lagune » (Py 2009, p. 27). Sur le plan pratique, de tels travaux feraient donc bien écho à ce que l'on perçoit au travers des aménagements réalisés dans la zone 1 durant la phase $1 \mathrm{~S}$, tels que l'assainissement et la stabilisation d'une portion de terrain encore dépendante des fluctuations de la nappe phréatique ou des écoulements d'eau saisonniers.

Rien n'interdit de penser que le bâtiment absidial érigé durant la phase d'installation (1T) ait pu être (en partie du moins) contemporain de la muraille, dont le parement interne se serait alors trouvé à quelque 4 ou 5 m de l'entrée de la maison, située précisément côté est. Une telle configuration est possible, mais on restituera plus volontiers un quartier encore ouvert, donnant sur les berges du bras mineur du Lez qui coulait à proximité (fig. 9). Que l'on privilégie ou non cette hypothèse, il convient de verser au dossier la mention, dans le sondage 27 du GAP, d'un niveau d'occupation situé au contact du substrat et s'engageant sous la base du rempart (Py 1988, p. 128, n. 45). Simple surface liée à la fréquentation du lieu, peu ou prou au moment du démarrage du chantier de construction de l'enceinte (comme cela a été proposé dans le cas de la zone 27) ou trace d'une phase antérieure, à l'image de ce qui est apparu dans la zone 1 ? La question reste en suspens.

\section{CARACTÈRES GÉNÉRAUX ET SPÉCIFICITÉS DE L'INSTALLATION ÉTRUSQUE À LATTARA}

Les données de la zone 1 ne confirment pas seulement ce qui était déjà perçu auparavant, à savoir la présence d'une communauté étrusque à Lattara au début du ve s. av. J.-C., mais renouvellent de manière substantielle les questions liées à la caractérisation et à l'interprétation de cette phase, que l'on peut désormais scinder en deux moment distincts. Au regard d'un faciès mobilier ne laissant que peu de place au doute sur l'identité des personnes occupant cet espace, durant le quart de siècle que couvre (au mieux) cette séquence stratigraphique, les caractéristiques intrinsèques de l'habitat invitent à replacer les découvertes de Lattara dans un contexte plus large, qui n'est autre que celui du monde étrusque à la fin de l'époque archaïque.

Il convient alors de revenir sur les faits observés, avec en premier lieu l'évidence d'une structuration raisonnée de l'espace qui s'est traduite par la mise en place d'un découpage orthonormé du terrain, matérialisé par un système de clôtures puis par une voirie, agencement dans lequel on est invité à reconnaître la trace d'une division en lots fonciers, voire d'une véritable cadastration. Dès lors, outre le fait que l'on se trouve dans un cas de figure évoquant les premières étapes d'une installation de type colonial, la comparaison s'impose avec les pratiques largement documentées dans le monde étrusque, relatives à la structuration de l'espace urbain selon une trame orthogonale (Jolivet 2015).

Plus encore, dans la mesure où la dimension symbolique - voire religieuse - liée à l'acte de fondation, propre à l'Etrusca disciplina, y joue un rôle essentiel (Sassatelli 1990 ; Briquel 2008), cela suggère de fait certaines pistes de réflexion quant au cas particulier de Lattara. Or sur ce point, si aucune évidence 
de bornage associé à une pratique rituelle n'a pu être démontrée dans la zone 1, un autre document doit en revanche être remis en perspective : il s'agit de la découverte - déjà ancienne - dans les strates les plus profondes situées au contact du rempart, dans la partie nord du site (sondage 27 du GAP), d'un galet gravé de signes énigmatiques, qui appelle la comparaison avec des pièces similaires mises au jour en Étrurie (Py 1995, p. 271-272) (fig. 12), où elles sont destinées à « consacrer une fondation, marquer les limites d'un territoire ou les lieux significatifs d'une cité » (Py 2009, p. 52). On pensera ici plus particulièrement aux galets inscrits ou marqués d'une croix (decussis) associés à des rites de fondation en lien avec la mise en place d'un plan régulateur, tels que ceux mis au jour en Étrurie padane, à Spina, Marzabotto ou encore à Padoue (Italie) (Patitucci, Uggeri 2017, p. 208). Peut-être faut-il alors rattacher à cette même ambiance, qui serait celle d'une fondation ritualisée, une autre découverte réalisée dans la zone 27. En effet, une broche à rôtir en fer, d'origine italique, a ici été abandonnée au contact du paléosol en association avec des fragments d'amphores (Lebeaupin dir. 2014, p. 176, fig. 10). L'hypothèse d'un dépôt intentionnel, lié ou non à une pratique de commensalité, a été avancée (ibid., p. 20) et prend effectivement tout son sens au moment de considérer dans sa globalité cette phase d'installation étrusque.

Un autre point de discussion concerne la morphologie du premier habitat qui fait suite à cette partition de l'espace. Il s'agit alors non seulement d'un habitat dispersé (dont l'implantation est potentiellement conditionnée par l'existence de lots prédéfinis), mais encore de constructions pouvant, comme c'est le cas dans la zone 1, faire appel à des techniques (le torchis) et des plans (absidiaux) qui, aux $\mathrm{VI}^{\mathrm{e}}-\mathrm{v}^{\mathrm{e}} \mathrm{s}$. av. J.-C., sont absents des contextes proprement urbains d'Étrurie méridionale, mais qui sont encore documentés ailleurs de manière plus ou moins ponctuelle.

La technique de construction en elle-même s'inscrit dans une tradition à la fois ancienne et pour ainsi dire universelle qui, en soi, n'est pas porteuse de sens en termes d'identité. Dans le contexte lattois, elle peut avant tout avoir été dictée par un souci de facilité de mise en œuvre et d'accessibilité des matériaux, la pierre n'étant pas disponible dans l'environnement proche du site. Preuve en est qu'à l'occasion de la construction de l'enceinte et des îlots d'habitation associés, les importantes quantités de pierres nécessaires à ce programme ont été acheminées depuis des gisements situés à une distance comprise entre 4 et $11 \mathrm{~km}$ de l'embouchure du Lez, supposant par là même une forme de coopération avec les populations indigènes établies à proximité (Lebeaupin dir. 2014, p. 323). Rien ne permet de dire que ces conditions aient été d'emblée réunies, mais c'est peut-être avant tout en raison du caractère premier de cette installation - intrinsèquement provisoire - que ce choix technique a été opéré, ce qui nous renvoie à des situations de primo-installation largement documentées par ailleurs et trop souvent interprétées, de manière simpliste, comme étant la marque d'une présence indigène préexistante (Gailledrat 2014, p. 243-246).

La notion d'adéquation entre choix technique et milieu est d'autant plus pertinente si l'on compare l'environnement lagunaire de Lattes avec celui de l'Étrurie padane, et plus précisément celui de certaines fondations nouvelles résultant de l'expansion étrusque qui s'opère aux $\mathrm{VI}^{\mathrm{e}}-\mathrm{v}^{\mathrm{e}} \mathrm{s}$. av. J.-C. en direction de la vallée du Pô et de l'Adriatique. On pensera notamment aux cas emblématiques de Spina (Ostellato), Forcello di Bagnolo

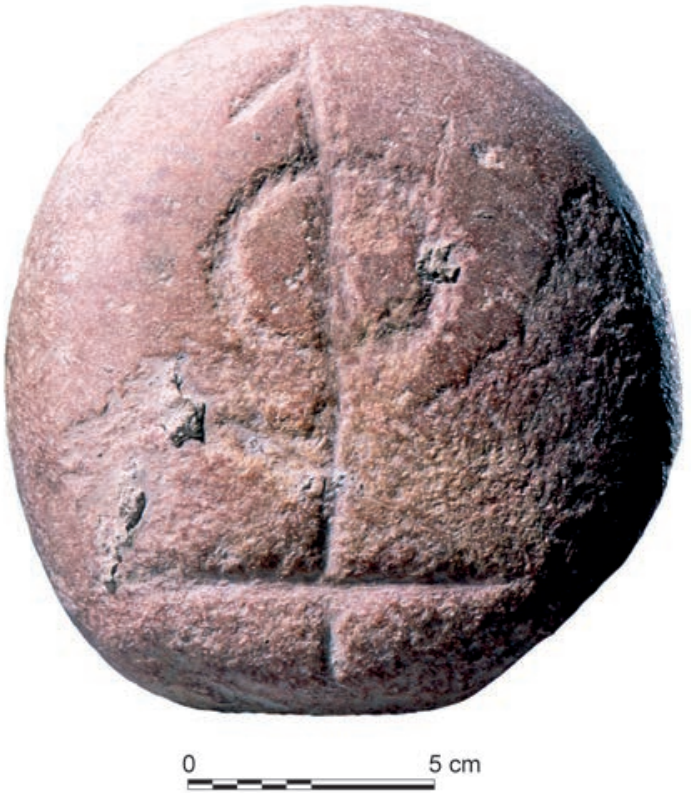

Fig. 12 - Galet gravé de Lattes, mis au jour dans une couche profonde du sondage 27 d'Henri Prades, au niveau de l'enceinte nord $(H .14,50 \mathrm{~cm}$; l. 13,50 cm ; ép. $7 \mathrm{~cm}$ ) (cliché : site archéologique Lattara - musée Henri-Prades).

San Vito (San Biagio di Bagnolo San Vito), Adria, Forzello (San Basilio di Ariano nel Polesine) ou encore Case nuove di Siccomonte (Capriolo di Fidenza), sites où la terre et le bois constituent les matériaux de base, mis en œuvre en association avec des techniques aussi variées que le torchis sur poteaux porteurs, le pan de bois ou peut-être aussi le blockbau, empruntant sur ce point à un registre architectural nord-alpin (Catarsi Dall'Aglio 1998 ; Salzani, Vitali 2002 ; De Marinis et al. 2002 ; De Marinis, Rapi dir. 2007 ; Quirino 2011 ; 2014 ; Cornelio Cassai et al. dir. 2017 ; Patitucci, Uggeri 2017).

Le contexte géographique dans lequel se trouvent les sites étrusques implantés dans la basse-vallée du Pô offre d'ailleurs un parallèle intéressant au moment d'apprécier les conditions dans lesquelles ces mêmes Étrusques se sont installés à Lattes. En effet, la proximité de l'eau y est parfaitement assumée au prix de travaux de terrassements et d'aménagements destinés à drainer et à stabiliser le terrain, ainsi qu’à Spina via un système complexe de pieux enfoncés dans le sol et de petits canaux creusés entre les îlots d'habitation (fig. 13). À Forcello di Bagnolo San Vito, le site établi sur une petite péninsule baignée par les eaux du fleuve Mincio et de la lagune est protégé des inondations par une levée de terre, tandis que de petits fossés de drainage entourent les îlots d'habitation (De Marinis et al. 2002 ; De Marinis, Rapi dir. 2007). À Orbetello, en Étrurie méridionale cette fois, la ville, établie sur une langue de terre entourée d'eau, est ceinte d'une muraille faisant également office de digue face aux battements de la lagune, soit une situation assez comparable à celle de Lattara (Py 2009, p. 51). Au-delà de la proximité immédiate de l'étang et du fleuve, l'aspect encore imparfaitement atterri du secteur correspondant à la zone 1 (et plus généralement de la bordure orientale du site ?) ne doit donc pas être considéré comme ayant été rédhibitoire pour des bâtisseurs disposant d'un savoir-faire en matière d'aménagement de ce type de milieu et devant, bon gré mal gré, s'adapter à la morphologie du terrain dont ils disposaient. 


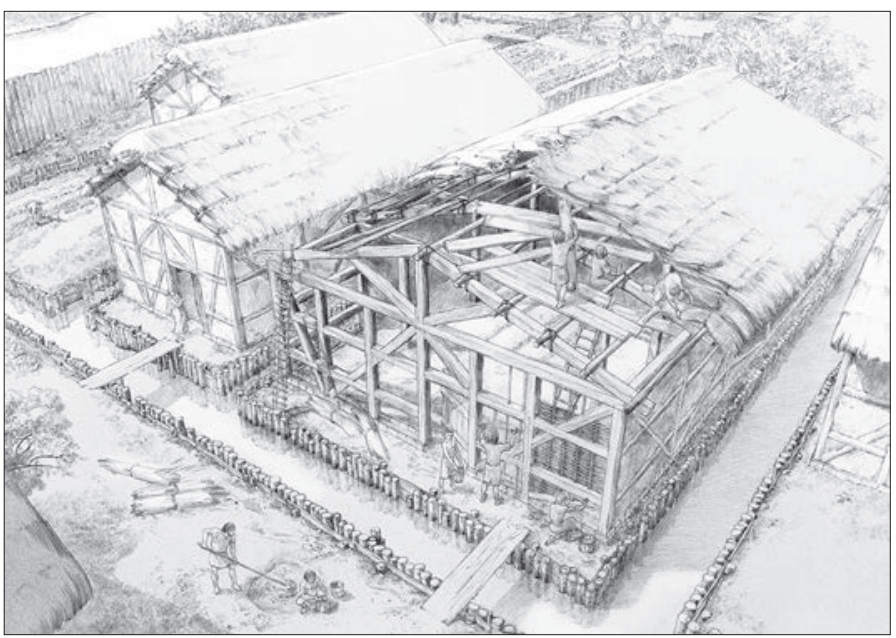

Fig. 13 - Proposition de restitution d'un quartier de l'habitat étrusque de Spina (Italie)(Museo Delta Antico, Comune di Comacchio ; réalisation : S. Boni, Studio Inklink, Firenze).

\section{UNE ARCHITECTURE ÉTRUSQUE?}

La physionomie du bâtiment absidial correspondant à la phase d'installation soulève d'autres questions, cette fois relatives au plan. L'interrogation première concerne les parallèles éventuellement offerts par le monde indigène au premier ou au début du second âge du Fer. La forme absidiale constitue en effet un type architectural répandu dans divers contextes chronologiques et culturels, y compris en Gaule méridionale, où elle ne semble pas en soi caractéristique d'une période ou d'un faciès donné (Garcia, Tréziny 2010). Attestée au Bronze final, on la retrouve au début du premier âge du Fer (Mailhac), puis durant les premières années du $\mathrm{VI}^{\mathrm{e}} \mathrm{s}$. av. J.-C. (Ruscino, la Monédière, Tamaris, Saint-Blaise), dans le courant de ce siècle (la Monédière, le Ravaner à Argelès-sur-Mer), et encore durant la plus grande partie du siècle suivant (Rocher de Roquebrune, Mas de Vignole, Lattara, Gailhan, la Condamine, Christol III, Quinquiris) (fig. 14). Tout au long des $\mathrm{VI}^{\mathrm{e}}-\mathrm{v}^{\mathrm{e}} \mathrm{s}$. av. J.-C., ces édifices absidiaux cohabitent le plus souvent avec d'autres constructions, de plan rectangulaire ou subrectangulaire. Leur raréfaction progressive va de pair avec le développement de l'habitat groupé, où la mitoyenneté des habitations au sein d'îlots impose logiquement les formes quadrangulaires, seul le site de Tamaris (fig. 14, $\mathrm{n}^{\circ}$ 4) offrant l'exemple de quelques bâtiments absidiaux accolés à de telles constructions au sein d'une trame urbanistique dense. Encore présent au début du $v^{\mathrm{e}} \mathrm{s}$. av. J.-C. dans des contextes d'habitats groupés à trame lâche (fig. 14, $\mathrm{n}^{\text {os }}$ 6-10), le plan absidial tend ensuite à ne plus être mis en œuvre que dans des contextes d'habitats ruraux, avec à la clé des dimensions importantes qui les distinguent nettement des types plus anciens (fig. 14, $\mathrm{n}^{\text {os }} 11-14$ ).

Le corpus disponible pour le Midi de la France demeure peu étoffé, et les plans parfois lacunaires. S'il est encore impossible d'établir une véritable typologie à l'échelle régionale, de dégager le cas échéant de véritables traditions architecturales propres à telle ou telle zone et d'en saisir l'évolution dans le temps, certaines tendances peuvent néanmoins être esquissées.

Les techniques de construction sont variées et leur évolution n'est pas linéaire : si la terre massive, et surtout le torchis, sont à l'origine exclusifs, l'apparition des solins en pierre et de l'adobe - en premier lieu dans des contextes «méditerranéisés », voire potentiellement mixtes (Saint-Blaise, Tamaris, la Monédière) (Gailledrat 2014) - aboutit à des réalisations hétérogènes d'un site à l'autre, et parfois composites (fig. 14, nos 6 [?], 10 et 11). Les solutions architecturales sont elles aussi diversifiées, et en partie conditionnées par les techniques employées : concernant le torchis, réserve étant faite d'un type de plan particulier, à trois nefs ${ }^{4}$, pour l'heure uniquement attesté au tout début du $\mathrm{VI}^{\mathrm{e}} \mathrm{s}$. av. J.-C. (fig. $14, \mathrm{n}^{\circ} 1$ ), cette technique est normalement associée aux plans à deux nefs (avec une travée axiale de poteaux supportant la faîtière) (fig. 14, nos $7,8,12-14$ ). La bauge ou l'adobe, généralement sur solins de pierre, est en revanche indistinctement associée à des plans à nef unique ou double nef (fig. 14, $\mathrm{n}^{\text {os }}$ 2-6 et 9-11), le poids des chevrons étant reporté (en partie ou totalement) par les murs qui assurent dans ce cas un véritable rôle porteur.

Entre le milieu du $\mathrm{vI}^{\mathrm{e}}$ et le début du ve s. av. J.-C., quatre morphotypes peuvent être identifiés. Le premier est constitué d'un plan monoabsidial, corps rectangulaire et deux nefs ${ }^{5}$; un deuxième de plan monoabsidial et de corps trapézoïdal à une ou deux nefs ; un troisième de plan biabsidial avec une ou deux nefs (qui affiche des similitudes avec le type le plus ancien) et un dernier, ovoïde, à deux absides et une nef. En premier lieu donc, se pose la question de la coexistence, au vi ${ }^{\mathrm{e}} \mathrm{s}$. av. J.-C., des plans mono ou biabsidiaux. En l'état, il est impossible de dire si les édifices de Saint-Blaise et, a fortiori, de la Monédière (fig. 14, $\mathrm{n}^{\text {os }} 2$ et 3) étaient de l'un ou l'autre type ${ }^{6}$ et donc dans quelle mesure ils pourraient se rapprocher - ou non - de l'exemple de Tamaris (fig. 14, $\mathrm{n}^{\circ}$ 4) dont, par ailleurs, la morphologie d'ensemble tend vers le type trapézoïdal illustré à une date plus récente au Rocher de Roquebrune (fig. 14, $\mathrm{n}^{\circ}$ 6). Dans le même temps, les superficies utiles (globalement comprises autour de 20-30 $\mathrm{m}^{2}$ ) ne sont pas déterminantes, tant elles apparaissent ubiquistes au regard de l'habitat de l'âge du Fer pris de manière générale, au-delà même des limites du Midi de la France.

Considérée à l'aune de ses diverses caractéristiques architecturales, l'UNF 145 de Lattara peut difficilement être considérée comme étant véritablement représentative de tel ou tel type, sachant que cette notion même de type demeure encore délicate à établir. Les rapprochements possibles, à partir de tel ou tel détail de mise en œuvre, avec les divers exemples languedociens ou provençaux recensés n'apportent guère de solutions définitives, bien qu'il semble opportun d'établir un parallèle

4. Un ensemble de quatre poteaux porteurs, probablement reliés entre eux par des entraits, assure ici la stabilité de la toiture.

5. Type générique auquel pourrait se rattacher l'UNF 145 de Lattes (fig. 14, $\left.\mathrm{n}^{\circ} 8\right)$.

6. Les restitutions proposées ici pour les maisons de la Monédière diffèrent de celles initialement avancées par André Nickels (Nickels 1989) et se fondent en partie sur les résultats des travaux de terrain menés en 2014 (fouilles A. Beylier, inédites). La «maison A » (fig. 14, $n^{\circ}$ 3), restituée par A. Nickels comme étant un bâtiment monoabsidial et comparé à des modèles grecs d'époque archaïque, doit être considérée de manière plus prudente : elle pourrait en effet très bien correspondre à un bâtiment biabsidial, similaire dans ses proportions à l'exemple plus récent du Plan de la Tour (fig. 14, n 9). Pour la «maison B », contemporaine de la précédente (fig. $14, n^{\circ} 5$ ), l'hypothèse première d'un très grand édifice absidial (dictée par la courbure de la portion de mur conservée) semble désormais peu réaliste ; le plan renvoie en revanche à un type ovoïde, désormais bien caractérisé sur le site durant cette période. 

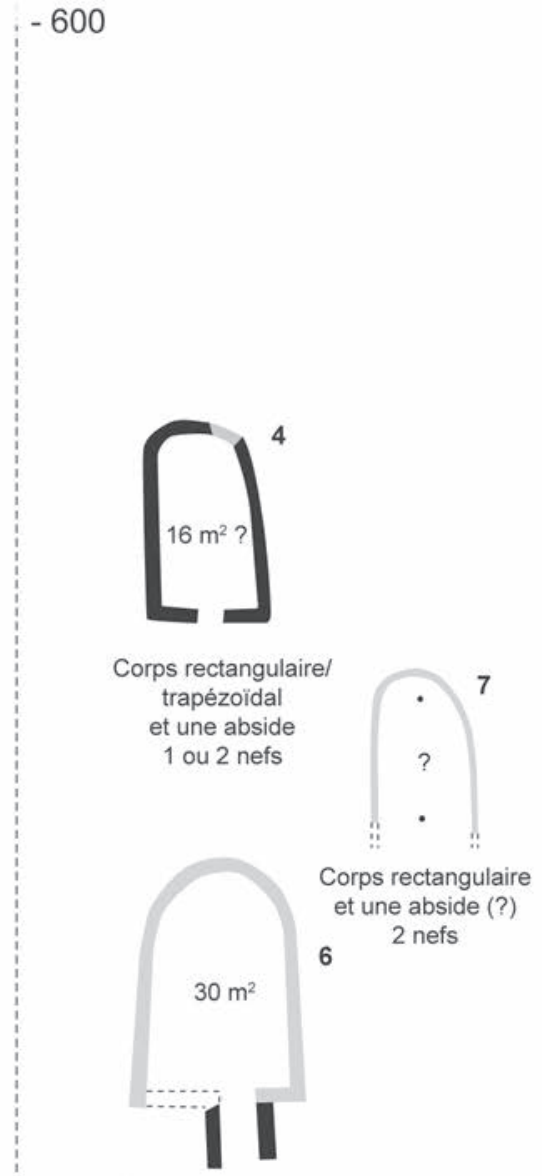

Corps trapézoïdal et une abside 1 ou 2 nefs



Corps rectangulaire
et une abside 1 ou 2 nefs

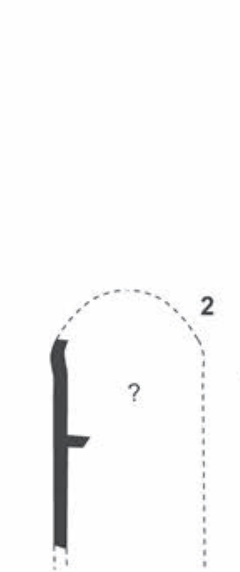

Corps rectangulaire et double abside (?)

1 ou 2 nefs

UNF 145

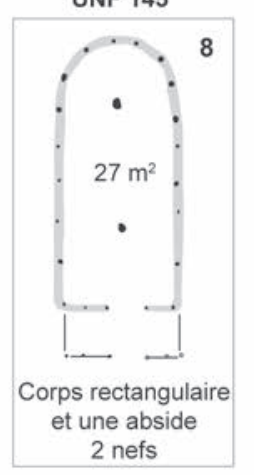
et double abside (?) 1 ou 2 nefs



Corps subrectangulaire et double abside 2 nefs

Corps rectangulaire et double abside
Corps rectangulaire

solin maçonné avec élévation en bauge ou adobe

élévation en torchis ou en bauge

- trou de poteau

tracé restitué


Corps ovoïde et double abside

1 nef

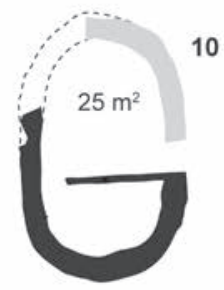

$$
\begin{aligned}
& \text { Corps ovoïde } \\
& \text { et double abside } \\
& 1 \text { nef }
\end{aligned}
$$



Fig. 14 - Bâtiments absidiaux de l'âge du Fer dans le Midi de la France. 1, Ruscino/Château-Roussillon (Pyrénées-Orientales) (vers 600 av. J.-C.) ; 2, Saint-Blaise (Saint-Mitre-les-remparts, Bouches-du-Rhône) (600-550 av. J.-C.) ; 3, la Monédière (Bessan, Hérault) (540-510 av. J.-C.) ; 4, Tamaris (Martigues, Bouches-du-Rhône) (575-525 av. J.-C.) ; 5, la Monédière (Bessan, Hérault) (540-510 av. J.-C.) ; 6, Rocher de Roquebrune (Le Muy, Var) (500400 av. J.-C.) ; 7, la Monédière (Bessan, Hérault) (500-450 av. J.-C.) ; 8, Lattes/Lattara (Hérault) (vers 500 av. J.-C.) ; 9, Le Plan de la Tour (Gailhan, Gard) (475-450 av. J.-C.) ; 10, Lattes/Lattara (Hérault) (vers 475 av. J.-C.) ; 11, Christol (Carcassonne, Aude) (500-450 av. J.-C.) ; 12, Quinquiris (Castelnaudary, Aude) (500-450 av. J.-C.) ; 13, la Condamine (Villeneuve-Minervois, Aude) (500-400 av. J.-C.) ; 14, Mas de Vignoles (Nîmes, Gard) (450-300 av. J.-C.) (DAO : É. Gailledrat). 


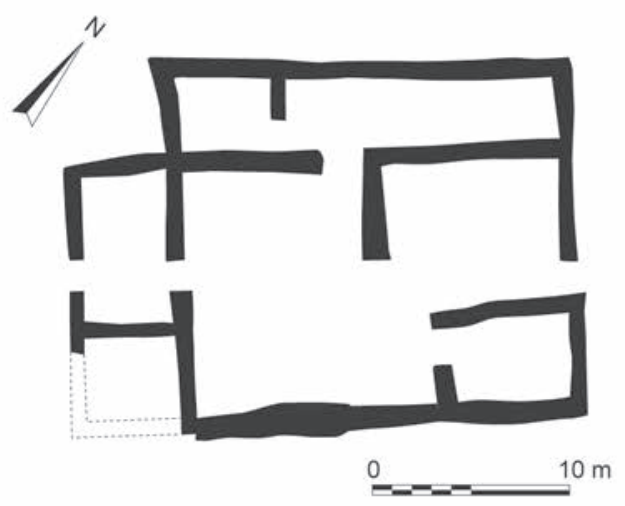

(A)

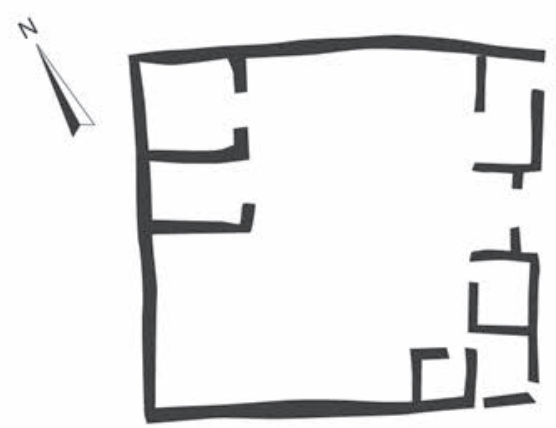

(B)

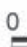

$10 \mathrm{~m}$

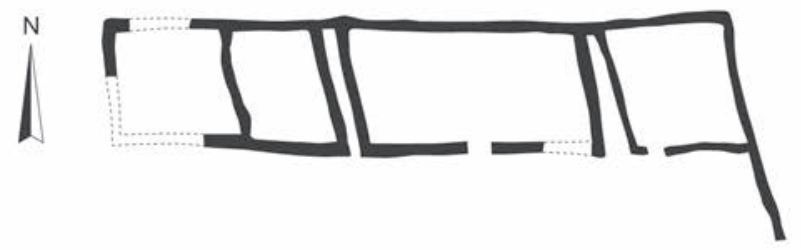

(C)
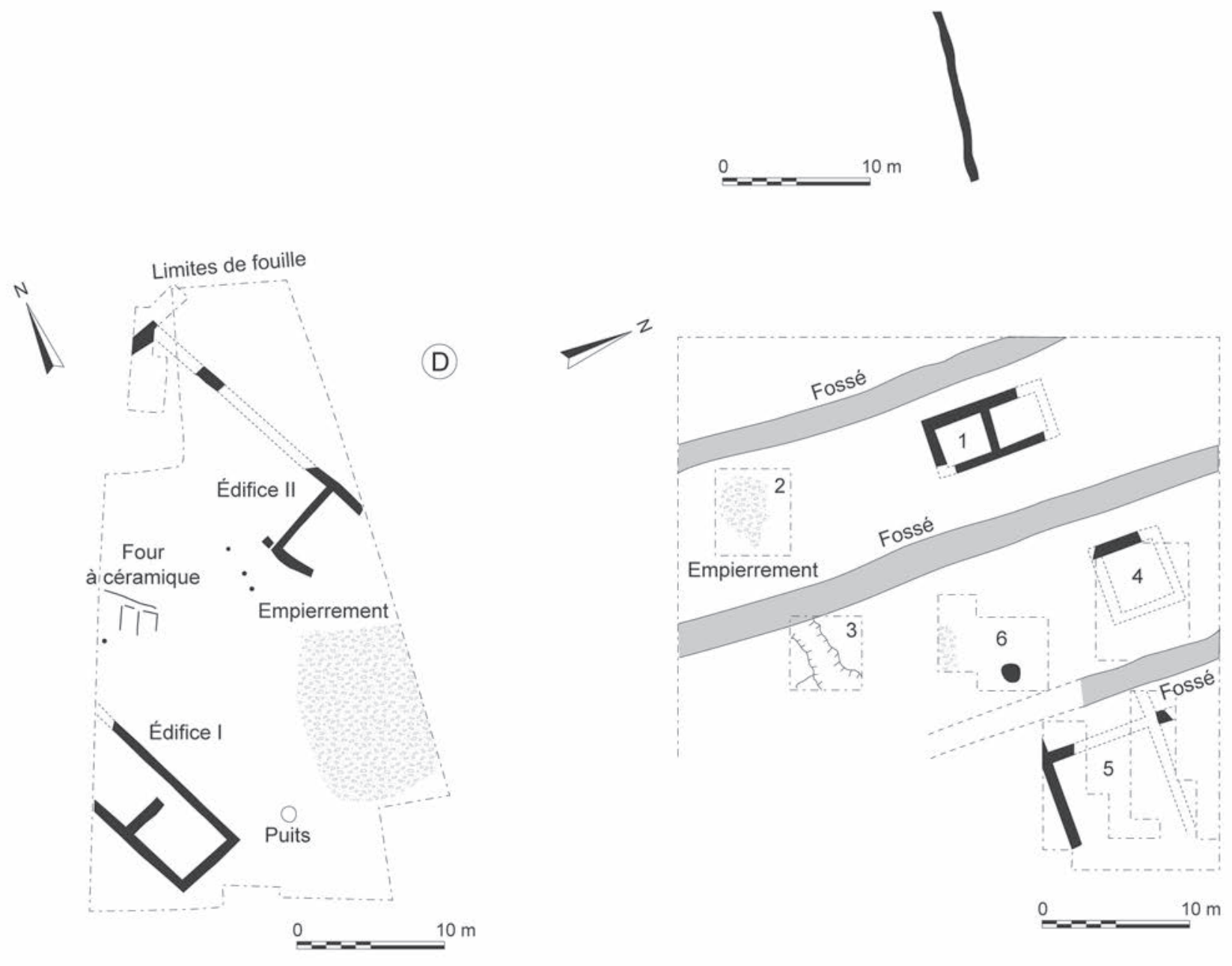

(E)

Fig. 15 - Plans de différents habitats ruraux étrusques des $v l^{\mathrm{e}}-v^{\mathrm{e}}$ S. av. J.-C. A, Valli di Capanne (Pian d'Alma, Scarlino) ; B, Poggio Alto (Marsiliana d'Albegna, Manciano), d'après Morandini 2011, p. 96, fig. 3 et p. 99, fig. 8 ; C, Podere Tartucchino (Semproniano), d'après Perkins, Attolini 1992, p. 74, fig. 2 ; D, Casalecchio di Reno (Bologne), d'après Massa-Pairault 1972, pl. I ; E, San Cassiano (Crespino), d'après Harari, Paltineri 2010, p. 67, fig. 5 (DAO : É. Gailledrat). 
avec le bâtiment de Christol (fig. 14, $\mathrm{n}^{\circ}$ 11) dont la conception d'ensemble paraît assez proche de celle de l'édifice lattois. On retiendra malgré tout pour Lattara l'image d'une réalisation relativement singulière, qui invite à explorer d'autres possibilités en termes de référents architecturaux. Il s'agit alors de contourner l'obstacle que représentent les possibles convergences entre des traditions culturelles différentes, qu'elles soient ou non indigènes ; en l'occurrence, il devient légitime de tourner nos regards du côté de l'Étrurie, dans la mesure où c'est bien dans un contexte de présence tyrrhénienne qu'intervient cette réalisation.

Les données propres à l'habitat étrusque de la fin de l'époque archaïque demeurent malheureusement peu nombreuses, en particulier lorsqu'il s'agit d'aborder la double question des contextes non spécifiquement urbains et de l'habitat à trame lâche. L'habitat rural archaïque, tel qu'il est connu en Toscane, englobe ainsi des réalités très distinctes entre la fin $\mathrm{vI}^{\mathrm{e}}$ et le début du $\mathrm{v}^{\mathrm{e}} \mathrm{s}$. av. J.-C. À titre d'exemple, tandis que la «ferme » de Podere Tartuchino (Semproniano) se présente comme un groupement de bâtiments simples et mitoyens associés à un espace enclos (fig. 15c), celles de Poggio Alto (Pian d'Alma de Marsiliana d'Albegna, Manciano), de Pian d'Alma (Scarlino) (fig. 15a et b) ou de l'Auditorium (Acquarossa) se présentent en revanche comme des maisons à cour de plan complexe, qui renvoient à des traditions architecturales développées en contexte urbain et qui s'inscrivent pour partie dans la continuité de modèles propres aux résidences aristocratiques (Morandini 2011).

En se tournant vers l'Étrurie padane, d'autres cas de figure peuvent être appréhendés. Le site de Casalecchio di Reno offre ainsi l'exemple d'un d'habitat à trame lâche ( $\mathrm{v}^{\mathrm{e}} \mathrm{s}$. av. J.-C.) où plusieurs bâtiments à solins de galets et élévations en adobes sont disposés selon un axe nord-ouest - sud-est, de part et d'autre d'un vaste espace ouvert auquel est associée une aire empierrée. L'édifice le mieux conservé (édifice I), de plan rectangulaire, se compose de deux pièces d'ampleur inégale : d'une largeur de 5,60 m environ et d'une longueur minimale de $13,70 \mathrm{~m}$, il est interprété comme une unité domestique renvoyant à un modèle d'habitation « archaïque », potentiellement divisée entre un espace de vie et une pièce plus spécifiquement vouée au stockage (Massa-Pairault 1972) (fig. 15d).

Toujours en Étrurie padane, le site de San Cassiano di Crespino se présente également comme un petit habitat rural (fin du vi $\mathrm{e}^{\mathrm{e}}$-début du IV $\mathrm{V}^{\mathrm{e}} \mathrm{s}$. av. J.-C.) comportant plusieurs édifices, distants les uns des autres d'une dizaine de mètres (Robino et al. 2009). Leur implantation est conditionnée par l'existence d'une trame régulière, matérialisée par une série de fossés de drainage parallèles et orientés nord-sud, qui rythment l'espace entre les différents bâtiments et autres structures bâties. Trois constructions de plan quadrangulaire ainsi qu'un «fondo di capanna» de plan curviligne ont été mis en évidence (fig. 15e). Ici, l'orientation des bâtiments quadrangulaires témoigne du respect du tracé régulateur qui conditionne manifestement l'ensemble de l'habitat. Une habitation de plan rectangulaire (incomplet) composée de deux pièces, mesurant au moins $8 \mathrm{~m}$ de long (peut-être 13) pour environ $4 \mathrm{~m}$ de large, renvoie au même modèle bipartite que celui précédemment décrit. Reposant sur des solins maçonnés de galets, les élévations de murs semblent avoir été bâties en pan de bois, technique attestée ailleurs dans la région padane (Harari, Paltineri 2010, p. 67-69). Le plan de la cabane $\left(n^{\circ} 2\right)$, matérialisée au sol par un radier de pierres, des

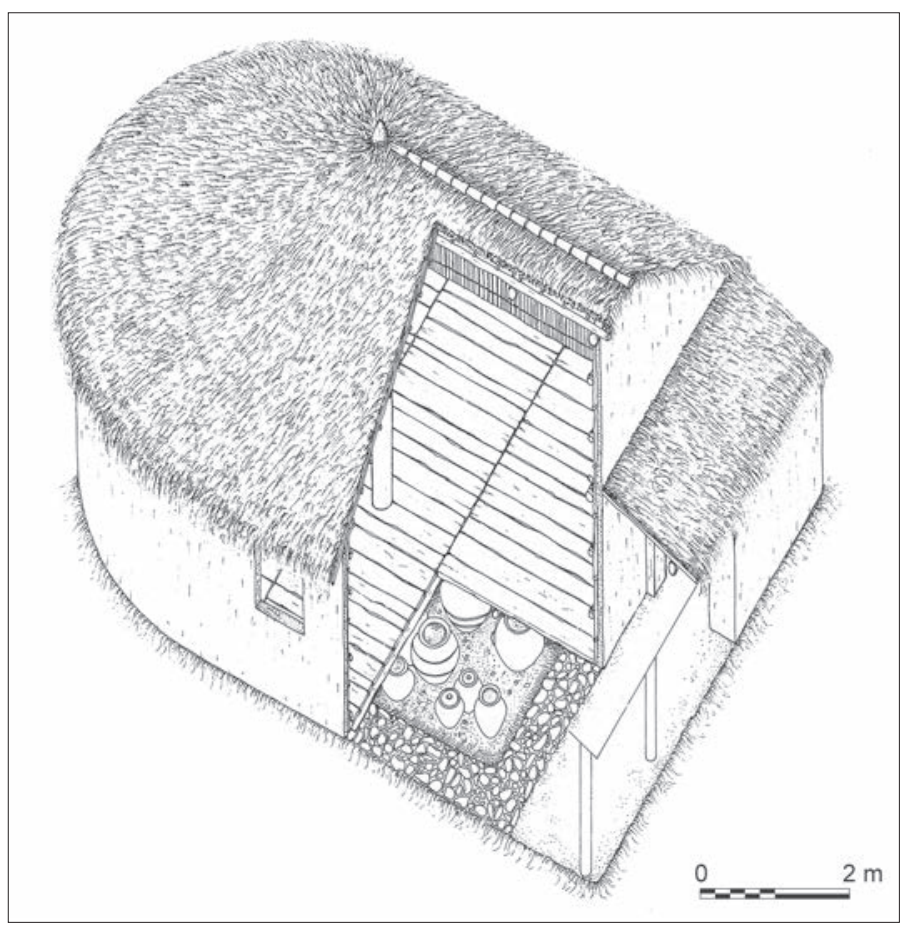

Fig. 16 - Proposition de restitution de l'habitation étrusque de Baggiovara/Case Vandelli (Italie) (Malnati 1988b, p. 264, fig. 206).

restes de terre crue et des trous de poteau, est plus incertain mais témoigne de l'utilisation du torchis sur poteaux porteurs pour ce qui a pu constituer une annexe à l'habitation. Malheureusement conjuguée à un mauvais état de conservation des vestiges, la relative imprécision des plans et des descriptions ne permet guère de détailler la morphologie de ce bâtiment, toutefois décrit comme ayant une largeur de $3,50 \mathrm{~m}$ et implanté selon un axe est-ouest (ibid., p. 67). On peut alors légitimement se demander si nous n'avons pas en réalité les vestiges d'une construction de plan absidial. Avec une abside à l'ouest, on pourrait en fait plus sûrement restituer un plan mono-absidial, avec une ouverture située côté est, bordée par le fossé de drainage qui passe à cet endroit. Pour invérifiable que soit cette hypothèse, les données disponibles ne permettent toutefois pas de l'écarter.

Le plan absidial n'est en effet pas inconnu dans le contexte de l'Étrurie padane à la fin de l'époque archaïque. C'est en tout cas ce que laisse entendre la découverte d'un édifice daté du début du v ${ }^{\mathrm{e}}$ s. av. J.-C. sur le site de Case Vandeli (Baggiovara) (Malnati 1988b). Ce dernier est matérialisé en premier lieu par une structure excavée interprétée comme une cave. Sur le pourtour de l'excavation est présent un large solin de galets (peut-être plutôt un radier d'accroche ou une sablière basse), ayant fonctionné avec une élévation en terre, probablement en bauge ou en torchis (?). Les dimensions, bien qu'incomplètes, permettent néanmoins de restituer un bâtiment assez vaste, d'au moins $6,50 \mathrm{~m}$ de large pour une dizaine de mètres de long (voire plus), semble-t-il précédé d'un auvent (fig. 16) ${ }^{7}$. Ce type de construction est apparemment loin d'être isolé : toujours à Baggiovara, sur le site voisin de Via Martiniana, diverses

7. La restitution proposée est cependant très hypothétique, notamment pour ce qui concerne la longueur du bâtiment. On peut en effet imaginer que seule une partie de l'habitation, en l'occurrence la partie arrière, ait accueilli une cave. La façade sud étant elle-même arasée, rien ne permet de dire que la partie aérienne de la construction ne se prolongeait pas vers l'est. 


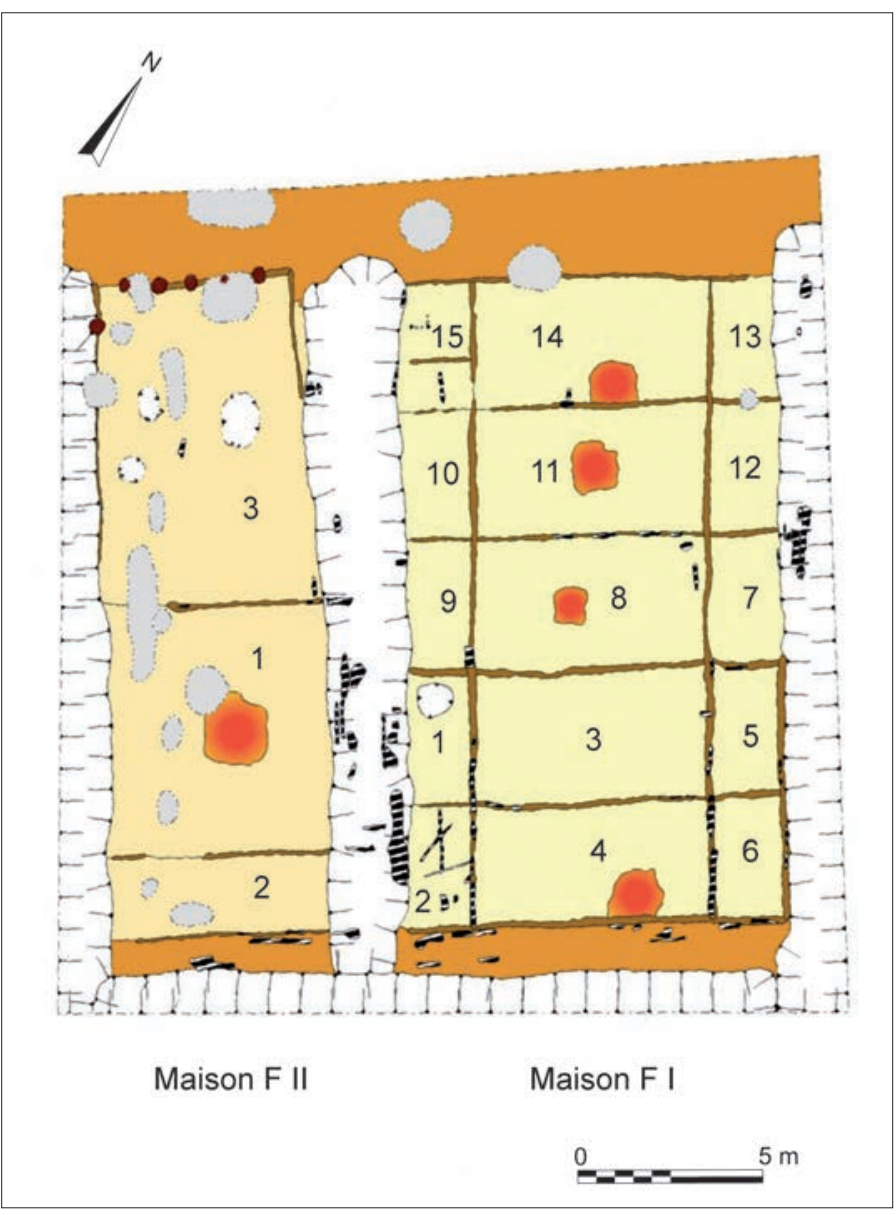

Fig. 17 - Plan des maisons Fl et Fll de Forcello di Bagnolo San Vito (Italie) (Quirino 2014, p. 394, fig. 1).

fosses et autres structures excavées ont été mises au jour et ont pour partie été interprétées comme des caves. Malheureusement, aucun plan cohérent ne peut être restitué à partir des trous de poteau disposés entre ces creusements (Stopani, Zamboni 2009), les mêmes interrogations étant posées pour le site de Cave San Lorenzo (Fiorano Modenese), dans un contexte chronologique similaire (Malnati 1988a ; Locatelli 2006). Pour le moins, ce type architectural semble être fondamentalement associé à des habitats ruraux avec, notamment pour la région padane, l'emploi répandu de techniques autres que la brique crue sur solin de pierres.

Force est de constater que cette hypothèse encore fragile prend véritablement corps au moment de considérer les vestiges du site déjà évoqué de Forcello di Bagnolo San Vito (De Marinis et al. 2002 ; De Marinis, Rapi dir. 2007 ; Quirino 2011 ; 2013 ; 2014 ; Croce et al. 2014) : le quartier mis au jour sur cet habitat fondé à la fin $\mathrm{du} \mathrm{VI}^{\mathrm{e}} \mathrm{s}$. av. J.-C. se présente sous la forme de deux entités architecturales, qui occupent l'angle nord-est d'un îlot et sont disposées selon un axe nord-ouest - sud-est, lequel coïncide avec la trame orthonormée qui régit l'habitat (Quirino dégagement ou à une ruelle bordée d'un fossé de drainage le long de la façade méridionale. Par ailleurs, d'autres creusements de ce type courent le long des grands côtés de cet ensemble, ainsi qu'entre les deux bâtiments (fig. 17).

Cet ensemble, qui est présenté comme étant composé de deux maisons, implicitement indépendantes, occupe un espace sensiblement carré d'environ $18 \mathrm{~m}$ de côté délimité par les fossés de drainage évoqués précédemment. La maison FII prend la forme d'un rectangle d'environ $17 \mathrm{~m}$ de long pour $5 \mathrm{~m}$ de large et se compose de trois pièces de taille inégale disposées en enfilade, communiquant semble-t-il entre elles. Cette division de l'espace révèle néanmoins l'existence de deux entités de dimensions identiques, l'une constituée d'une pièce unique ( $\mathrm{n}^{\mathrm{o}} 3$ ), l'autre de deux pièces communicantes ( ${ }^{\mathrm{os}} 1$ et 2 ). La maison FI adopte quant à elle un plan radicalement différent dans la mesure où l'ensemble forme un rectangle d'environ $17 \mathrm{~m}$ de long pour $10 \mathrm{~m}$ de large, qui comprend une quinzaine de pièces agencées de manière régulière. L'incertitude concernant l'existence ou non de portes assurant la communication d'une pièce à l'autre pose évidemment question au moment d'apprécier le fonctionnement de cette unité architecturale, dont le caractère domestique semble néanmoins évident. Quoi qu'il en soit, la disposition de ces pièces suggère en fait la juxtaposition de cinq lots rectangulaires, composés chacun d'une pièce principale oblongue - le plus souvent munie d'un foyer - précédée, puis prolongée par une pièce barlongue plus petite.

La régularité d'ensemble du plan évoque à la fois l'existence de modules bien définis et l'emploi d'une unité de mesure qui, selon les fouilleurs, ne serait autre que le pied « attique » de 29,60 cm, utilisé à la même époque à Marzabotto (MassaPairault 1997), peut-être combiné ici en modules de 3 pieds de côté, soit 0,888 m (Quirino 2013 ; 2014). Selon le schéma proposé, la maison FII serait ainsi définie par un rectangle de 60 pieds de long pour 18 de large (soit $20 \times 6$ modules de $0,888 \mathrm{~m}$ ) ; la maison FI par un rectangle de même longueur pour 33 pieds de large ${ }^{8}$ (soit 20 x 11 modules de 0,888 m). Si le découpage proposé en modules de 3 pieds peut être discuté, le schéma d'ensemble apparaît quoi qu'il en soit des plus cohérents. La longueur d'un peu plus de $17 \mathrm{~m}$, commune aux maisons I et II, renvoie ainsi directement aux mesures constatées à Marzabotto (lots de 60 pieds de côté, équivalant - tout comme ici, à Forcello - à la moitié de la largeur d'un îlot) ou encore à Spina (Quirino 2014, p. 298). Cela conforte un peu plus le constat de schémas urbanistiques rigoureux et parfaitement établis, communs aux sites qui témoignent de l'expansion étrusque en région padane à la fin $\mathrm{du} \mathrm{vI}^{\mathrm{e}}$-début du $\mathrm{v}^{\mathrm{e}} \mathrm{s}$. av. J.-C., indépendamment des techniques de construction employées qui, de Marzabotto à Spina, dépendent largement des potentialités du milieu.

De fait, la morphologie particulière de la maison I de Forcello pose un problème de définition fonctionnelle, dans la mesure où peut être émise l'hypothèse d'unités domestiques indépendantes bien que rassemblées sous un même toit. Hormis l'espace $n^{\circ} 3$, toutes les grandes pièces rectangulaires sont munies d'un foyer, de sorte que nous pourrions avoir ici un bloc accueillant en

8. Compte tenu de l'espace sur lequel empiètent les fossés de drainage, il n'est pas impossible que le tracé initial ait en réalité compté 36 pieds de large (et non 33), soit $20 \times 12$ modules de $0,888 \mathrm{~m}$. 
réalité cinq unités distinctes, constituées chacune d'un vestibule, d'une grande pièce principale et d'une pièce arrière. Il s'agit là d'un schéma d'organisation de l'espace domestique des plus classiques, mais que l'on s'attend plutôt à rencontrer dans le cadre d'un habitat non mitoyen. Leur agrégation pourrait ici être motivée par une forme relativement simple de lotissement, mise en place au début de l'histoire du site. En dépit de variations minimes en termes de surface, ces unités pourraient témoigner d'une répartition égalitaire de l'espace entre autant de familles nucléaires.

La comparaison avec Lattes est ici incontournable. En effet, la superposition des plans de la maison à abside de la phase IT de Lattara (UNF 145) avec l'une ou l'autre des supposées unités domestiques incluses dans la maison I de Forcello révèle une adéquation quasi-parfaite : la longueur ainsi que la largeur du bâtiment d'un côté, la division interne de l'espace de l'autre, sont en effet identiques à quelques centimètres près (fig. 18). La seule différence concerne évidemment la forme (monoabsidiale d'un côté, quadrangulaire de l'autre), mais on peut précisément y voir un argument supplémentaire pour considérer les différentes entités de la maison I de Forcello comme étant des adaptations d'une configuration architecturale standard, aux contraintes imposées par la mitoyenneté. Une telle adéquation au niveau du plan et des dimensions ne manque pas d'interroger, a fortiori quand on constate la synchronie quasi parfaite entre les deux gisements et le contexte dans lequel ces constructions prennent place.

Plus globalement, cette architecture appelle quelques commentaires au moment de considérer le cas de Lattara. À Forcello, il est remarquable de constater que le report d'un plan canonique préexistant, employé ailleurs dans le cas de constructions indépendantes, fait ici l'objet d'une adaptation qui ne se limite pas à la forme quadrangulaire. En effet, dans la mesure où ces unités domestiques sont bel et bien mitoyennes, il est inconcevable d'imaginer qu'elles aient pu conserver leur structure première, à savoir une toiture à double pente reposant sur une faîtière disposée dans l'axe longitudinal du bâtiment. La maison I se présente en revanche comme un bâtiment massif, pour lequel est restituée une toiture à double pente logiquement disposée dans le sens de la longueur de l'édifice (nord-ouest - sud-est). Celle-ci était inévitablement associée à une charpente complexe ${ }^{9}$ avec une hauteur au niveau de la faitière dépassant les $6 \mathrm{~m}^{10}$, tandis que la présence de fossés situés à la fois le long des grands côtés des deux maisons FI et FII et entre celles-ci, répond à la nécessité de drainer les eaux de ruissellement provenant des toitures. La monumentalité de tels édifices, qui témoigne d'une parfaite maîtrise des techniques de construction - et en particulier de la charpenterie -, rend d'autant moins surprenantes les caractéristiques du bâtiment étrusque de la zone 27 de Lattara, dont les dimensions hors normes (au regard des standards indigènes) et la qualité de la mise en œuvre ont été soulignées.

9. Une telle charpente est parfaitement compatible avec une architecture en blockbau ou à pan de bois (les fouilleurs privilégiant la première hypothèse) ; l'absence de poteaux axiaux est quoi qu'il en soit notable et démontre que la panne faîtière devait reposer sur un système de fermes, assemblées à l'aplomb des séparations existant entre les différentes unités domestiques, ainsi qu'au niveau des pignons nord et sud.

10. Calcul établi sur la base de parois (est et ouest) d'une hauteur d'environ $2 \mathrm{~m}$ et d'une toiture végétale inclinée au minimum à $35^{\circ}$.

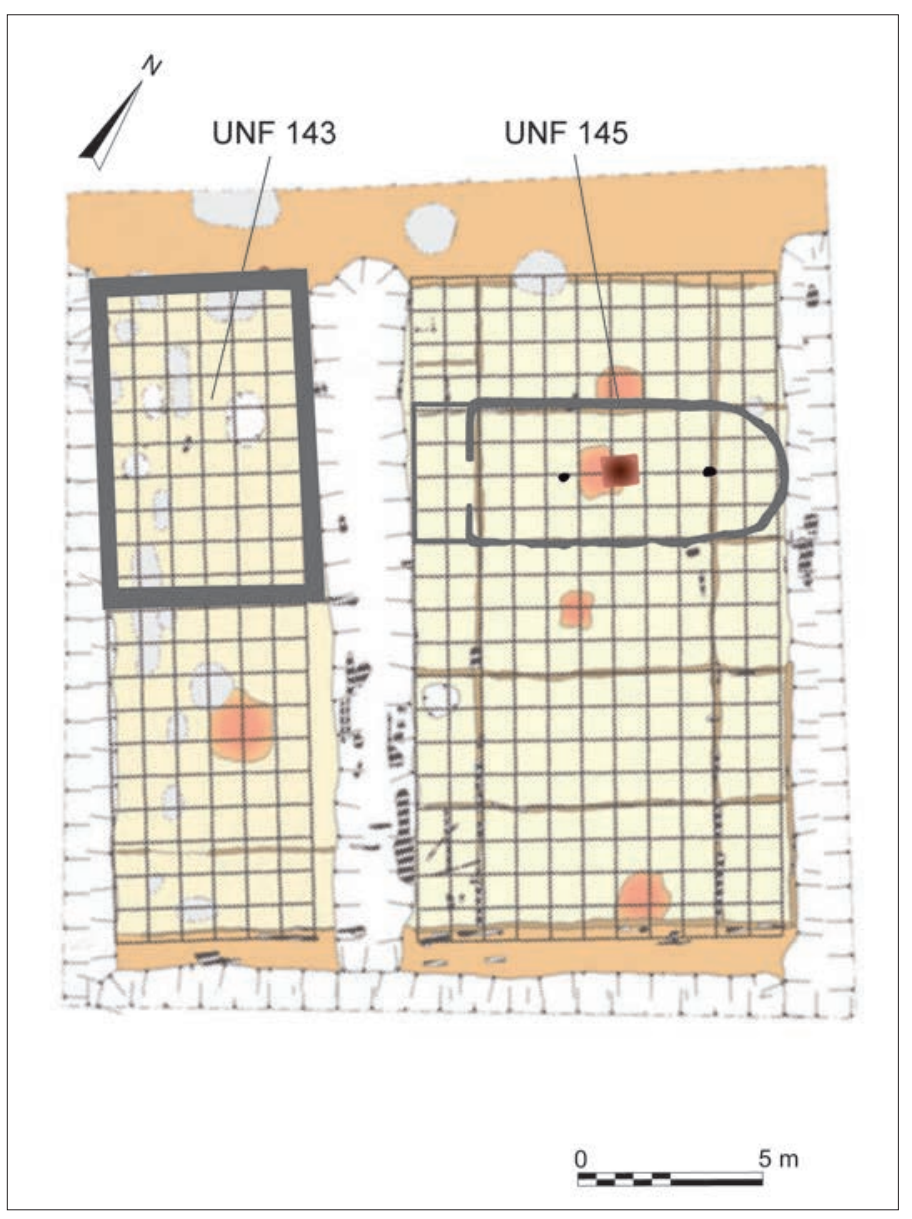

Fig. 18 - Plan des maisons Fl et Fll de Forcello di Bagnolo San Vito (Italie), avec indication d'une grille métrologique reproduisant des modules de $0,888 \mathrm{~m}$, correspondant chacun à 3 pieds attiques de 29,60 cm (d'après Quirino 2014, p. 397, fig. 5) et superposition des UNF 143 et 145 de Lattes (DAO : É. Gailledrat).

La maison FII de Forcello répond, on l'a vu, à un schéma tout autre. À considérer qu'il s'agit bel et bien d'une seule unité fonctionnelle à caractère domestique, les quelque $80 \mathrm{~m}^{2}$ de surface utile tranchent avec la trentaine de mètres carrés attribuable à chaque unité de la maison I. Dans la mesure où l'ensemble (I et II) paraît occuper la moitié de la largeur d'un îlot (Quirino 2013, p. 107, fig. 25), la question d'un lien fonctionnel unissant les deux entités peut être posée, et ce d'autant plus que durant la phase suivante (phase C, vers 470/450 av. J.-C.), ce même lot voit la construction d'un vaste édifice occupant la plus grande partie de l'espace disponible. Ce nouveau bâtiment est matérialisé au sol par de larges trous de poteau et des négatifs de sablières basses, avec un plan complexe qui, structurellement, le rapproche très directement de la «ferme » de Marsigliana d'Albegna (Morandini 2011), voire des maisons de Marzabotto (Massa-Pairault 1997), tout en faisant une nouvelle fois appel à une unité de mesure fondée sur un pied de 29,60 cm (Quirino 2013, p. 105-107, fig. 18-24).

Quoi qu'il en soit, la maison FII est caractérisée par la juxtaposition de deux modules d'environ $9 \mathrm{~m}$ de long pour un peu plus de $5 \mathrm{~m}$ de large, équivalents à un rectangle de 30 x 18 pieds. Or, ici encore, une concordance troublante peut être établie avec les données de la zone 1 de Lattara, et plus précisément avec le bâtiment (ou la pièce ?) rectangulaire qui 




Fig. 19 - A, Plan coté de I'UNF 143 ; B-C, propositions de lecture métrologique sur la base du pied attique de 29,60 cm (DAO : É. Gailledrat).

constitue l'UNF 143, dont la construction intervient durant la phase $1 \mathrm{~S}$, soit postérieurement au démantèlement de la maison à abside préexistante (fig. 18). La concordance entre la longueur du corps de l'UNF 145 (entendu sans le porche) et celle de l'UNF 143 a été soulignée précédemment, suggérant la possibilité d'un lien structurel entre les deux constructions, a priori pourtant radicalement différentes. Le fait qu’à Forcello ces deux modèles coexistent, non seulement au sein d'une même phase, à la construction d'un bâtiment au plan somme toute atypique et dont la superficie utile $\left(38 \mathrm{~m}^{2}\right)$ ne dénote pas au regard de celle des maisons à pièce unique du premier âge du Fer, en Gaule méridionale ou ailleurs ? Peut-on à l'inverse y voir la reproduction d'un module plus spécifiquement étrusque, régi par l'emploi d'une unité de mesure reconnue par ailleurs (on pense notamment au pied « attique » de 29,60 cm)?

La difficulté à reconnaître l'emploi de cette mesure a été évoquée en préambule, compte tenu de l'absence de limites autres que celles de l'UNF 143 et de l'incertitude quant aux choix opérés en termes de construction à partir d'un plan préétabli. Elle demeure néanmoins possible, et amène de fait à s'interroger sur la morphologie plus globale de cet îlot durant la phase $1 \mathrm{~S}$. Tandis que l'emploi du pygmè de $33 \mathrm{~cm}$ environ semble ici peu opérante, la surface hors œuvre du bâtiment s'inscrirait dans un rectangle (dont l'angle sud-est est légèrement décalé) de 31 pieds de long pour 20 pieds de large (fig. 19). Rien ne nous dit cependant que les murs aient été érigés à l'intérieur de ces limites : dans la mesure où existe une mitoyenneté avec d'autres espaces bâtis, ou voués à l'être, il est parfaitement concevable que tel ou tel mur empiète - ou non - sur ces tracés, voire les outrepasse, ce que montre notamment l'exemple des maisons de Marzabotto.

Un premier élément de réflexion nous est fourni par la concordance des mesures entre le corps du bâtiment absidial (phase 1T) et l'UNF 143 (phase 1S), qui n'est opérante que dans la mesure où l'on prend comme repère l'axe des murs est et ouest de cette dernière. On a souligné le décalage, au regard du mur de façade nord de l'UNF 143, du départ de mur est-ouest situé dans l'angle nord-est de la zone de fouille, qui laisse à penser que le contact entre ces murs pourrait précisément coïncider avec le positionnement d'un tracé est-ouest. Enfin, bien que l'on ne dispose que de limites approximatives, la distance entre le rempart et l'UNF 143 est comparable à la longueur de cette dernière entité. Si l'on formule l'hypothèse selon laquelle la façade orientale constituait un mur mitoyen - entendu un mur établi à cheval sur un tracé nord-sud -, la distance entre la limite occidentale de l'UNF 143 et le tracé restitué du rempart - établi approximativement d'après sa tranchée d'épierrement, repérée en surface - serait alors comprise entre 17 et $18 \mathrm{~m}$. Plus exactement, cela coïnciderait avec deux rectangles de 30 pieds de long (soit 2 x 8,88 $\mathrm{m}=17,76 \mathrm{~m}$ ), soit un total de 60 pieds qui évoque directement les mesures observées au niveau des maisons FI et FII de Forcello, ou encore les maisons de l'îlot V3 de Marzabotto. Plus encore, cette mesure ne serait pas incompatible avec l'idée d'une largeur équivalente à 18 pieds (Forcello, maison FII), pour peu que l'on considère les façades nord et sud de l'UNF 143 comme étant bâties, tantôt en deçà, tantôt au-delà de cette limite (fig. 19b), une largeur de 20 pieds étant par ailleurs tout à fait envisageable (fig. 19c).

À ce stade, force est de reconnaître que le caractère lacunaire de la documentation - accentué par le fait que la construction de l'îlot est demeurée inachevée - ne nous permet ni de restituer avec certitude la physionomie de ce quartier, ni de préciser la morphologie de la ou des maisons destinées à occuper cet espace. Ceci étant, plusieurs points doivent être soulignés : en premier lieu, une trame orthogonale a bien servi au tracé des constructions et l'emploi de modules fondés sur l'emploi d'un pied d'environ $30 \mathrm{~cm}$ est plausible ; ensuite, il est possible d'estimer la superficie minimale de cet ensemble bâti (îlot ?) à environ $250 \mathrm{~m}^{2}$; enfin, l'hypothèse d'un îlot double fondé sur 
la simple répétition d'un module rectangulaire coïncidant avec l'UNF 143 semble peu vraisemblable, en particulier compte tenu de la morphologie du secteur occidental. De fait, l'hypothèse de maisons à plusieurs pièces, voire associant des espaces couverts et non couverts, est ici tout à fait envisageable, suggérant par là même la possibilité de plans complexes. Pour autant, peut-on envisager à Lattara l'existence de vastes maisons, comparables - tant par leur plan que par leurs mesures - à celles de Marzabotto (fig. 5) ? Si techniquement rien ne s'y oppose, cela semble néanmoins peu probable compte tenu des contraintes existant en termes de topographie et surtout d'espace disponible, l'échelle du site étant évidemment réduite.

Le site de Fonteblanda, à Orbetello (Italie), en Étrurie méridionale, offre en revanche un nouveau point de comparaison des plus parlants : fondé vers le milieu du vi $\mathrm{e}$. av. J.-C. au débouché du fleuve Albegna, il est établi dans un environnement lagunaire et se présente comme une création nouvelle, apparemment destinée à servir de débouché aux productions viticoles de l'hinterland (Ciampoltrini 2003 ; 2012). Les fouilles y ont révélé l'existence d'un habitat établi selon un plan régulier orthonormé : trois portions d'îlots d'habitation, accueillant également des activités artisanales, abritent une série d'unités de dimensions comparables et de plan sensiblement carré. Les mesures observées laissent envisager l'emploi comme unité de base du pied attique de 29,60 cm, de sorte que les îlots occuperaient des lots d'environ $8,90 \mathrm{~m}$ de côté, équivalents à 30 pieds. La ruelle séparant les deux îlots occidentaux, tout autant que les voies secondaires et principales qui rythment l'ensemble, paraît également dictée par ce même système métrologique (fig. 20).

De Forcello à Lattara, l'existence d'une division de l'espace prenant comme base une mesure de 30 pieds de long a été soulignée, mais l'habitat tardo-archaïque de Fonteblanda offre en outre une piste interprétative sérieuse pour pouvoir restituer la morphologie du quartier érigé en limite orientale du site de Lattes durant la phase 1S. En effet, le report d'une grille fondée sur la juxtaposition de trois blocs de 30 pieds de côtés, tels que définis à Fonteblanda, s'accommoderait bien avec les données de fouille existantes et permettrait ainsi de restituer, de manière hypothétique, un îlot de près de $27 \mathrm{~m}$ de long, disposé est-ouest, adossé au rempart ou séparé de celui-ci par une venelle, dans ce cas bordé au nord comme au sud par une ruelle et à l'ouest par un axe de circulation (nord-sud) plus important ${ }^{11}$. Selon un tel schéma, les maisons constitutives de l'îlot 1 pourraient effectivement comporter plusieurs pièces distinctes, intégrant le cas échéant des espaces ouverts ou semi-ouverts, à l'image des divisions précisément observées à Fonteblanda, où chaque bloc constitutif d'une unité domestique comporte entre deux et quatre pièces de plan carré ou rectangulaire. Les proportions de ces dernières, bien que souvent voisines d'un ensemble à l'autre, n'en demeurent pas moins relativement hétérogènes et témoignent, au-delà d'un modèle commun, d'une certaine liberté prise dans l'agencement interne des différents lots.

11. Une telle configuration est d'autant plus plausible qu'elle préfigure de fait celle du quartier durant les phases suivantes, où l'îlot 1 se voit bordé à l'ouest par un des axes de circulation principaux (rue 100) ceinturant le « cœur de ville » et desservant les quartiers périphériques adossés au rempart, tout en constituant un lien direct entre la porte (restituée) située au nord et la zone portuaire (Py 2009, p. 73-76).
Si ce parallèle entre Fonteblanda et la phase 1S de Lattara demeure conjecturel, eu égard au caractère partiel des plans disponibles, il permet néanmoins d'entrevoir, à une échelle comparable, une piste interprétative permettant de saisir -au-delà des questions de métrologie - la morphologie d'ensemble du lotissement alors mis en place. Ce parallèle prend d'ailleurs tout son sens au moment de considérer le caractère de ces implantations, toutes deux synonymes de programmes urbanistiques opérés dans le cadre de sites nouvellement implantés, et donc potentiellement pensés selon des schémas préétablis dont l'existence, en Étrurie, est aujourd'hui bien établie.

$$
\begin{aligned}
& * \\
& * \quad *
\end{aligned}
$$

Ces observations tendent non seulement à confirmer, tout en le précisant, le caractère étrusque de Lattara au tout début du $\mathrm{V}^{\mathrm{e}} \mathrm{s}$. av. J.-C., mais invitent également à replacer cette présence tyrrhénienne dans un contexte plus global qui est celui d'une expansion - fondamentalement commerciale - opérée depuis les centres d'Étrurie méridionale entre la fin $\mathrm{du}_{\mathrm{VI}} \mathrm{e}^{\mathrm{e}}$ et le début $\mathrm{du} \mathrm{v}^{\mathrm{e}}$ s. av. J.-C., un mouvement auquel il faut probablement rattacher l'installation des Étrusques à Alalia (Corse) dans le dernier tiers du $\mathrm{vI}^{\mathrm{e}}$ s. av. J.-C., suite au départ des Phocéens préalablement installés sur place et dans les circonstances que relate l'historien grec Hérodote (Histoires, I, 165-166). À la même époque, outre le dynamisme de la production viticole dont témoigne, entre autres, Fonteblanda, la fondation de nouveaux sites donnant accès à la vallée du Pô (Marzabotto), tout autant que la création des emporia de la zone adriatique ou, côté tyrrhénien, de l'emporion ligure de Genova (Milanese 1987), constituent autant de signes d'un important développement économique, accompagné de mobilités qui, dans certains cas (on pensera à la région padane) sont synonymes d'une véritable « colonisation».

À Lattara, quel qu'ait été le degré d'implication des populations indigènes, entre la concession d'une maigre portion de terre à l'embouchure du Lez et une participation effective à la construction ainsi qu'à la vie de cet établissement, sa fondation reflète à ce titre une entreprise volontariste, d'autant plus compréhensible qu'elle intervient dans un secteur géographique - le Languedoc oriental - qui, durant une grande partie du $\mathrm{VI}^{\mathrm{e}}$ s. av. J.-C., a été au cœur des réseaux de distribution étrusques dans le golfe du Lion. Cette notion de réseau est certes ambiguë, dans la mesure où il serait illusoire d'attribuer aux seuls négociants tyrrhéniens la paternité du transport et de la commercialisation des amphores vinaires embarquées sur les ports de la côte toscane. Comme cela a été précédemment souligné, les Grecs eux-mêmes, particulièrement actifs dans la seconde moitié du $\mathrm{VI}^{\mathrm{e}} \mathrm{s}$. av. J.-C., non seulement sur les emporia de la côte tyrrhénienne tels Gravisca, mais encore sur ceux de l'Adriatique, ont à l'évidence joué un rôle dans ce processus (Bats 1998 ; Bourdin 2006). L'existence d'un commerce direct entre l'Étrurie et le sud de la Gaule ne saurait pour autant être écartée, impliquant non seulement Massalia - cité à la fois largement consommatrice du vin toscan dans la première moitié $\mathrm{du} \mathrm{vI^{e }}$ s. av. J.-C. et potentiel centre de redistribution -, mais encore - probablement - différents emporia des côtes provençales ou languedociennes. 




Fig. 20 - A, plan de l'habitat étrusque de Fonteblanda (Italie) (d'après Ciampoltrini 2016, p. 18) ; B, proposition de restitution de l'îlot 1 de Lattes (DAO : É. Gailledrat). 
Si une perte de vitesse du courant tyrrhénien est perceptible à la fin de ce siècle, conséquence directe de la concurrence croissante des produits massaliètes, la fondation de Lattara s'appuie tout autant sur le dynamisme global du négoce méditerranéen qui caractérise cette période que sur un intérêt particulier porté par les Étrusques à ce secteur. En l'état actuel de nos connaissances, Lattara se présente durant environ un quart de siècle comme une véritable enclave tyrrhénienne adossée au monde indigène, et plus précisément encore à la vaste agglomération de la Cougourlude qui abrite alors d'évidentes fonctions emporiques (Gailledrat 2015) et accorde une place prépondérante aux apports en provenance du monde grec. La différence entre les deux sites quant à leur faciès d'importation respectif (Daveau, Py 2015) suffit à montrer le caractère particulier de l'établissement situé à l'embouchure du Lez, qui fait office de débarcadère pour les cargaisons en provenance d'Étrurie - dont l'épave du Grand Ribaud F nous donne une image des plus parlantes (Long et al. 2006) -, mais ne renvoie pas l'image d'un emporion cosmopolite accueillant des produits d'origine variée.

Les données acquises à Lattara montrent en revanche le caractère planifié et méthodique lié à l'implantation d'une communauté tyrrhénienne, avec à la clé des schémas architecturaux et urbanistiques adaptant ou reproduisant des modèles proprement étrusques, précisément mis en œuvre en Italie septentrionale durant cette période clé qui couvre la fin ${\mathrm{du} \mathrm{VI}^{\circ}}^{\circ}$ et le début $d u v^{e} s$. av. J.-C. Plusieurs interrogations subsistent néanmoins, parmi lesquelles celles relatives aux différences de plans et d'orientations, perceptibles tant au niveau de la zone 1 (entre les phases 1T et 1S) qu'entre la zone 1 et la zone 27.

Concrètement, et a fortiori en considérant la rigueur censée accompagner une planification urbaine proprement étrusque, on constate tout d'abord que le tracé orthonormé établi au moment de l'installation (phase 1T, état 1) n'est pas exactement repris au moment de la construction de l'UNF 145 (phase 1T, état 2) qui, pourtant, intervient pour ainsi dire dans la foulée : les tracés initiaux présentent en effet un décalage de $3^{\circ}$ par rapport aux points cardinaux alors que l'UNF 145 est strictement implantée selon un axe est-ouest, orientation qui se voit ensuite reprise au moment de la construction de l'îlot (phase 1S). En revanche, les bâtiments de la zone 27 ne répondent à aucune de ces orientations, dans la mesure où nous avons ici des axes décalés de près de $20^{\circ}$ par rapport aux points cardinaux. Pour autant, ces variations sont-elles porteuses de sens ? Il est évidemment impossible de répondre avec certitude à cette question, tant il est vrai que l'on pourrait invoquer une simple contingence liée à la topographie du lieu, entre espace contraint et forme irrégulière de la presqu'île sur laquelle est implantée l'habitat. Ceci étant, les exemples de Forcello ou de Spina nous montrent bien que de telles conditions n'ont en rien constitué des obstacles insurmontables au moment de mettre en place une trame urbaine parfaitement orthonormée. De fait, on pourrait également invoquer l'existence de projets successifs qui, bien que très rapprochés dans le temps, auraient été liés à différentes phases d'implantation. Sans même avoir besoin d'imaginer que cela puisse refléter l'implication de diverses cités d'Étrurie (le faciès mobilier apparaît particulièrement homogène ${ }^{12}$ ), rien ne nous dit

12. Le mobilier céramique, et en particulier les amphores, semble désigner comme origine la cité de Caere (Py 2009, p. 47). en effet que cette implantation étrusque ait été réalisée en une fois et par un seul et même contingent de personnes : de petits groupes de marchands, d'artisans, accompagnés ou non de leurs familles, ont très bien pu se greffer progressivement à un noyau préexistant. Le fait même qu'existe au niveau de la zone 1 une phase transitoire, matérialisée par la construction de l'UNF 145, va dans le sens de cette hypothèse qui, par ailleurs, n'est pas sans évoquer certains scénarios désormais envisagés dans le cadre plus général des implantations de type colonial, grec ou autre.

À ce stade, il convient également de prendre en compte un autre paramètre, relatif à l'incertitude qui entoure ce que l'on considère être « la » fondation de Lattara. En d'autres termes, la question a depuis longtemps été posée de la signification qu'il fallait donner à la présence, en divers points du site, de mobiliers résiduels clairement datables de la seconde moitié $\mathrm{du} \mathrm{VI}^{\mathrm{e}} \mathrm{s}$. av. J.-C. et, de fait, antérieurs aux niveaux d'occupation les plus anciens reconnus à ce jour (Py 2009, p. 49). Ces rares documents (par ailleurs exclusivement étrusques : canthares en bucchero nero et amphores de type A-ETR $1 / 2$ et $3 \mathrm{AB}$ ) témoignent a minima d'une fréquentation du site, à une époque où l'habitat voisin de la Cougourlude connaît une phase d'expansion remarquable. L'hypothèse d'un simple point d'accostage parmi d'autres peut être avancée (Gailledrat 2015, p. 41) ${ }^{13}$, mais celle d'une installation pérenne, préexistante à celle actuellement reconnue, ne peut être totalement écartée. Elle le peut d'autant moins que, pour l'heure, les deux seuls secteurs où le substrat a pu être atteint (zones 1 et 27) se situent en périphérie de l'habitat protohistorique dont les limites sont, on l'a vu, fixées à la charnière des $\mathrm{vl}^{\mathrm{e}}-\mathrm{v}^{\mathrm{e}} \mathrm{s}$. av. J.-C. par la construction de l'enceinte. En d'autres termes, cela signifie que nous ne savons rien de ce qui se passe au cœur de l'agglomération, ni même de la topographie exacte du lieu, a fortiori si l'on considère la rapidité avec laquelle la morphologie de cette bande de sable, issue de la progradation du delta du Lez, a pu évoluer en quelques années à peine. Sur ce point, les données de la zone 1 invitent en effet à la plus grande prudence, tant ce secteur semble encore imparfaitement atterri au moment de la primo-installation, et que l'on peut très bien imaginer un premier habitat de taille réduite, installé en retrait sur un terrain potentiellement plus stable.

Bien qu'indémontrable en l'état (et d'autant plus fragile que les mobiliers résiduels évoqués proviennent des quartiers périphériques du site, et non du centre de ce dernier), l'idée d'un établissement primitif mis en place au milieu ou dans la seconde moitié du $\mathrm{VI}^{\mathrm{e}}$ s. av. J.-C. - potentiellement étrusque si l'on s'en tient aux mobiliers erratiques signalés précédemment pourrait contribuer à expliquer les modalités qui sont celles du, ou des lotissements, qui interviennent vers 500 av. J.-C. et qui témoigneraient dans ce cas, non pas de la création ex nihilo, mais de l'extension d'un comptoir (tyrrhénien ?) préexistant. Peut-être même faudrait-il voir dans cette entreprise de consolidation d'une implantation antérieure une des raisons ayant conduit à la désertion soudaine du site, avant que n'intervienne une réoccupation synonyme de réappropriation indigène de l'espace, accompagnée d'une relation privilégiée avec Massalia, désormais omniprésente dans la région.

13. La question demeure concernant les points susceptibles d'avoir été utilisés comme débarcadère pour les produits acheminés à la Cougourlude, sachant qu'il serait illusoire de considérer la presqu'île qui accueille Lattara comme étant un point de passage obligé. 


\section{BIBLIOGRAPHIE}

\section{ABRÉVIATIONS}

ADAL Association pour le développement de l'archéologie en Languedoc-Roussillon.

$\begin{array}{ll}\text { AFEAF } & \text { Association française pour l'étude de l'âge du Fer. } \\ \text { ARALO } & \text { Association pour la recherche archéologique en Languedoc oriental. } \\ \text { CCJ } & \text { Centre Camille-Jullian. } \\ \text { CNRS } & \text { Centre national de la recherche scientifique. } \\ \text { CUF } & \text { Collection des universités de France. } \\ \text { EFR } & \text { École française de Rome. } \\ \text { MEFRA } & \text { Mélanges de l'École française de Rome - Antiquité. } \\ \text { PULM } & \text { Presses universitaires de la Méditerranée. } \\ \text { PUR } & \text { Presses universitaires de Rennes. } \\ \text { RAN } & \text { Revue archéologique de Narbonnaise. }\end{array}$

\section{SOURCES ANCIENNES}

Anonyme de Ravenne : Cosmographia, éd. G. Parthey, M. Prinder, Berlin, Friderici Nicolai, 1860.

Hérodote : Histoires, Livre I, éd. et trad. P.-E. Legrand, Paris, Les Belles Lettres (coll. CUF, série grecque, 72), 1932.
Pline L'Ancien : Histoire Naturelle, Livre IX, éd. et trad. E. de SaintDenis, Paris, Les Belles Lettres (coll. CUF, série latine, 146), 1955.

Pomponius Mela : Chorographie, éd. et trad. A. Silberman, Paris, Les Belles Lettres (coll. CUF, série latine, 283), 1988.

\section{RÉFÉRENCES}

Barruol G. 1988 : Le toponyme Lataral Lattara, in Py M. (dir.), Mélanges d'Histoire et d'Archéologie de Lattes, Caveirac, ARALO (coll. Lattara, 1), p. 5-13.

Bats M. 1998 : Marseille archaïque. Étrusques et Phocéens en Méditerranée nordoccidentale, MEFRA, 110-2, p. 609-633.

Bats M. 2012 : L'arrivée du vin étrusque sur le littoral de Méditerranée nord-occidentale $\left(\mathrm{VI}^{\mathrm{e}}-\mathrm{V}^{\mathrm{e}}\right.$ s. av. J.-C.), in Ciacci A. et al. dir. 2012, p. 377-389.

Bourdin S. 2006 : Fréquentation ou intégration : les présences allogènes dans les emporia étrusques et ligures ( $\mathrm{VI}^{\mathrm{e}}-$ $\mathrm{IV}^{\mathrm{e}}$ siècles av. J.-C.), in Clément F., Tolan J., Wilgaux J. (dir.), Espaces d'échanges en Méditerranée. Antiquité et Moyen Âge, Rennes, PUR, p. 19-39.

Briquel D. 2008 : La città murata in Etruria, aspetti religiosi, in La città murata in Etruria. Atti del XXV Convegno di Studi Etruschi ed italici (Chianciano Terme, Sarteano, Chiusi, 30 marzo-3 aprile 2005), Pise, Rome, Fabrizio Serra editore, p. 121133.

Catarsi Dall'Aglio M. 1998 : L'insediamento etrusco di Case nuove di Siccomonte a Capriolo di Fidenza (Parma), in Rebecchi F. (dir.), Spina e il Delta Padano. Atti del convegno internazionale di studi «Spina.
Due civiltà a confronto », Ferrara, 21 gennaio 1994, Rome, L'Erma di Bretschneider, p. 247-254.

Ciacci A., Rendini P., Ziffero A. (dir.) 2012 : Archeologia della vite e del vino in Toscana e nel Lazio. Dalle tecniche dell'indagine archeologica alle prospettive della biologia molecolare, Florence, Università di Siena (coll. Quaderni del Dipartimento di archeologia e storia delle arti-Università di Siena, 65), $832 \mathrm{p}$.

Ciampoltrini G. 2003 : L'insediamento arcaico di Fonteblanda e l'urbanistica "ippodamea" fra Orvieto e Vulci, in Della Fina G. M. (dir.), Tra Orvieto e Vulci. Atti del X Convegno Internazionale di Studi sulla Storia e l'Archeologia dell'Etruria, Orvieto, 2002, Rome, Quasar (coll. Annali della Fondazione per il Museo Claudio Faina, 10), p. 279-291.

Ciampoltrini G. 2012 : Vie e porti del vino nella valle dell'Albegna in età etrusca (VIv secolo a.C.), in Ciacci A. et al. dir. 2012, p. 391-401.

Ciampoltrini G. 2016 : Il porto del vino etrusco. L'insedamento arcaico di Fonteblanda, Pise, I Segni dell'AuserArcheologia a Lucca en nella Valle del Serchio, 47 p.
Collectif 1988 : Modena dalle origini all'anno Mille. Studi di Archeologia e storia, Modène, Panini, vol. 1-2, 1144 p.

Colonna G. 1980 : Graffiti etruschi in Linguadoca, Studi Etruschi, 48, p. 181-185.

Cornelio Cassai C., Giannini S., Malnati L. (dir.) 2017 : Spina. Scavi nell'abitato della città etrusca 2007-2009, Sesto Fiorentino, All'Insegna del Giglio (coll. Quaderni di Archeologia dell'Emilia Romagna, 37), $208 \mathrm{p}$.

Croce E., Amicone S., Castellano L., Vezzoli G. 2014 : Analisi di una tecnica edilizia in terra cruda nell'insediamento etrusco-padano del Forcello di Bagnolo San Vito (Mantova), Notizie Archeologiche Bergomensi, 22, p. 137-160.

Daveau I., Py M. 2015 : Grecs et Étrusques à Lattes : nouvelles données à partir des fouilles de La Cougourlude, in Roure R. (dir.), Contacts et acculturations en Méditerranée occidentale - Hommages à Michel Bats. Actes du colloque d'Hyères, 15-18 septembre 2011, Paris, Aix-enProvence, Errance/CCJ (coll. Études massaliètes, 12), p. 31-42.

Daveau I., Chardenon N., Da Costa C., Dubesset D., Henry É., Py M. 2015 : Un port à Lattes avant Lattara ? Le village du Premier âge du Fer de « la Cougourlude» 
(Hérault), in Roure R., Olmer F. (dir.), Les Gaulois au fil de l'eau, Actes du $37^{\text {e }}$ Colloque international de l'AFEAF (Montpellier, 8-11 mai 2013), Bordeaux, Ausonius (coll. Mémoires, 39-1), p. 87-114.

De Marinis R. C., Rapi M. (dir.) 2007 ( $2^{\text {e }}$ éd.) : L'abitato etrusco del Forcello di Bagnolo S. Vito (Mantova): le fasi arcaiche, Catalogue d'exposition, L'abitato etrusco del Forcello di Bagnolo S. Vito (Mantova): le fasi arcaiche, Villa Revi Berni, 8 febbraio-20 marzo 2005, Florence, Comune di Bagnolo San Vito (MN)/ Ministero per i Beni e le Attivitá CulturaliSoprintendenza per i Beni Archeologici della Lombardia/Museo Archeologico Nazionale di Mantova/Università degli Studi di Milano, $311 \mathrm{p}$.

De Marinis R. C., Barrati G., Longhi C., Mangani C. 2002 : L'insediamento etrusco del Forcello di Bagnolo San Vito (Mantova), in Peretto C. (dir.), Analisi informatizzata e trattamento dati delle strutture di abitato di età preistorica e protostorica in Italia, Florence, Istituto italiano de preistoria e protostoria, p. 303-318.

Gailledrat É. 2014 : Espaces coloniaux et indigènes sur les rivages d'ExtrêmeOccident méditerranéen ( $X^{e}-I I t^{e}$ s.av.n. ère), Montpellier, PULM, 293 p.

Gailledrat É. 2015 : New Perspectives on Emporia in the Western Mediterranean: Greeks, Etruscans and Native Populations at the Mouth of the Lez (Hérault, France) during the Sixth-Fifth Centuries BC, Journal of Mediterranean Archaeology, 281, p. 23-50.

Gailledrat É. 2018 : Sailors and landsmen in the Emporia of southern Gaul, in Gailledrat É., Dietler M., Plana Mallart R. (dir.), The Emporion in the Ancient Western Mediterranean. Trade and Colonial Encounters from the Archaic to the Hellenistic Period, Montpellier, PULM, p. 115-127.

GarciaD.2014: La Celtiqueméditerranéenne. Habitats et sociétés en Languedoc et en Provence. VIII III $^{e}$ siècles av. J.-C., Paris, Errance (coll. Les Hespérides), 247 p.

Garcia D., Tréziny H. 2010 : Maisons à absides dans le monde grec et en Gaule méditerranéenne, in Tréziny H. (dir.), Grecs et indigènes de la Catalogne à la Mer Noire, Paris, Aix-en-Provence, Errance/ CCJ (coll. Bibliothèque d'Archéologie Méditerranéenne et Africaine, 3), p. 371378.

Gori S. (dir.) 2006 : Gli Etruschi da Genova ad Ampurias, Atti del XXIV Convegno di Studi Etruschi ed Italici, Marseille-Lattes, 26 settembre-1 ottobre 2002, Pise, Rome, Istituti editoriali e poligrafici internazionali, $689 \mathrm{p}$.

Gras M.1985 : Trafics tyrrhéniens archaïques, Rome, EFR (coll. Bibliothèque des Écoles françaises d'Athènes et de Rome, 258), $773 \mathrm{p}$.

Harari M., Paltineri S. 2010 : Edilizia etrusca nella chora di Adria, in Bentz M., Reusser C. (dir.), Etruskisch-italische und römisch-republikanische Häuser, Wiesbaden, Reichert verlag, p. 65-74.

Janin T., Py M. (dir.) 2008 : Dossier : Lattara (Lattes, Hérault) : nouveaux acquis, nouvelles questions sur une ville portuaire protohistorique et romaine, Gallia, 65, p. 5-230.

Jolivet V. 2015 : La cité orthogonale et le monde étrusque, in Bourdin S., Paoli A., Reltgen-Tallon A. (dir.), La forme de la ville de l'Antiquité à la Renaissance, Rennes, PUR, p. 155-166.

Jorda C., Chabal L., Blanchemanche P. 2008 : Lattara entre terres et eaux. Paléogéographie et paléoboisements autour du port protohistorique, in Janin T., Py M. dir. 2008, p. 11-21.

Lebeaupin D. (dir.) 2014 : Les origines de Lattara et la présence étrusque. Les données de la zone 27, Lattes, ADAL (coll. Lattara, 22), 347 p.

Lebeaupin D., Séjalon P. 2008 : Lattara et l'Étrurie. Nouvelles données sur l'installation d'un comptoir vers 500 av. J.C., in Janin T., Py M. dir. 2008, p. 45-64.

Locatelli D. 2006 : Età etrusca: la fattoria di Cave San Lorenzo, in Labate D. (dir.), Fiorano e la valle del torente Spezzano: archeologia di un territorio, Catalogo Mostra (Fiorano Modenese, 13 maggio-2 dicembre 2006), Florence, All'Insegna del Giglio (coll. Quaderni di Archeologia dell'Emilia Romagna, 14), p. 40-50.

Long L., Gantès L.-F., Rival M. 2006 : L'épave Grand Ribaud F. Un chargement de produits étrusques du début du $\mathrm{v}^{\mathrm{e}} \mathrm{s}$. av. J.-C., in Gori S. dir. 2006, p. 455-495.

Malnati L. 1988a : Fiorano Modenese-Cava San Lorenzo: resti di una abitazione di età etrusca, in Collectif 1988, vol. 1, p. 258261.

Malnati L. 1988b : Lo scavo di una fattoria etrusca a Baggiovara-Case Vandelli, in Collectif 1988, vol. 1, p. 262-271.

Massa-Pairault F.-H. 1972 : L'habitat archaïque de Casalecchio di Reno près de Bologne. Structure planimétrique et technique de construction, MEFRA, 84-1, p. 145-197.

Massa-Pairault F.-H. 1997 : Marzabotto. Recherches sur l'Insula V, 3, Rome, EFR (coll. de l'EFR, 228), $284 \mathrm{p}$.

Milanese M. 1987 : Scavi nell'oppidum preromano di Genova(Genova-S.Silvestro 1), Rome, L'Erma di Bretschneider (coll. Studia archeologica, 48), $390 \mathrm{p}$.
Morandini F. 2011 : Le fattorie arcaiche di Pian d'Alma (Scarlino-GR) e Marsiliana d'Albergna (Manciano-GR): modello "urbano" esportato in campagna o modello "extra-urbano" radicato nella tradizione?, in Ellero A., Luciani F., Zaccaria Ruggiu A. (dir.), La Città. Realtà e valori simbolici, Padoue, S.A.R.G.O.N., p. 79-100.

Nickels A. 1989 : La Monédière à Bessan (Hérault). Le bilan des recherches, Documents d'archéologie méridionale, 12, p. 51-119.

Patitucci S., Uggeri G. 2017 : Spina. Topografia, urbanistica, edilizia: un aggiornamento, Atti dell' Academia delle Scienze di Ferrara, 94, p. 181-220.

Perkins P., Attolini I. 1992 : An Etruscan Farm at Podere Tartuchino, Papers of the British School at Rome, 60, p. 71-134.

Py M. 1984 : La Liquière (Calvisson, Gard). Village du premier âge du Fer en Languedoc oriental, Paris, CNRS (coll. Suppl. à la RAN, 11), $363 \mathrm{p}$.

Py M. 1985 : Les gisements lagunaires au premier âge du Fer, in L'occupation des rivages de l'étang de Mauguio, Hérault, au Bronze final et au $1^{\text {er }}$ age du Fer, III. Synthèses et annexes, Caveirac, ARALO (coll. ARALO, cahier no 13), p. 47-84.

Py M. 1988 : Sondages dans l'habitat antique de Lattes : les fouilles d'Henri Prades et du Groupe archéologique Pain Levé (19631985), in Py M. (dir), Mélanges d'Histoire et d'Archéologie de Lattes, Caveirac, ARALO (coll. Lattara, 1), p. 65-146.

Py M. 1990 : Culture, économie et société protohistorique dans la région nîmoise, Rome, EFR (coll. de l'EFR, 131), 2 vol., $957 \mathrm{p}$.

Py M. 1995 : Les Étrusques, les Grecs et la fondation de Lattes, in Arcelin P., Bats M. Garcia D., Marchand G., Schwaller M. (dir.), Sur les pas des Grecs en Occident. Hommages à André Nickels, Paris, Lattes, Errance/ADAL (coll. Études massaliètes, 4), p. 261-276.

Py M. 2009 : Lattara (Lattes, Hérault). Comptoir gaulois méditerranéen entre Étrusques, Grecs et Romains, Paris, Errance, $343 \mathrm{p}$.

Py M. 2016 : Observations et conjectures sur les fortifications de Lattara (Lattes, Hérault), in Chazelles C.-A. de, Schwaller M. (dir.), Vie quotidienne, tombes et symboles des sociétés protohistoriques de Méditerranée nord-occidentale, Lattes, ADAL (coll. Monographies d'archéologie méditerranéenne, Hors série 7-1), p. $223-$ 238.

Py M., Adroher Auroux A. M., Sanchez C. 2001 : Dicocer 2. Corpus des céramiques de l'Âge du Fer de Lattes (fouilles 19631999), Lattes, ADAL (coll. Lattara, 14), 2 vol., 1306 p. 
Py M., Lebeaupin D., Séjalon P., Roure R. 2006 : Les Étrusques et Lattara : nouvelles données, in Gori S. dir. 2006, p. 583-608.

Quirino T. 2011 : Le case F I e F II del Forcello di Bagnolo San Vito (MN): analisi preliminare di due abitazioni etrusche di fine VI secolo a.C., Notizie Archeologiche Bergomensi, 19, p. 379-390.

Quirino T.2013 : Forcello di Bagnolo San Vito $(\mathrm{MN})$ : dalle strutture abitative alla forma urbana. Alcune riflessioni sull'architettura etrusca della pianura padana, Padusa, XLVIII, p. 89-107.

Quirino T. 2014 : La casa F I del Forcello di Bagnolo San Vito (MN) e il suo confronto in ambito celtico: problemi aperti di architettura padana, in Barral P., RoulièreLambert M.-J., Saracino M., Vitali D. (dir.), Les Celtes et le Nord de l'Italie (Premier et Second Âges du fer). Actes du $X X X V I^{e}$ colloque international de l'AFEAF (Vérone, 17-20 mai 2012), Dijon, Revue archéologique de 1'Est (coll. Suppl. à la
Revue archéologique de l'Est, 36), p. 393400.

Robino M. T. A., Paltineri S., Smoquina E. 2009 : Scavi dell'Università di Pavia a San Cassiano di Crespino (RO). Un complesso abitativo etrusco nella chora di Adria, in Atti del Congresso internazionale di Archeologia Classica, Roma, 22-26 settembre 2008, Associazione Internazionale di Archeologia Classica [URL : http://www.fastionline.org/ docs/FOLDER-it-2009-157.pdf, consulté le 01/09/2019].

Roux J.-C. 1999 : Histoire et évolution de l'habitat dans la zone 1 de Lattes, les îlots $1 \mathrm{~B}, 1 \mathrm{C}$ et $1 \mathrm{D}$ au Iv ${ }^{\mathrm{e}}$ siècle avant notre ère, in Py M. (dir.), Recherches sur le quatrième siècle avant notre ère à Lattes, Lattes, ADAL (coll. Lattara, 12), p. 11-128.

Salzani L., Vitali D. 2002 : Gli scavi archeologici nel podere Forzello a San Basilio di Ariano Polesine, in L'alto e medio Adriatico tra vi e v secolo a.C., Atti del convegno internazionale, Adria, 19-
21 marzo 1999, Padusa, XXXVIII, p. 115138.

Sassatelli G. 1990 : Culti e riti in Etruria padana: qualche considerazione, in Bartoloni G. (dir.), Anathema: regime delle offerte e vita dei santuari nel Mediterraneo Antico, Atti del Convegno Internazionale (Roma, 15-18 giugno 1989), Rome, Università degli studi di Roma La Sapienza (coll. Scienze dell'Antichità. Storia, Archeologia, Antropologia, 3-4, 19891990), p. 599-617.

Stopani C.,Zamboni L.2009: L'insediamento di Baggiovara-via Martiniana (MO), in Chiaramonte Treré C. (dir.), Archeologia Preromana in Emilia Occidentale. La ricerca oggi tra monti e pianura, Atti della Giornata di Studi (Milano, 5 aprile 2006), Milan, Cisalpino, p. 349-423.

Tréziny H. 1989 : Métrologie, architecture et urbanisme dans le monde massaliète, $R A N$, 22, p. 1-46. 